Running Head: IMPLICIT THEORIES AND SELF-REGULATION

Mindsets Matter: A Meta-Analytic Review of Implicit Theories and Self-Regulation

\author{
Jeni L. Burnette \\ University of Richmond \\ Ernest O'Boyle \\ University of Iowa \\ Eric M. VanEpps \\ Carnegie Mellon University \\ Jeffrey M. Pollack \\ University of Richmond \\ Eli J. Finkel \\ Northwestern University
}

In Press, Psychological Bulletin

May 9, 2012 


\title{
Mindsets Matter: A Meta-Analytic Review of Implicit Theories and Self-Regulation
}

\begin{abstract}
This review builds on self-control theory (Carver \& Scheier, 1998) to develop a theoretical framework for investigating associations of implicit theories with self-regulation. This framework conceptualizes self-regulation in terms of three crucial processes: goal setting, goal operating and goal monitoring. In this meta-analysis, we included articles that reported a quantifiable assessment of implicit theories and at least one self-regulatory process or outcome. Using a random effects approach, meta-analytic results (total unique $N=28,217 ; k=113$ ) across diverse achievement domains (68\% academic) and populations (age range $=5-42 ; 10$ different nationalities; $58 \%$ from United States; 44\% female) demonstrated that implicit theories predict distinct self-regulatory processes, which, in turn, predict goal achievement. Incremental theories, which, in contrast to entity theories, are characterized by the belief that human attributes are malleable rather than fixed, significantly predicted goal setting (performance goals, $r=-.151$; learning goals, $r=.187$ ), goal operating (helpless-oriented strategies, $r=-.238$; mastery-oriented strategies, $r=.227$ ), and goal monitoring (negative emotions, $r=-.233$; expectations, $r=.157$ ). The effects for goal setting and goal operating were stronger in the presence (vs. absence) of ego threats such as failure feedback. Discussion emphasizes how the present theoretical analysis merges an implicit theory perspective with self-control theory to advance scholarship and unlock major new directions for basic and applied research.
\end{abstract}

$$
\text { Abstract }=221 ; \text { Overall Word Count }=32,266
$$

KEY WORDS: implicit theories, self-regulation, self-control theory, achievement 
Implicit Theories and Self-Regulation 2

\section{Mindsets Matter: A Meta-Analytic Review of Implicit Theories and Self-Regulation}

Why do some students seek to gain competency, whereas others seek to outperform their

peers? Why do some athletes redouble their efforts when facing setbacks, whereas others respond with helplessness? Why do some dieters feel confident in their ability to face challenges to their weight-loss goals, whereas others feel they lack the requisite skills? Research on implicit theories has sought to answer these and similar questions for decades, examining how lay beliefs, namely incremental theories (beliefs that human attributes can be improved or developed) and entity theories (beliefs that human attributes are fixed or invariant), influence self-regulation (Dweck \& Leggett, 1988; Molden \& Dweck, 2006).

Although research on implicit theories originated within an academic context, scholars have extended the theory to additional achievement domains, such as athletics (e.g., Kasimatis, Miller, \& Marcussen, 1996; Ommundsen, 2003), weight management (Burnette, 2010), and leadership (Burnette, Pollack, \& Hoyt, 2010). Across these contexts, implicit theories have been postulated to be linked to various self-regulatory processes, including goal setting (e.g., Robins \& Pals, 2002), social comparison (Nussbaum \& Dweck, 2008), overcoming stereotype threat (e.g., Aronson, Fried, \& Good, 2002), selective information attention (Mangels, Butterfield, Lamb, Good, \& Dweck, 2006), and remedial action (e.g., Hong, Chiu, Dweck, Lin, \& Wan, 1999).

Although many studies have demonstrated support for the hypothesis that implicit theories predict self-regulatory processes (e.g., Kray \& Haselhuhn, 2007; Nussbaum \& Dweck, 2008; Thompson \& Musket, 2005), other studies have shown either null effects (e.g., Biddle, Wang, Chatzisarantis, \& Spray, 2003; Doron, Stephan, Boiche, \& Le Scanff, 2009; Ommundsen, Haugen, \& Lund, 2005) or even a reversal of theoretically expected effects (Bråten \& Strøms $\varnothing$, 2005). Meta-analytic procedures are particularly well-suited to literatures characterized by (apparently) contradictory empirical findings, especially when such procedures can bolster 
theoretical and empirical coherence by incorporating relevant moderator variables. Thus, the present review seeks to address empirical ambiguities and to highlight key moderators of links between implicit theories and self-regulatory processes and outcomes.

Additionally, although the multidisciplinary research linking implicit theories to diverse self-regulatory processes is clear on the independent variable side (i.e., implicit theories), it has lacked theoretical structure on the dependent variable side (i.e., self-regulation). Thus, a primary goal of the current meta-analysis is to impose theoretical coherence on the link between implicit theories and self-regulation by employing a broad, integrative framework. Specifically, we capitalize upon the richness and precision of Carver and Scheier's (1998) model of self-control, which identifies three core processes underlying self-regulation: goal setting, goal operating, and goal monitoring. We conceptualize these three processes in terms of two distinct constructs that have appeared in the empirical implicit theories literature to date: performance goals and learning goals for goal setting, helpless-oriented strategies and mastery-oriented strategies for goal operating, and negative emotions and expectations for goal monitoring (see Table 1). In addition to investigating the strength of associations between implicit theories and self-regulatory processes (as well as relevant moderators of these links), we also examine which of these selfregulatory processes promote the crucial self-regulatory outcome of goal achievement.

Finally, in addition to addressing empirical and theoretical ambiguities, we discuss how conceptualizing the implicit theories literature from the perspective of self-control theory yields an abundance of immediately accessible directions for future research. In pursuit of these three goals - meta-analytically reviewing the literature, bolstering theoretical coherence, and identifying directions for future research—we introduce the Setting/Operating/Monitoring/Achievement (SOMA) Model, which synthesizes the implicit theories literature with Carver and Scheier's $(1982,1998)$ self-control theory. 
The SOMA Model, which is illustrated in Figure 1, distills our empirical and theoretical approach. First, we integrate theorizing from the implicit theories and the self-control literatures (a) to examine the associations of implicit theories with the self-regulatory processes of goal setting (performance goals and learning goals), goal operating (helpless strategies and mastery strategies), and goal monitoring (negative emotions and expectations); and (b) to identify potentially important moderators of these associations (Figure 1, Paths a-n). Second, we examine the associations of implicit theories and the self-regulatory processes with goal achievement, and we examine an important theoretical moderator of these associations (Figure 1, Paths o-w). In addition, we also explore in auxiliary analyses (not depicted in Figure 1) whether two study characteristics moderate the implicit theory and self-regulatory process links: (a) domain of implicit theory (non-academic vs. academic) and (b) type of implicit theory assessment (experimentally induced vs. naturally occurring).

Results from 28,217 participants, who were drawn from 113 independent samples, reveal which self-regulatory processes are most strongly predicted by implicit theories and which selfregulatory processes most strongly predict achievement. These meta-analytic results also reveal which theoretical and methodological moderators influence the magnitude of these main-effect associations. Taken together, the present theoretical analysis and meta-analytic synthesis provide an overview of the current state of the literature linking implicit theories and self-regulation and build toward a novel agenda for future research. Before elaborating on the SOMA Model, we first review the implicit theory perspective and synthesize it with self-control theory.

\section{Implicit Theories}

Just as scientists develop theories to explain the phenomena they investigate, laypersons develop theories about human characteristics such as intelligence, personality, and athletic ability. Unlike scientists' theories, these lay theories are frequently implicit; that is, they are not explicitly 
articulated in the mind of the person holding them. Implicit theories are schematic knowledge structures that incorporate beliefs about the stability of an attribute and organize the way people ascribe meaning to events (Ross, 1989). This assumption — that personal beliefs are critical for understanding human behavior - has been influential in psychology for many decades. Piaget, for example, suggested that the development of meaning systems is just as important as logical thinking in shaping behavior (Piaget, 1928/1964; Piaget \& Garcia, 1991). Similarly, Kelly (1955) suggested that, "man looks at his world through transparent templates which he creates and then attempts to fit over the realities of which the world is composed" (p. 8-9).

Building on these theoretical traditions, an implicit theory perspective suggests that beliefs about the malleable versus fixed nature of human attributes influence self-regulatory processes and outcomes (e.g., Dweck, 2009; Dweck \& Molden, 2005; Molden \& Dweck, 2006). Research has found that these belief systems converge around two main themes: incremental and entity theories (Dweck \& Leggett, 1988). Incremental theorists believe that human attributes, such as intelligence, are malleable and therefore that they are changeable through hard work. In contrast, entity theorists believe that human attributes are fixed and therefore that they cannot be developed. These beliefs focus on control, not stability (Dweck, 2012). As we review the research on implicit theories and synthesize it with self-regulation theory, it is important to bear in mind several basic empirical findings regarding the nature of implicit theories. Across a range of studies and diverse populations, research suggests that (a) entity and incremental theories are endorsed approximately equally; (b) people can hold different theories in different domains (e.g., intelligence vs. athletics), and ego threats in a given domain are frequently irrelevant to implicittheories-relevant dynamics in other domains; and (c) theories are generally uncorrelated with the Big Five trait dimensions, self-esteem, education, and cognitive complexity (Dweck, Chiu, \& Hong, 1995; Niiya, Crocker, \& Bartmess, 2004; Plaks \& Stecher, 2007; Spinath, Spinath, 
Riemann, \& Angleitner, 2003; Tabernero \& Wood, 1999). Implicit theories are conceptually similar to constructs related to worldviews (Plaks, Grant \& Dweck, 2005) and to such variables as essentialist beliefs (Bastian \& Haslam, 2006) and group entitativity (Rydell et al., 2007). In addition, although differences in implicit theories are often conceptualized at a dispositional level (see Dweck, 2009), these theories, like other schemas and beliefs, exhibit some degree of day-today and moment-to-moment fluctuation (e.g., Franiuk, Pomerantz, \& Cohen, 2004). Indeed many scholars have primed implicit theories (e.g., Burnette, 2010; Hong et al., 1999), and temporarily changed them in both one-shot laboratory experiments (e.g., Spray, Wang, Biddle, Chatzisarantis, \& Warburton, 2006) and longer-term interventions (e.g., Blackwell, Trzesniewski, \& Dweck, 2007; Burnette \& Finkel, 2012).

Regardless of achievement context or methodological approach, implicit theories are hypothesized to be related to an array of self-regulatory processes (e.g., Molden \& Dweck, 2006). Namely, it is hypothesized that incremental theorists set goals focused on learning, employ mastery-oriented strategies to reach these goals, and report greater confidence and expectations when evaluating the potential for goal success. In contrast, it is hypothesized that entity theorists set goals focused on performance, employ helpless-oriented strategies in the face of challenges to goal pursuits, and report feeling vulnerable and anxious when evaluating past and future performance. However, although many scholars have provided evidence for these proposed links (e.g., Kray \& Haselhuhn, 2007; Nussbaum \& Dweck, 2008; Thompson \& Musket, 2005), others have shown null effects (e.g., Biddle et al., 2003; Doron et al., 2009; Ommundsen et al., 2005). For example, in a sample of adults returning to school, implicit theories failed to predict goal setting or goal engagement (Dupeyrat \& Mariné, 2005). Other scholars have even shown reversals of expected effects; for example, one study found that incremental, relative to entity, theories 
predicted less confidence by new teachers in their ability to accomplish their tasks (Bråten \& Strømsø, 2005).

In summary, although implicit theories are hypothesized to relate to self-regulatory processes, research has yet to summarize the nature or strength of this effect across studies, domains, and populations. Additionally, the literature lacks theoretical integration on the dependent variable side (self-regulation). To bolster theoretical coherence, summarize existing research, and address potential discrepancies, we employed meta-analytic procedures not only to establish the strength and direction of the effect of implicit theories on specific self-regulatory processes but also to identify when implicit theories relate to self-regulation and goal achievement. In the ensuing sections, we first elaborate on how implicit theories can be merged with self-control theory before describing a key moderator of relations.

\section{Self-Regulation}

As noted previously, we use Carver and Scheier's $(1982,1998)$ self-control theory to organize the self-regulation literature for this review. Figure 1 introduces our SOMA Model and organizes our review of links between implicit theories and self-regulatory processes and outcomes. The model is not simple, but it is a simplification insofar as it assumes purely linear and unidirectional relations. The SOMA Model uses the feedback loop structure of self-control theory to outline the direct links between implicit theories and the three primary self-regulatory processes derived from the feedback loop. We first discuss the nature of the feedback loops before outlining how these processes translate to our SOMA Model.

Carver and Scheier $(1982,1998)$ frequently introduce their feedback loop model of selfregulation with a discussion of a thermostat that is programmed to start heating if the temperature is currently below a certain level, to start cooling if the temperature is currently above that level, and to turn off if the temperature is precisely at that level. For example, if it is currently $67^{\circ}$ 
(Fahrenheit; the input value or current state) in one's house and one is chilly, one might set the thermostat to $70^{\circ}$ (the setting process) before leaving to run some errands. From that point on, the system "self-regulates," beginning by emitting more heat into the house (operating on the environment to change its state), and then periodically testing to learn whether the temperature in the house matches $70^{\circ}$ (the monitoring process). If the current temperature deviates from $70^{\circ}$, the thermostat will emit more heat if the temperature is below $70^{\circ}$, whereas it will emit less heat, or perhaps even turn on the air conditioner, if the temperature is above $70^{\circ}$. A simplified version of this model (which we adapted from Carver \& Scheier, 1998, p. 22), depicting the action feedback loop linking goal setting, goal operating, goal monitoring, and the input function, is shown in Figure 2. Carver and Scheier $(1982,1998)$ suggest that this thermostat process is analogous to the selfregulation of behavior, and that insight provides a crucial foundation for our SOMA Model.

As depicted in Figure 1, the SOMA Model synthesizes self-control theory's emphasis on goal setting, goal operating, and goal monitoring with research in the implicit theories domain to develop a broad, integrative analysis of how and when implicit theories facilitate self-regulatory processes and, ultimately, goal achievement. In the ensuing sections, we illustrate the concrete hypotheses emerging from this theoretical synthesis, systematically walking through each path in the SOMA Model and clarifying the structure of our meta-analytic review. We first review the postulated direct associations of implicit theories with the three primary self-regulatory processes_-goal setting, goal operating, and goal monitoring. We then discuss moderators of each link. We conclude with an overview of the postulated direct associations of self-regulatory processes with achievement and discuss the relevant moderators of these links as well.

\section{Goal Setting}

Goal setting involves establishing specific reference points, or desired end states (Carver \& Scheier, 1982; Moskowitz \& Grant, 2009). One important question we address in this report is, 
"Where does the standard of comparison come from?” (Carver \& Scheier, 1982, p. 113). We suggest that implicit theories serve as an important influence on the nature of these standards. Specifically, we suggest that beliefs about the malleable versus fixed nature of ability predict two central constructs linking implicit theories to goal setting: the setting of performance-oriented goals and the setting of learning-oriented goals.

We structure our review of goal setting around achievement goal theory, which has been influential in the motivation literature for several decades (Senko, Hulleman, \& Harackiewicz, 2011). Early work primarily focused on the distinction between performance goals (also called ego-involved, normative, or ability goals; Ames, 1992; Nicholls, 1984) and learning goals (also called task or mastery goals; Ames, 1992; Elliot \& Harackiewicz, 1996; Middleton \& Midgley, 1997). When pursuing performance goals, individuals strive to demonstrate their ability, frequently relative to others (e.g., Leondari \& Gialamas, 2002). Examples in the current analysis included students focusing on achieving the grade they wanted (e.g., Dupeyrat \& Mariné, 2005; Robins \& Pals, 2002) and focusing on their achievement compared to others (e.g., Thompson \& Musket, 2005). When pursuing learning goals, individuals strive to master a skill, usually for the internal satisfaction such mastery provides (e.g., Maurer, Mitchell, \& Barbeite, 2002). Examples in the current analysis included students expressing that the knowledge gained in school is more important than getting good grades (e.g., Robins \& Pals, 2002) and students expressing that they study because they like to learn (e.g., Dupeyrat \& Mariné, 2005).

Although scholars have linked the implicit theories perspective to achievement goal theory for decades, this work has generated inconsistent conclusions. For example, some studies demonstrate that, compared to entity theorists, incremental theorists are less likely to set performance goals and more likely to set learning goals (e.g., Mangels et al., 2006; Robins \& Pals, 2002). Other studies, however, demonstrate null effects (e.g., Dupeyrat \& Mariné, 2005; Maurer et 
al., 2002; Sarrazin et al., 1996), and still others report reversals of hypothesized relations (e.g., Biddle et al., 2003). For example, within a physical activity context, incremental theories of athletic ability were positively correlated with performance goals (e.g., Biddle et al., 2003; Stevenson \& Lochbaum, 2008), whereas an implicit theory perspective might have hypothesized that these two constructs would be negatively correlated.

We suggest that this discrepancy is likely driven, in part, by the distinction between approach and avoidance subcomponents of performance and learning goals (Barron \& Harackiewicz, 2001; Elliot \& Church, 1997; Grant \& Dweck, 2003). This approach/avoidance distinction has not always been articulated in implicit theory research. That is, much of the research on implicit theories, especially early work before the approach/avoidance distinction was introduced, has focused on implicit theories as predictors of learning and performance orientations without incorporating information relevant to approach or avoidance orientations. In contrast, other research has employed either (a) a trichotomous framework linking implicit theories to performance-approach, performance-avoidance, and learning goals (e.g., Bråten \& Strømsø, 2006; Payne, Youngcourt, \& Beaubien, 2007); or (b) a $2 \times 2$ framework linking implicit theories to performance-approach, performance-avoidance, learning-approach, and learning-avoidance goals (e.g., Howell \& Buro, 2009; Stevenson, 2006). Because achievement goal theory offers theoretical and empirical support for attending to the approach/avoidance distinction when examining performance and learning goals, we examined such distinctions as moderators of the SOMA Model links between implicit theories and goal setting processes.

Approach-oriented goals are directed toward acquiring a desirable outcome, whereas avoidant-oriented goals are directed toward avoiding an undesirable outcome (Elliot, 1999). In the current analysis, an example of an approach-oriented performance goal involves students reporting that doing better than other students in school was important to them and would make them feel 
successful (Bråten \& Strosmo, 2006; Chen \& Pajares, 2010; Elliot \& McGregor, 2001). An example of an avoidant-oriented performance goal involves students reporting that their main goal was to avoid looking stupid in front of their peers (Chen \& Pajares, 2010). An example of an approach-oriented learning goal involves students reporting that they wanted to learn as much as possible (Cury, Elliot, Da Fonseca, \& Moller, 2006; Elliot \& McGregor, 2001). Finally, an example of an avoidant-oriented learning goal involves students reporting that they wanted to avoid missing out on learning opportunities (Elliot \& McGregor, 2001). This approach/avoidance distinction is only relevant as a moderator for goal setting processes as such distinctions do not exist for goal operating or goal monitoring processes.

In summary, two crucial issues remain ambiguous in research directly linking implicit theories to goal setting. The first issue pertains to the strength and direction of the associations of implicit theories with performance goals and with learning goals. On the basis of foundational theorizing in the implicit theories literature (Dweck \& Leggett, 1988), we hypothesize that implicit theories will predict goal setting processes, with entity theorists especially likely to set performance goals oriented toward proving their ability and incremental theorists especially likely to set learning goals oriented toward developing mastery. After all, one of the most immediate consequences of believing that ability is fixed (entity beliefs) is that people will try to demonstrate that they possess the ability in question, and one of the most immediate consequences of believing that ability can be developed (incremental beliefs) is that learning has value. This analysis aligns with research suggesting that the two theories represent fundamentally different ways of conceptualizing the self, which yield different pathways toward the generation and maintenance of self-esteem (Dweck \& Leggett, 1988). For entity theorists, self-esteem is fueled by achieving performance goals, which provide information that one possesses the desired attribute. For incremental theorists, self-esteem is fueled by achieving learning goals, which provide information 
that one has acquired mastery. In summary, we expect implicit theories to be important predictors of reference values with entity theorists focusing more on performance goals and incremental theorists more on learning goals.

The second issue pertains to the role of the approach/avoidance distinction in moderating the direct links between implicit theories and goal setting. For performance goals, although entity theorists prioritize performance goals more than incremental theorists do, we suggest that this difference is especially strong for performance-avoidance goals - that is, for performance-related goals relevant to avoiding failure. Entity theorists tend to fear failure feedback because they interpret it as evidence of their inadequate ability, whereas incremental theorists tend to be less fearful of such feedback because they interpret it as useful information toward the longer-term goal of learning and developing mastery. Consequently, we suggest that entity theorists are especially likely to set goals oriented toward avoiding failure in performance domains. In contrast, we suggest that the magnitude of the discrepancy between entity and incremental theorists' emphasis on performance goals is especially weak (perhaps even nonexistent) for performanceapproach goals - that is, for performance-related goals relevant to approaching success. After all, both entity and incremental theorists value goal achievement, and incremental theorists might even value it as much as entity theorists do. Seminal research has empirically supported the idea that entity and incremental theorists differ for performance-avoidance goals but not for performance approach goals (Dweck \& Leggett, 1988; Leggett, 1985). Such research revealed large differences between incremental and entity theorists in the avoidance of challenging performance situations that could yield negative feedback but negligible differences in the approach of such situations (Dweck \& Leggett, 1988, Table 3)

For learning goals, although incremental theorists prioritize learning goals more than entity theorists do, we are especially confident that this difference will emerge for learning-approach 
goals - that is, for learning-related goals relevant to approaching success. Incremental theorists tend to value learning for its own sake, so developing mastery is inherently gratifying for them, whereas entity theorists tend not to value learning except insofar as it demonstrates their ability. Consequently, we suggest that incremental theorists are especially likely to set goals oriented toward approaching success in learning domains. In contrast, we do not have strong intuitions regarding the magnitude of the discrepancy between entity and incremental theorists' emphasis on learning-avoidance goals - that is, on learning-related goals relevant to avoiding missed learning opportunities (which represents the quadrant of the $2 \times 2$ achievement goal theory model that deviates from the trichotomous model). On one hand, incremental theorists might set particularly strong learning-avoidance goals because failing to capitalize upon a learning experience is especially painful for them; this analysis suggests that approach/avoidance should not moderate the link between implicit theories and the setting of learning goals (because incremental theorists would set similarly strong learning-approach and learning-avoidance goals). On the other hand, incremental theorists might be much more attentive to learning-related successes than to learningrelated failures, in which case they might be similar to entity theorists regarding learningavoidance goals; this analysis suggests that approach/avoidance should moderate the link between implicit theories and the setting of learning goals (because incremental, relative to entity, theorists would set especially strong learning-approach goals but not especially strong learning-avoidance goals). Although limited work within implicit theories has tested the full $2 \times 2$ achievement goal theory model, one study supports this moderation hypothesis of approach/avoidance for learning goals, with implicit theories predicting learning-approach but not learning-avoidance goals (Stevenson \& Lochbaum, 2008). Our meta-analytic synthesis can begin to shed light on which of these two possibilities regarding learning-avoidance goals is better-supported by the extant evidence. 
To examine issues related to implicit theories and goal setting, we conducted two metaanalyses. First, we tested the direct link between implicit theories and the setting of performance and learning goals (Figure 1, Paths a and b). Second, we tested whether approach/avoidance (Figure 1, Paths $\mathrm{c}$ and d) moderated the association of implicit theories with these goal setting processes.

\section{Goal Operating}

Goal operating involves activities directed toward goal achievement (Carver \& Scheier, 1998). Specifically, once individuals have set a certain goal, they must engage in one of two processes if they are to achieve effective self-regulation. One process, which is depicted in the dashed Path a' in the feedback loop model depicted in Figure 2, is to discern which actions are most likely to yield success and to begin implementing those actions. For example, a student who, at the start of the semester, sets the goal of achieving an A in her calculus course might set aside 8:30 to 10:00 p.m. every weeknight to work on problem sets (Path a'). The second process, which resides at the interface of Paths a and b in Figure 2 (in the Goal Monitoring triangle), is to monitor one's goal state or rate of progress relative to the goal and, if necessary, update one's assessment of which actions are most likely to yield success and to begin implementing those actions. For example, once our student has learned of her performance on her first calculus exam, she can compare her grade against her goal, and, upon detecting a discrepancy between her input function and her desired end-state, decide to visit her instructor's weekly office hours for additional tutoring (Paths a, b, and c). In general, and in line with self-control theory (Carver \& Scheier, 1998), goal operation encompasses activities, strategies, and behaviors used to reach one's goal or address discrepancies.

Perhaps as a result of the longstanding disconnect between implicit theory research and self-control theory, the implicit theory literature typically has been vague about whether 
incremental and entity theorists should differ in their immediate goal operation processes (Path a') or whether such differences should emerge only after the goal monitoring process has revealed a discrepancy (Paths a, b, and c). Indeed, many implicit theory studies examining operating processes have focused solely on the latter (i.e., addressing discrepancies), and others have failed to establish whether discrepancies exist. For example, in a recent weight management study, the association of implicit theories with goal operation was only examined after dieting setbacks indicating a discrepancy between one's goal and one's current achievement (Burnette, 2010). In the present section, we review literature and theory relevant to a possible direct link between goal setting and goal operating (Path a'). We discuss the second set of processes (Paths a, b, and c) below, in the sections on goal monitoring and on moderating variables related to discrepancies. Do incremental and entity theorists differ in their goal operation, even in the absence of a discrepancy? We suggest that the answer is likely yes, and we draw upon theoretical work in the implicit theories and self-control traditions for two specific reasons for this affirmative answer. First, we suggest that the different goal setting or reference values that incremental and entity theorists establish predict different operating strategies. Given that entity theorists seek to protect their self-esteem by avoiding information that might indicate a lack of ability, they are especially likely to adopt goal operating strategies that could protect their self-esteem in the event of failure. For example, entity theorists tend to adopt avoidant and self-handicapping strategies in achievement contexts to conceal potential incompetence even before discrepancies arise (Shih, 2009). They also tend to engage in emotion-focused coping strategies when confronting achievement-related stress. Such strategies often lead to behavioral disengagement (Compas, Connor-Smith, Saltzman, Thomsen, \& Wadsworth, 2001). In contrast, incremental theorists typically tend not to exhibit self-esteem-protecting strategies in achievement settings. Rather, they tend to engage in problem-solving and other active self-regulatory strategies (Doron et al., 2009). 
Second, building on Carver and Scheier's (1982) early theorizing, and on social-cognitive theorizing more generally, we suggest that implicit theories serve as a cognitive framework that guides how individuals interpret and react to achievement situations, even in the absence of discrepancies such as failure feedback. Specifically, implicit theories serve as an organizing structure that precedes self-regulation regarding any specific goal; they precede any specific instantiation of goal setting, goal operating, or goal monitoring. For example, entity theorists of intelligence tend to arrive at an academic achievement context, even before learning anything specific about that context in particular, with the belief that this context is likely to be riddled with threats to self-perceptions of one's ability. In contrast, incremental theorists of intelligence tend to arrive at an academic achievement context with the belief that this context is riddled with opportunities to develop mastery. Thus, these different mindsets trigger different goal operation processes, even in the absence of a discrepancy.

In summary, drawing on the integration of implicit theory and self-control literature, we expect implicit theories to directly predict goal operating strategies. In this article, we focus on two central constructs linking implicit theories to goal operating: adoption of helpless-oriented strategies and adoption of mastery-oriented strategies. Dweck and colleagues discussed these two distinct responses early in their work on implicit theories (Diener \& Dweck, 1978, 1980; Dweck, 1975). In the early implicit theory literature, helpless-oriented strategies originally described the view that circumstances were out of one's control (Dweck, 1975), but it evolved to include a range of helpless-oriented reactions (e.g., diverting attention and resources away from one's goal; Diener \& Dweck, 1978, 1980). An example of a helpless-oriented strategy in the current analysis was failing to devote adequate resources to the goal (e.g., procrastination; Howell \& Buro, 2009). In contrast to helpless-oriented strategies, mastery-oriented strategies describe an overall "hardy response" revealing persistence and tenacity (Dweck, 2000, p. 6). An example of a mastery- 
oriented strategy in the current analysis was increasing practice time (e.g., Cury, Da Fonseca, Zahn, \& Elliot, 2008). Incremental theorists, compared to entity theorists, are hypothesized to be less likely to adopt helpless-oriented strategies and more likely to adopt mastery-oriented strategies when trying to reach their goals (e.g., Chen et al., 2008; Dweck, 2000; Dweck \& Leggett, 1988; Dweck \& Molden, 2005; Elliott \& Dweck, 1988; Hong et al., 1999; Nichols, White, \& Price, 2006; Pintrich, 2000; Wang \& Biddle, 2001; Wang, Chatzisarantis, Spray, \& Biddle, 2002). For example, within an academic context, students with incremental, compared to entity, theories of intelligence reported increasing goal-pursuit efforts, such as planning and seeking support, when confronting examinations (Doron et al., 2009).

However, although much work supports the direct link between incremental theories and goal operating processes, other work reports null effects (e.g., Howell \& Buro, 2009; Shih, 2009). To examine these potential ambiguities in the literature regarding direct links between implicit theories and goal operating processes, we examine the overall size of the direct effect of implicit theories on helpless- and mastery-oriented strategies (Figure 1, Paths e and f).

\section{Goal Monitoring}

Goal monitoring involves a consideration of potential constraints and available resources for obtaining success (Carver \& Scheier, 1982). Specifically, as depicted in Figure 2, once individuals have set their goals and operated in a certain way (Figure 2, Path a'), they must monitor the degree to which this operation has helped them make progress (Figure 2, Path d), ideally getting them closer to the desired goal state and increasing their potential to achieve it in the future (Figure 2, Paths a and b). Monitoring plays an important role in self-regulation because it reveals what an individual has or has not accomplished and helps to identify if additional operation is needed and what strategies are most appropriate (Figure 2, Path c) (e.g., Pintrich, 2000; Sitzmann \& Ely, 2011). 
The type of monitoring depicted in Figure 2 illustrates a variant of what Carver and Scheier (1998) call an action loop, which assesses the magnitude of a discrepancy. However, Carver and Scheier (1998) also discuss a monitoring-relevant meta loop, which assesses the "rate of discrepancy reduction in the monitoring system over time ..." What's important to the meta loop isn't merely whether discrepancies are diminishing in the action loop but also how rapidly they are diminishing” (p.121, emphasis in original). In short, the action loop monitors distance from the goal, whereas the meta loop monitors velocity, or rate of progress toward the goal. For example, if a student wants to achieve an end-of-quarter grade of an $85 \%$, and she earns a $70 \%$ on the first of six exams, the distance is 15 points. If she earns a $75 \%$ and an $80 \%$, respectively, on the next two exams, she might conclude that although she is closing the gap in terms of distance, her rate of progress is too slow (as she now needs to earn a $95 \%$ average on the last three exams to offset the $75 \%$ average on the first three). Carver and Scheier $(1990,1998)$ suggest (a) that the action and meta loops function simultaneously, but that they yield different outcomes; and (b) that subjective affect and expectancies regarding future goal achievement are strongly influenced by rate of progress in the meta loop, but not particularly influenced by discrepancies in the action loop.

The literature linking implicit theories to goal monitoring has not differentiated between the action and meta loops. In principle, scholars can investigate monitoring dynamics in both the action loop (by assessing actual or perceived discrepancies between a current input function and a desired end-state) and the meta-loop (by assessing actual or perceived discrepancies between one's current velocity and one's desired velocity). In practice, scholars in the implicit theories literature have conducted very few direct investigations of monitoring dynamics in the action loop and, to our knowledge, no direct investigations of monitoring dynamics in the meta loop. Perhaps this neglect is not surprising given that the current analysis is the first to build a broad model 
integrating implicit theory research with self-control theory. To our knowledge, only two studies, too few to meta-analyze meaningfully, have examined monitoring vis-à-vis the action loop, so we postpone our analysis of such monitoring dynamics until the Discussion section. However, many studies have examined monitoring vis-à-vis the meta loop. In particular, abundant research has examined affect and expectancies regarding future goal success, which are the two processes that Carver and Scheier (1998) suggest result from the detection of large versus small velocity discrepancies in the meta-loop. We suggest that these processes serve as compelling, albeit indirect, proxies for the rate-of-change monitoring process in the meta loop.

Affect functions as an indicator of how successful one's goal operating efforts have been in promoting the desired rate of change toward goal achievement. Indeed Carver and Scheier (2012), in some of their most recent writings, note: “...the error signal in this loop (meta loop) is manifest in experience as affect" (p. 8). When one's current rate of change meets or exceeds one's desired rate of change, one experiences positive emotions like happiness and excitement; when it falls below one's desired rate of change, one experiences negative emotions like sadness and anxiety (Carver, 2004; Carver \& Scheier, 1990). The literature linking implicit theories to goal-related affect predominantly emphasizes feelings of helplessness, vulnerability, and anxiety (e.g., Cury et al., 2008; Plaks \& Stecher, 2007), so we focus exclusively on these helpless-oriented negative emotions in this review. Complementing this work emphasizing negative affect is work emphasizing expectations, which function as an indicator of one's likelihood of achieving one's desired rate of progress (and, ultimately, goal achievement) in the future. The literature linking implicit theories to goal-related expectations predominantly emphasizes likelihood estimates pertaining to expected future success on goal-relevant phenomena such as on future dieting attempts (Burnette, 2010). 
We hypothesize that incremental and entity theorists are likely to differ in their tendencies toward negative affect and expectancies vis-à-vis their goal-pursuits for two reasons, one veridical and one perceptual. The veridical reason is that entity theorists, relative to incremental theorists, may tend to progress toward their goals less quickly, in large part due to their elevated tendencies toward procrastination and self-handicapping and toward those avoidant and emotion-focused coping strategies that often lead to behavioral disengagement (Compas et al., 2001; Shih, 2009). Given that people have a lifetime of goal-pursuit experiences under their belts upon arriving to any specific goal-pursuit context, we suggest that people possess at least somewhat accurate perceptions of the rate at which they tend to progress toward their goals. As noted by Carver and Scheier (1998), "repeated experience can cause expectations to become more solidified in memory. In judging what will happen next, people sometimes rely on those memories as much as (or more than) their current experience" (p. 171). As such, we suggest that entity theorists, relative to incremental theorists, are likely to develop the accurate impression that they tend to progress toward their goals less quickly, an impression that is likely to manifest itself in elevated levels of negative affect and diminished expectations for future success.

The perceptual reason for our hypothesis that incremental and entity theorists are likely to differ in their tendencies toward negative affect and expectancies vis-à-vis their goal-pursuits is that incremental theorists are more likely to interpret any given rate of change (a) as evidence that they are developing mastery at the desired rate (if the actual rate reaches or exceeds the target rate) or (b) as providing information that is relevant to the goal operation processes that might be helpful in promoting mastery in the future. Entity theorists, in contrast, are more likely to perceive any rate of change that leaves them short of complete goal achievement as a demonstration, to themselves and perhaps also to others, that they still lack the ability to achieve the goal. Consequently, above and beyond any implicit theories differences in veridical assessments of 
one's tendencies to make rapid progress toward goal achievement, entity theorists might be especially prone toward negative affect and pessimistic assessments regarding future expectancy.

Consistent with this analysis, compelling evidence suggests that incremental theories, relative to entity theories, predict weaker tendencies toward negative emotion and more optimistic expectations from the goal monitoring process. For example, in a computer training study, trainees assigned to an incremental condition in which they were led to believe that their computer abilities are malleable experienced less anxiety than did trainees assigned to an entity condition in which

they were led to believe that their computer abilities are fixed (Martocchio, 1994). Such tendencies also emerge in qualitative research. For example, when presented with failure feedback after working on a challenging academic task, a student with an incremental theory reported that he or she had the skills to reach their goal (strong expectancies), whereas a student with an entity theory noted that he or she "wouldn't feel smart enough to make it" on future tasks (Dweck, 2000, p. 46). In general, although studies offer empirical support for the negative link between incremental theories and negative affect and the positive link between incremental theories and expectations (e.g., Burnette, 2010; Maurer et al., 2002; Tabernero \& Wood, 1999; Wang \& Biddle, 2003), others report null results (e.g., Garofano, 2006; Spray et al., 2006; Stump, Husman, Chung, \& Done, 2009), and some report links trending in the opposite direction (e.g., Bråten \& Strømsø, 2005; Dupeyrat \& Mariné, 2001). To examine these ambiguities in the literature, we examine the overall size of the direct effect of implicit theories on negative emotions and positive expectation evaluations (Figure 1, Paths g and h).

\section{Moderation by Ego-Threat}

Overall, we expect implicit theories to be related to the self-regulatory processes of goal setting, goal operating, and goal monitoring (see Table 1 and Figures 1 and 2). We hypothesize that strong incremental theories (i.e., weak entity theories) should be positively related to learning 
goals, mastery-oriented strategies, and expectations and negatively related to performance goals, helpless-oriented strategies, and negative emotions. We not only explore the strength of these relations, but we also explore relevant theoretical moderators, examining when such relations exist. Specifically, for goal setting, we examine approach and avoidance subcomponents of the goal orientations. Approach and avoidance is only relevant as a moderator for goal setting as such distinctions do not exist for goal operating and goal monitoring processes. However, across all processes (see Figure 1), we examine whether across-study variability linking implicit theories to self-regulatory processes might result in part from the existence (and occasional neglect) of a theoretically important moderating construct: ego threat.

Ego threat refers to "any event or communication having unfavorable implications about the self' (Baumeister, Heatherton, \& Tice, 1993, p. 143). Although operationalizations of ego threat can confound threats to self-esteem with threats to public image and/or decreased control (Leary, Terry, Allen, \& Tate, 2009), most conceptualizations of ego threat within the implicit theory literature have focused on threats to one's ability (e.g., Burnette, 2010; Hong et al., 1999; Leondari \& Gialamas, 2002). In the current analysis, we use the term "ego threat" to capture a broad array of potential threats to the self, with a focus on information that indicates a discrepancy between desired and actual end states. Examples include failure feedback and setbacks (Burnette, 2010; Dweck, 2000; Hong et al., 1999).

Factors like failure feedback, which enter the feedback loop as part of the input function, suggest that alterations to the self-regulatory processes are necessary. We suggest that when such alterations are needed, the previously discussed differences between entity and incremental theorists' self-regulatory processes should be even stronger. That is, these theories have the greatest effect when individuals confront challenges to their goal pursuits (Dweck, 2012). For example, although incremental and entity theorists exhibited limited disparities in math 
achievement in the less challenging elementary school environment, they showed a continuing divergence in math grades as they transition to the more difficult environment of middle school (Blackwell et al., 2007; Dweck, 2012). When entity theorists struggle in their goal-pursuits (i.e., when they experience ego-threat), they are especially likely to doubt their ability. In contrast, when incremental theorists struggle in their goal pursuits, they believe that the struggle is part of the learning process and, consequently, they remain optimistic that they can still succeed in the future. For example, after experiencing failure, one young student with an incremental theory, “pulled up his chair, rubbed his hands together, smacked his lips, and exclaimed, 'I love a challenge!'” and another said, "You know, I was hoping this would be informative" (Dweck and Leggett, 1988, p. 258). Not only do incremental theorists believe they can succeed in the future even in the wake of failure feedback, but some seem to thrive on such opportunities. In contrast, entity theorists fear such feedback as it indicates, for them, an immutable lack of an ability. In short, when confronting ego threat, entity theorists prioritize proving their ability, whereas incremental theorists focus on improving their ability. We suggest that these variations in responses to challenges, and in the meaning assigned to failure feedback, will increase the incremental-versus-entity differences in the self-regulatory processes of goal setting, operating and monitoring even stronger in the presence (vs. absence) of an ego-threat.

For goal setting, whereas entity theorists confronting a threat or discrepancy tend to focus even more than usual on proving their ability and to focus even less than usual on learning as they strive to protect their self-esteem (e.g., Mangels et al., 2006), incremental theorists confronting a threat or discrepancy tend to focus even more than usual on learning as they strive to grow and develop, as that is their principal means of bolstering their self-esteem. Thus, reference points (goals) will be more strongly related to implicit theories in the presence (vs. absence) of discrepancies or ego-threats. We suggest that these goal setting dynamics have direct implications 
for goal operating. For example, when entity theorists confront setbacks, they tend to be especially prone toward giving up the pursuit of the relevant goal (Aronson et al., 2002). In contrast, when incremental theorists confront setbacks, they tend to continue to persist in the pursuit of the relevant goal as they try to develop mastery (Dweck, 2000). In other words, when confronting ego-threats, entity theorists' goal operating strategies become even more helpless-oriented, whereas incremental theorists' goal operating strategies become even more mastery-oriented.

Our theoretical analysis suggests that ego-threat should moderate the links between implicit theories and goal monitoring in a manner parallel to its moderating effects involving goal setting and goal operating. However, the implicit theories literature does not allow for firm predictions because the best available measures of monitoring are not only indirect - tapping the immediate affective and cognitive consequences of monitoring — but also mismatched with assessments of ego threat. Specifically, these indirect measures represent the consequences of monitoring rate of change in the meta loop rather than the consequences of discrepancies in the action loop (Carver \& Scheier, 1990, 1998), whereas the implicit theories literature assesses (or manipulates) ego threat vis-à-vis the action loop, rather than the meta loop (e.g., failure feedback on an exam rather than slow rate of progress).

Consider the state of affairs depicted in Figure 3. Panel A presents the hypotheses we can derive from the synthesis of implicit theories and self-control theory. When both the ego threat measure and the monitoring-relevant dependent measure pertain to the discrepancy, or distance, between the current input function and the desired end-state (Cell 1), the association of incremental (vs. entity) beliefs with monitoring should be stronger when ego threat is present rather than absent. The same prediction emerges when both the ego threat measure and the monitoring-relevant dependent measure pertain to the rate of change, or velocity, between the current and desired rate of change (Cell 4). In contrast, when the ego threat measure is velocity- 
relevant (e.g., progress is too slow) and the dependent measure is distance-relevant (e.g., earning a C- on a given exam) (Cell 2), or vice versa (Cell 3), the extant literature offers few clues, if any, for deriving strong hypotheses. For example, given that negative affect and future success expectations result from monitoring in the meta loop and not from monitoring in the action loop (Carver \& Scheier, 1990, 1998), it is not clear whether ego threats relevant to the action loop should moderate links between implicit theories and dependent measures relevant to monitoring in the meta loop (e.g., negative affect).

To see how tricky it is to derive monitoring-relevant hypotheses regarding ego threat moderation, consider the state of the extant literature, which is depicted in Panel B of Figure 3. This panel illustrates that although the implicit theories literature has amassed meta-analyzable empirical evidence for the cell tapping distance-relevant measures of ego threat and velocityrelevant measures of monitoring (Cell 7), it has not done so for the other three cells (Cells 5, 6, and 8). Mentally superimposing the two panels of Figure 3 reveals that the implicit theories literature has only amassed meta-analyzable empirical evidence for a cell where extant theory does not allow for strong hypotheses (see Cells 3 and 7 in Figure 3). On the one hand, one might expect a moderating effect if the discrepancies/ego-threats in the implicit theories literature encompassed information about both distance and velocity, at least at a perceptual level. For example, an entity theorist who receives a failing grade on an exam might simultaneously interpret this to mean that (a) they were not reaching their desired end state (i.e., ego-threat related to distance) and (b) they would never progress towards their goal (i.e., slow or no rate of progress; ego-threat related to velocity). This theorizing would suggest moderation by ego-threat in the current analyses even though there is a mismatch in assessments. On the other hand, based on self-control theory, Carver and Scheier (1990) suggest that affect is not relevant if the discrepancies/ego-threats are in the action loop, as is standard in the implicit theories literature; it is only relevant for assessing rate of 
progress in the meta-feedback loop. From this perspective, only if rate of progress is slower than expected (ego-threat in the meta loop; see Panel A, cell 4) should the relation between implicit theories and indirect assessments of monitoring in the meta loop (i.e., affect and expectations) be moderated. Considering these competing hypotheses and given the state of the extant literature, we explore whether ego threat (in the action loop) moderates the link between incremental (vs. entity) beliefs and monitoring-relevant outcomes (negative emotions and expectancies for the future), but we do not advance firm predictions.

In summary, although we expect that ego-threat will moderate associations of implicit theories with both goal setting and goal operating, the mismatch in assessments for goal monitoring makes moderational predictions more exploratory. To test our two ego-threat moderating predictions for goal setting and operating and the two competing hypotheses outlined above for monitoring, we examine if implicit theories and all self-regulatory process links are especially strong in the presence versus absence of an ego-threat (paths i through $n$ in Figure 1).

\section{Goal Achievement}

In the preceding review, we described how the present work examines implicit theories and self-regulatory processes, using Carver and Scheier's (1982) tripartite model to organize our findings. In addition to examining the links from implicit theories to the self-regulatory processes introduced previously, we also investigate the links from both implicit theories and self-regulatory processes to self-regulatory outcomes (i.e., achievement). The meta-analytic review allows for an empirical investigation of which of the self-regulatory processes mediate the implicit theoryachievement association most powerfully (see Figure 1).

The investigation of goal achievement also helps to address two primary areas of disagreement in the literature. The first is how implicit theories are related to achievement. Dweck and others have suggested that incremental and entity theorists typically do not differ in their 
baseline abilities (e.g., Dweck \& Leggett, 1988; Schunk, 1995), but rather that implicit theories should indirectly predict achievement by influencing certain self-regulatory processes in response to ego threats (Dweck, 2000). This theorizing suggests a mediated moderation model in which implicit theories interact with ego threats to predict self-regulatory processes, which in turn predict achievement (see Figure 1). Thus, implicit theories are postulated to exhibit a weak direct association with achievement. For example, in one study, although students adopting incremental versus entity theories could not be distinguished by ability upon entering middle school, incremental theorists, relative to entity theorists, were more successful at maintaining their motivation, and, consequently, kept their grade point average up as they progressed through a challenging transition to adolescence (Blackwell at el., 2007; Dweck, 2009). In another study, although dieters adopting incremental versus entity theories could not be distinguished by initial body weight, incremental theorists lost more weight compared to entity theorists as they sought to cope with challenges to their dieting goals (Burnette, 2010). However, although these and other studies support the theoretical proposition that implicit theories should not be related to initial ability or performance, still other studies have provided evidence that implicit theories do directly predict achievement (e.g. Kray \& Haselhuhn, 2007; Siegle, Rubenstein, Pollard, \& Romey, 2010). This main effect is perhaps not surprising based on the reasoning we outlined above for direct links between implicit theories and self-regulatory processes. We examine the strength of the direct link between implicit theories and achievement, which we expect to be robust but modest, to help address ambiguities in the literature (Figure 1, Path o).

The second area of disagreement we seek to address is how self-regulatory processes are related to achievement within the context of implicit theories. For example, achievement goal theory suggests that performance goals are positively related to achievement, whereas learning goals are typically unrelated (e.g., Elliot, 1999; Harackiewicz, Barron, Pintrich, Elliot, \& Thrash, 
2002). In contrast, an implicit theory perspective suggests that performance goals are negatively related to achievement, whereas learning goals are positively related (Dweck, 2000). Additionally, a recent overview of the motivation literature asserts that "learning goals lead to better achievement than performance goals" (Bargh, Gollwitzer, \& Oettingen, 2010, p. 278). However, even within implicit theory research, there are contradictory findings. For example, although some research supports the hypothesis that learning goals lead to success and performance goals do not (e.g., Dupeyrat \& Mariné, 2005), other researchers find null effects or the opposite pattern (e.g., Cury et al., 2006).

We suggest that disagreements between the achievement goal theory and the implicit theories traditions are due, in part, to variations conceptualizations of goal orientations. A cornerstone of achievement goal theory is that distinctions between approach and avoidance are critical for understanding subsequent outcomes of goal orientations (e.g., Harackiewicz et al., 2002). Namely, this theory suggests that performance-avoidance goals are associated with negative outcomes (e.g., Elliot, 1997; Elliot \& Church, 1997), whereas performance-approach goals are associated with positive outcomes, including greater achievement (e.g., Elliot, 1999; Harackiewicz et al., 2002). Research on learning goals within the goal achievement literature has rarely shown links with performance, regardless of approach or avoidance subcategories (e.g., Harackiewicz et al., 2002), although learning goals (especially learning-approach) are related to other positive outcomes, such as goal engagement and enjoyment (e.g., Barron \& Harackiewicz, 2001; Church, Elliot, \& Gable, 2001; Pintrich \& Garcia, 1991). In contrast to achievement goal theory, research within an implicit theory context has demonstrated positive associations of learning goals with achievement outcomes, but primarily for approach-oriented goals (e.g., Cury et al., 2006). However, within the implicit theory literature, there are discrepancies regarding the size and direction of the link between performance goals and achievement. In seeking to address such 
discrepancies, we report the overall effect of performance and learning goals on achievement (Figure 1, Paths $\mathrm{p}$ and $\mathrm{q}$ ), although we expect the moderating role of approach and avoidance to be crucial (Figure 1, Paths r and s).

In addition to addressing discrepancies in the literature by examining associations of both implicit theories and goal setting processes with achievement, we also examine associations of goal operating and goal monitoring with achievement. For goal operating, whereas helpless strategies are hypothesized to hinder achievement, mastery-oriented strategies are hypothesized to promote it (e.g., Folkman, Lazarus, Gruen, \& DeLongis, 1986). For example, in one study, students holding an incremental theory responded to academic challenges with sustained effort, whereas students holding an entity theory responded with disengagement from the goal (e.g., they did not want to study that subject matter again in the future). The incremental theorists, because of their persistence, ultimately outperformed the entity theorists, ending up with higher grades (e.g., Cury et al., 2006; Fryer, 2010; Dweck \& Sorich, 1999; Henderson \& Dweck, 1990; ; Law, 2009). However, other studies find very small or non-significant relations among goal operating processes and achievement (e.g., Blackwell et al., 2007; Burnette, 2010). In the current analysis, we test whether helpless strategies are negatively linked (Figure 1, Path t) and whether mastery strategies are positively linked (Figure 1, Path u) to achievement.

Turning to goal monitoring, negative emotions, as a signal that one's goal-pursuit progress fails to meet one's expectations (Carver \& Scheier, 1990), can reinforce self-defeating patterns, lower evaluations of prospective outcomes, and ultimately undermine goal achievement (e.g., Cervone, Kopp, Schaumann, \& Scott, 1994; Pekrun, Goetz, Titz, \& Perry, 2002). In contrast, limiting feelings of vulnerability and anxiety can facilitate achievement (Keith \& Frese, 2005; Porath \& Bateman, 2006). However, negative emotions can also provide feedback, signaling that different strategies are needed, which can promote learning and spark motivation to avoid future 
instances that cause such negative states (e.g., Baumeister, Vohs, DeWall, \& Zhang, 2007; Carver \& Scheier, 1998). From an implicit theory perspective, incremental theorists are hypothesized to engage in more active coping, focusing their energy on correction and avoiding feelings of anxiety, and thus often are thought to outperform entity theorists (e.g., Dweck, 2000; Mangels et al., 2006). In addition, incremental theorists are hypothesized to remain confident in their ability and skills to reach future goals, and such expectations evaluations are expected to relate to greater achievement (e.g., Aspinwall \& Taylor, 1992; Brissette, Scheier, \& Carver, 2002; Carver \& Scheier, 1998). For example, within a self-regulated learning context, individuals with higher (vs. lower) expectations set more challenging goals, developed more adaptive strategies for learning, persisted longer, and ultimately performed better (Locke \& Latham, 2002; Sitzmann \& Ely, 2011; Zimmerman, 2002). However, research within an implicit theory context does not always support such relations. For example, in one study, incremental (vs. entity) theorists maintained more positive expectations in the wake of a setback, but such expectations did not directly predict achievement (Burnette, 2010). Despite some inconsistencies linking expectations directly to achievement within implicit theory research, building on a long line of work linking affect and cognition to achievement, we test whether negative emotions are negatively related to achievement (Figure 1, Path v), and whether expectations are positively linked (Figure 1, Path w) to achievement.

\section{The Present Review}

In the present meta-analytic review, we assess the associations of implicit theories with the self-regulatory processes of goal setting, goal operating, and goal monitoring to offer a new, integrative framework for conceptualizing findings relevant to self-regulation. This SOMA Model framework (see Figure 1) imposes theoretical coherence on this broad and diverse literature, and our meta-analytic procedures empower us to resolve ambiguities in the extant literature. Our 
moderational analyses tested whether approach/avoidance moderated any of the four links involving goal setting — the links of incremental theories with both performance goals and learning goals, and the links of both of those types of goals with goal achievement (Figure 1, Paths c, d, r, and s) and whether the presence or absence of an ego threat moderated any of the associations of incremental theories with the six self-regulatory processes (Figure 1, Paths i through $n$ ).

Finally, in addition to these two theoretically derived moderators, we also explored whether two relevant study characteristics moderated links between implicit theories and the six self-regulatory processes. First, research on implicit theories originated within an academic context (68\% of included studies) and has since been extended to a diverse array of achievement domains (e.g., dieting; Burnette, 2010; athletics; Ommundsen, 2003). We explored whether effects are stronger in academics or if they apply equally across contexts by examining if domain of implicit theory (academic vs. non-academic) moderated any of the primary associations. Second, although implicit theories are dispositional constructs (Dweck, 2009), these theories, like other types of schemas and beliefs, can also be temporarily activated. Consequently, they can be primed through one-time laboratory experiments (e.g., Burnette, 2010) and even altered through longerterm interventions (e.g., Blackwell et al., 2007). In summary, in addition to our two theoretically driven moderators, we explored whether domain of implicit theory (academic vs. non-academic) and type of implicit theory assessment (naturally assessed via self-report vs. experimentally induced) moderated any of the primary associations between implicit theories and self-regulatory processes.

We examined the association of implicit theories with self-regulatory processes and outcomes across a range of contexts (e.g., academics, leadership, management, health, athletics, technology), ages (pre-kindergarten through middle adulthood), and cultures (e.g., Australia, France, Greece, Hong Kong, Singapore, United States). Additionally, we examined associations 
across a range of disciplines, including school psychology (e.g., Doron et al., 2009), health psychology (e.g., Burnette, 2010), sports psychology (e.g., Ommundsen, 2003), developmental psychology (e.g., Bempechat, London, \& Dweck, 1991), STEM-related fields (e.g., women in math; Davis, Burnette, Allison, \& Stone, 2011), leadership studies (e.g., Hoyt, Burnette, \& Innella, 2011), organizational behavior (e.g., Maurer et al., 2003), and neuroscience (e.g., Mangels et al., 2006). Thus, results are not only applicable to diverse contexts and populations, but also to a broad array of fields and subfields of psychology.

The current meta-analysis examined the associations of implicit theories with diverse selfregulatory processes and outcomes across nearly 30,000 observations. This approach not only clarified the strength of these associations but also when and how implicit theories predict selfregulatory processes and outcomes. In summary, the current meta-analysis examined if incremental (vs. entity) theories are consequential for self-regulatory processes and ultimately goal achievement. Before discussing meta-analytic findings, we discuss our methodology.

\section{Method}

\section{Search Strategy and Inclusion Criteria}

We conducted an initial search using the following electronic databases: ABI Inform, ERIC, PsycInfo, Dissertation Abstracts International, and Google Scholar. Search terms included various combinations of the keywords implicit theory, implicit theories, Dweck, fixed, malleable, incremental, and entity. We also conducted a legacy search by "back-tracking" an article by its references to identify additional potentially useful articles that may have been missed in the electronic search. To obtain unpublished and in-press articles, we sent a request to the listserv for the Society for Personality and Social Psychology and contacted individual scholars who are prolific in the area. Our search started with the seminal work of Dweck and Leggett (1988) and concluded in October, 2010. That is, we did not include articles published before 1988 or after 
October, 2010 (other than those obtained through calls for unpublished manuscripts). ${ }^{1}$ This initial search yielded 2,624 possible citations relevant to implicit theories. We identified 236 citations (i.e., published articles, dissertations, theses, and unpublished data) related to Dweck's implicit theory perspective (Dweck \& Leggett, 1988) for possible inclusion in the meta-analysis.

These 236 citations were further analyzed (based on the abstract and, where relevant, the full text of the article) for inclusion in this quantitative synthesis to examine whether the following five inclusion criteria were met. First, sufficient information for computing a bivariate association (e.g., $d, r$, group means) that could be used to calculate an effect size must have been included (or could be obtained from an author). Second, each effect size must have reflected a unique sample. For example, an article that used multiple measures of implicit theories on a single sample could only be entered into the database once. ${ }^{2}$ Third, there had to be a minimum number of included studies $(k)$ of 3 . Although a meta-analysis, in the narrowest of interpretations, only requires two bivariate effects, a $k$ of three is typically cited as the minimum number from which population estimates should be computed (e.g., Bhaskar-Shrinivas, Harrison, Shaffer, \& Luk, 2005), as the precision of such estimates increases as the $k$ increases (Hunter $\&$ Schmidt, 1990). Fourth, we only included articles written in English, although this criterion excluded only $3.8 \%$ of the initial 236 articles. Fifth, implicit theories in a quantifiable form (e.g., assessed with a self-report instrument, experimentally induced) and at least one of the six self-regulatory processes or an achievement outcome, as established by the SOMA Model, must have been included. We excluded findings and articles focusing on implicit theories of relationships (e.g., Finkel, Burnette, \& Scissors, 2007;

\footnotetext{
${ }^{1}$ If data from any unpublished manuscripts were published before this article was accepted for publication, we updated effects and references to include the most recent findings.

2 If multiple relevant effects were reported, we averaged the correlates to obtain the effect size (Hunter \& Schmidt, 2004) and corrected the variance of the averaged effect size (Borenstein, Hedges, Higgins, \& Rothstein, 2009). In the case where a study used multiple samples, each sample was included as a separate entry as long as it met the other inclusion criteria.
} 
Franiuk, Cohen, \& Pomerantz, 2002; Knee, 1998), person perception (e.g., Chiu, Hong, \& Dweck, 1997; Plaks, Grant, \& Dweck, 2005), trust rebuilding (Haselhuhn, Schweitzer, \& Wood, 2010), organization-level implicit theories (Murphy \& Dweck, 2010), consumer evaluations of brand personalities (Park \& John, 2010), inhibited social behavior (Valentiner, Mounts, Durik, \& GierLonsway, 2011), social interactions (e.g., Beer, 2002; Erdley, Cain, Loomis, Dumas-Hines, \& Dweck, 1997; Haselhuhn et al., 2010), and confronting prejudice (Rattan \& Dweck, 2010) because such articles did not include theoretically relevant self-regulatory processes within achievement contexts. Decisions about ambiguous cases were made through conversation among the authors of the current paper, with an emphasis on theoretical relevance to our SOMA Model. The vast majority of studies that were excluded from the meta-analysis were eliminated either (a) because implicit theories and/or self-regulatory processes were discussed in the manuscript but were not measured empirically or, more frequently, (b) because the authors assessed none of the SOMA Model processes: goal setting, goal operating, goal monitoring, or goal achievement.

Final analyses included 85 citations_-published articles, dissertations, theses, and unpublished data - with a total of 113 independent participant samples $(N=28,217)$ across diverse achievement domains (68\% academic) and populations (age range $=5-42 ; 10$ different nationalities; 58\% from United States; 44\% female). The 113 samples yielded 273 total effect sizes. Thus, on average, each sample reported 2.42 relevant relations between implicit theories and a self-regulatory process or outcome (e.g., relation between implicit theory and learning goal and relation between learning goal and achievement). Most (73\%) of the included studies assessed implicit theories as an individual difference variable. Implicit theory assessments across domains typically used a standard assessment adapted from the original measure of implicit theories of intelligence (e.g., "No matter who you are, you can significantly change your intelligence level"; Dweck, 2000, p. 178). In studies assessing (as opposed to manipulating) implicit theories and 
reporting reliability, this predictor variable was generally reliable (mean Cronbach's $\alpha=.80$ ). In studies assessing a self-regulatory process or outcome and reporting reliability, the outcome variable was generally reliable (mean Cronbach's $\alpha=.79$ ). Table 1 presents characteristics of, and example items for, all six of the self-regulatory processes.

\section{Coding Strategy}

Once we established the set of articles to be included, we categorized variables within each included study into a distinct self-regulatory process (i.e., goal setting, goal operating, goal monitoring) or achievement outcome. Two authors (both of whom were trained and well-versed in the areas of self-control theory, implicit theories research, and meta-analytic coding procedures) independently categorized the variables into one of six processes_-performance goals, learning goals, helpless-oriented strategies, mastery-oriented strategies, negative emotions, or expectations - and coded achievement outcomes and moderators. We provide examples of each self-regulatory process category, including example assessment items, in Table 1. We assessed the reliability between coder ratings for the six self-regulatory processes across all studies using a

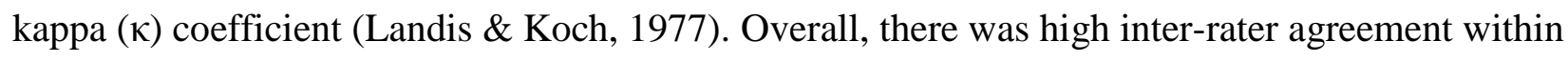
the self-regulatory categorical assessments $(\kappa=.88 ; 95 \%$ Confidence Interval $=.86-.91)$ across all studies included in final analyses (total unique $N=28,217 ; k=113$ ).

To determine approach/avoidance categories for moderation analyses, we relied on authors' reports of assessments and thus did not have two coders categorize this moderator; this procedure was similar to entering data as an assessment of implicit theories, something that also did not require inter-rater agreement. In contrast, we did have two independent coders determine ego threat categories for moderation analyses. Threatening contexts that threatened ability evaluations, such as setbacks (e.g., Burnette, 2010) and failures (e.g., Hong et al., 1999), were coded as a threat condition. Overall, there was high inter-rater agreement for ego-threat $(\kappa=.87$; 
$95 \%$ Confidence Interval $=.77 ; .98)$ across all studies included in final analyses (total unique $N=$ 28,217; $k=113$ ). Discrepancies in coding were addressed, as needed, via discussion among the authors of the current paper.

\section{Demographics Related to Primary Studies}

The following demographic information characterizes the unique studies included across the meta-analyses examining the six self-regulatory processes and the self-regulatory outcome of achievement. If one study reported a relation between implicit theories and more than one selfregulatory process or outcome, it was included only once in the following description of the overall sample of primary research included in analyses. The research reports contributing data to the analyses included published studies (77\%), dissertations (9\%), and unpublished studies (14\%). The participants ranged in age from 5-42 (37\% were school-aged between 5 and 17; 49\% were university-aged between 18 and 23; 14\% were adult-aged between 24 and 42). Across all studies providing demographic data, approximately $44 \%$ of the participants were female. Participants hailed from 10 nations: Australia, France, Greece, Hong Kong, Norway, Singapore, Spain, Taiwan, United Kingdom, and the United States. Samples from the United States made up the majority $(58 \%)$.

\section{Publication Bias}

Publication bias occurs when any systematic process prevents a manuscript from being published based upon something other than the relevance and rigor of the study. Publication bias occurs most frequently when a study's findings are not statistically significant or the findings are contrary to accepted theory. The failure for studies with such findings to be published can result in an inflation of the observed effect size, a persistent concern for meta-analytic reviews (Bösch,

Steinkamp, \& Boller, 2006; McDaniel, Rothstein, \& Whetzel, 2006). We tested for publication bias through two of the most common techniques: Duval and Tweedie's (2000) trim and fill 
technique and Rosenthal's (1979) fail-safe N technique. The trim and fill technique examines the asymmetry of the distribution of effect sizes, trims the required number of studies to achieve a symmetrical distribution, and then determines the number of studies potentially missing due to systematic suppression. In trim and fill, asymmetry is equated with publication bias because sampling error is random and thus should be evenly distributed around the population effect size. The fail-safe $\mathrm{N}$ estimates the number of studies with the mean sample size needed to null a finding - that is, it specifies how many additional studies with no effect would have to exist in the population of studies for the results of the meta-analysis to be non-significant. We also report results for publication status (yes vs. no) as a potential moderator across the links between implicit theories and the six self-regulatory processes.

\section{Meta-Analytic Procedures}

Techniques and corrections. We incorporated procedures from both Hunter and Schmidt (2004) and Lipsey and Wilson (2001), as the combination of these techniques allows for psychometric corrections and continuous moderators. We applied techniques recommended by Lipsey and Wilson (2001) to report the mean effect sizes and the meta-regression tests of moderation. For our primary analyses, we used a random effects approach, as recommended when the between-study heterogeneity in effect sizes is expected to be influenced by more than just sampling error (e.g., substantive moderators, methodological characteristics, and statistical artifacts). We used Hunter and Schmidt (2004) equations to adjust correlations for measurement unreliability. When possible, we performed corrections for unreliability at the level of the individual sample, but when the requisite information was unavailable, we did so using the mean reliability from the reliability distribution generated from the primary samples. The same procedure was used for the moderators when information was not reported within the study. Although we corrected the effects for one statistical artifact (i.e., unreliability), other artifacts may 
potentially affect the between-study heterogeneity, making a random effects approach the most appropriate for overall analyses. We report both the observed $(r)$ and corrected effects $\left(r_{\mathrm{c}}\right)$ in the tables and Results section, but we present the observed effects in the abstract and figures.

Outlier detection. We searched for outliers through a visual inspection of the data, searching for any effect size more than three standard deviations from the population coefficient, and evaluating overall effect size movement through a "one-study removed" analysis (Borenstein, Hedges, Higgins, \& Rothstein, 2009). ${ }^{3}$ Although formal outlier detection techniques exist (e.g., Huffcutt \& Arthur, 1995; Patsopoulos, Evangelou, \& Ioannidis, 2008; Viechtbauer \& Cheung, 2010), their performance is largely untested in the presence of multiple non-orthogonal moderators, which is likely the case in the present work. Thus, when influential cases were detected, we returned to the original article and confirmed magnitude and direction. We identified 4 (Hoyt et al., 2012; Mangels et al., 2006; Plaks \& Stecher, 2007; Taberno \& Wood, 1999) total outliers across all 273 effects analyzed. When running analyses with these 4 outliers included, point estimates remained relatively stable, but the inclusion of these studies substantially increased the $I$-squared statistic (measure of heterogeneity) which further suggested that these effects may indeed be outliers. Thus, we excluded the 4 outliers from final analyses. ${ }^{4}$

Statistical tests of moderators. Our statistical indicator of potential moderation, the $I$ squared statistic (Higgins, Thompson, Deeks, \& Altman, 2003), is the ratio of true heterogeneity to total variation in observed effect sizes. The $I$-squared statistic ranges from zero to one, with

\footnotetext{
${ }^{3}$ A one study removed analysis is an outlier detection technique where the analysis is run $k$ times. The first analysis is the full analysis minus the first study only. The second is the full analysis minus the second study only. So if there were 5 studies total, then the analysis would be $2,3,4,5$, then $1,3,4,5$, then $1,2,4,5$, then $1,2,3,5$, then $1,2,3,4$. If any one of the above analyses was substantially smaller or larger than the others, then the study not included in that analysis would be considered an outlier. For example, if the results showed $r$ 's of .30, .32, .29, .31 and .07, then in all likelihood the 5th study is an outlier because when it is dropped the overall effect changes drastically.
} 
higher values indicating greater heterogeneity of effect sizes and increased likelihood of moderators. We used $I$-squared rather than the $Q$-statistic or tau-squared because it is less affected by the scaling of the measures or the number of included studies (Borenstein et al., 2009). One popular heuristic is that an $I$-squared value greater than 25 percent indicates that a search for moderation is justified (Higgins et al., 2003).

We employed fixed effects meta-regression for testing moderation, one of the more commonly used approaches to meta-regression in the medical and psychological sciences. However, there are a number of different techniques for conducting tests of moderation in metaanalysis. For example, maximum likelihood performs well when testing multiple moderators simultaneously (Viechtbauer, 2005), but this approach has the disadvantage of Type II errors and multivariate normality assumptions. When $k$ 's are small, which was often the case in the current work, the normality assumption is more likely to be violated and such violations can compromise accuracy of estimates. Further, some scholars have suggested multilevel approaches to tests of moderation (Bryk \& Raudenbush, 1992), as well as traditional subgroup analysis (e.g., Hunter \& Schmidt, 2004). Depending on the number of studies, type of data, and research question, all of these techniques have merit. Although we only report the fixed effects results for moderation analyses, we also conducted these analyses using method of moments and maximum likelihood. All three approaches yielded similar effect sizes. ${ }^{5}$

\section{Results}

We used Comprehensive Meta-Analysis 2.0 (Borenstein et al., 2005) to perform all analyses. We calculated the statistical power $(1-\beta)$ of the overall analyses using random effects equations from Hedges and Pigott (2001) to determine the needed power to detect a correlation of

\footnotetext{
${ }^{4}$ The analyses with the outliers included are available from the authors by request. ${ }^{5}$ The results for maximum likelihood and method of moments are available from the second author by request.

${ }^{5}$ The results for maximum likelihood and method of moments are available from the second author by request.
} 
.20. The value of .20 was chosen as it represents the midpoint between a small to moderate effect by Cohen's (1988) standards. The results of these power analyses are presented in Tables 2 and 3.

We structure our presentation of the results around the SOMA Model (see Figure 1). First, we report the direct associations of implicit theories with the self-regulatory processes of goal setting, goal operating, and goal monitoring, examining our theoretically driven moderators along the way (see Table 2; Paths a-n in Figure 1). Next, although not included in the SOMA Model, we explore whether one of the effects within a given self-regulatory process is stronger than the other one (see Table 2): (a) Within goal setting, are incremental theories more strongly related to performance goals or learning goals? (b) Within goal operating, are incremental theories more strongly related to helpless-oriented strategies or mastery-oriented strategies? (c) Within goal monitoring, are incremental theories more strongly related to negative emotions or expectations? Next, we report the direct associations of incremental theories and the self-regulatory processes with goal achievement, examining whether approach/avoidance moderates the associations of the goal setting processes with goal achievement (see Table 3; Paths o-w in Figure 1). After reporting results for all 23 paths in the SOMA Model (see Tables 2 and 3), we report the exploratory moderation results examining the study characteristics of achievement domain and implicit theory assessment approach. Finally, we conclude with a discussion of the results regarding possible publication bias.

\section{Implicit Theories and Self-Regulatory Processes}

\section{Goal Setting (Paths a-d)}

Main effects (Paths a-b). Results for goal setting are presented in the first two rows of Table 2 and in Figure 4. Higher numbers represent stronger incremental-oriented relative to entityoriented theories, stronger performance-oriented goals, and stronger learning-oriented goals. Consistent with our hypotheses, results revealed a negative association of incremental theories 
with performance-oriented goals (Path a; $\left.r=-.151 ; r_{c}=-.196\right)$ and a positive association of incremental theories with learning-oriented goals (Path $\mathrm{b} ; r=.187 ; r_{c}=.241$ ). According to Cohen's (1988) conventions, these effects are small-to-moderate in magnitude. In addition, the magnitude of the two associations (ignoring the direction of the effect) was significantly different, $B=.062, p<.001$. The association of incremental theories with performance goals was slightly smaller than the association of incremental theories with learning goals.

Moderation by Approach/Avoidance (Paths c-d). Before testing whether the associations of incremental theories with performance goals and learning goals were moderated by approach/avoidance, we examined whether the amount of variability in these associations indicated that moderation was likely in principle. As presented in Table 2, the $I$-squared statistic was greater than 25 percent, which suggests that there was considerable variability across effect sizes beyond what would be expected by sampling error alone and suggests that tests of moderation are sensible.

As presented in Table 2, and consistent with our hypotheses, the approach/avoidance distinction (approach $=0$, avoid $=1$ ) significantly moderated the association of incremental theories with performance goals (Path c; $B=-.130, p<.001$ ), with incremental theories exhibiting a stronger negative association with performance-avoidance goals than with performanceapproach goals. The approach/avoidance distinction also significantly moderated the association of incremental theories with learning goals (Path $\mathrm{d} ; B=-.144, p<.001$ ), with incremental theories exhibiting a stronger positive association with learning-approach goals than with learningavoidance goals.

\section{Goal Operating (Paths e-f)}

The results for goal operating are presented in the middle two rows of Table 2 and in Figure 4. Consistent with our hypotheses, results revealed a negative association of incremental 
theories with helpless-oriented strategies $\left(r=-.238 ; r_{\mathrm{c}}=-.323\right)$ and a positive association of incremental theories with mastery-oriented strategies $\left(r=.227 ; r_{\mathrm{c}}=.313\right)$. According to Cohen's (1988) conventions, these effects are moderate in magnitude. In addition, the magnitude of the two associations (ignoring the direction of the effect) was significantly different, $B=-.033, p<.05$. The association of incremental theories with helpless-oriented strategies was slightly stronger than the association of incremental theories with mastery-oriented strategies.

\section{Goal Monitoring (Paths g-h)}

The results for goal monitoring are shown in the last two rows of Table 2 and in Figure 4. Consistent with our hypotheses, results suggest a negative association of incremental theories with negative emotions $\left(r=-.233 ; r_{\mathrm{c}}=-.292\right)$ and a positive association of incremental theories with expectations $\left(r=.157 ; r_{\mathrm{c}}=.196\right)$. According to Cohen's (1988) conventions, these effects are small-to-moderate in magnitude. In addition, the magnitude of the two associations (ignoring the direction of the effect) was not significantly different, $B=.038, p>.05$.

\section{Moderation by Ego-Threat}

Moderation (Paths i-n). As presented in Table 2, the $I$-squared statistic was greater than 25 percent for all six tests linking implicit theories to self-regulatory processes, which suggests that there was considerable variability across effect sizes and suggests that tests of moderation are sensible. Consistent with our hypotheses, ego threat (no ego threat $=0$, ego threat $=1$ ) significantly moderated the association of incremental theories with performance goals - this negative association was especially strong in the presence vs. absence of ego threat (Path e; $B=$ $.104, p<.05$; see Figure 4 and the first pair of bars in Figure 5). Ego threat also significantly moderated the association of incremental theories with learning goals - this positive association was especially stronger in the presence than in the absence of an ego threat (Path $\mathrm{f} ; B=.100, p<$ .001 ; see Figure 4 and the second pair of bars left in Figure 5). Turning to goal operation, and 
consistent with our hypotheses, ego threat also significantly moderated the association of incremental theories with both helpless-oriented strategies - this negative association was especially strong in the presence vs. absence of ego threat $(B=-.096, p<.01$; see Figure 4 and the third pair of bars in Figure 5) — and mastery-oriented strategies - this positive association was especially stronger in the presence than in the absence of an ego threat $(B=.138, p<.001$; see Figure 4 and the fourth pair of bars in Figure 5).

Considering the disconnect between our theoretical analysis and the associations available in the literature (see Figure 3), we did not advance directional hypotheses regarding potential moderation by ego-threat of the associations of incremental beliefs with goal monitoring processes. Exploratory analyses revealed that ego threat did not significantly moderate the association of incremental theories with either negative emotions $(B=.089, \mathrm{p}>.05$; see Figure 4 and the fifth pair of bars in Figure 5) or expectations $(B=-.016, p>.05$; see Figure 4 and the sixth pair of bars in Figure 5). Indeed, if anything, these effects, which did not reach statistical significance, were trending in the opposite direction from the effects for goal setting and goal operating processes, which suggests that the statistical power considerations are unlikely to explain these null effects.

\section{Implicit Theories, Self-Regulatory Processes and Achievement (Paths o-w)}

The results for goal achievement are shown in Table 3 and in Figure 4. Before presenting these results, we make two quick notes. First, the structure of Table 3 differs from that of Table 2 in the placement of the columns and rows because for Table 3 the primary outcome is achievement, whereas for Table 2 the primary outcomes were self-regulatory processes. Specifically, whereas Table 2 places the model-implied dependent variables (the self-regulatory processes) in the rows and the model-implied independent variable (incremental theories) in the columns, Table 3 places the model-implied independent variables (implicit theories and self- 
regulatory processes) in the rows and the model-implied dependent variable (goal achievement) in the columns. Second, in analyzing the seven potential direct links to achievement (i.e., Figure 1, Paths o, p, q, t, u, v, w), there is only one theoretically relevant moderator. Namely, for goal setting, we examined the approach/avoidance distinction. We did not examine if ego threat or the study characteristics moderated these links as such moderation was postulated to come earlier in the psychological chain. That is, we expected ego threat (and study characteristics, if such findings emerged) to moderate relations between implicit theories and self-regulatory processes, not relations with achievement. We present the results of the seven potential direct links with achievement and the approach/avoidance moderation analyses (Figure 1, Paths $\mathrm{r}$ and $\mathrm{s}$ ) below.

Implicit theories and achievement (Path o). The results for the relation between incremental theories and goal achievement are shown in the top row of Table 3 and in Figure 4. Results revealed a positive association of incremental theories with achievement $\left(r=.095 ; r_{\mathrm{c}}=\right.$ .141). According to Cohen's (1988) conventions, this effect is small in magnitude.

Goal setting and achievement (Paths p-s). For goal setting, performance goals correlated negatively, albeit nonsignificantly, with achievement $\left(r=-.022 ; r_{\mathrm{c}}=-.024\right)$, whereas learning goals correlated positively, albeit nonsignificantly, with achievement $\left(r=.032 ; r_{\mathrm{c}}=.039\right)$. These findings did not support our hypotheses. The magnitude of the association between performance goals and achievement and learning goals and achievement did not differ significantly, $B=.009, p$ $>.05$.

Despite the null main effects linking goal setting processes to achievement, approach/avoidance moderated these hypothesized links. The approach/avoidance distinction significantly moderated the association of performance goals with achievement - this association was more positive for performance-approach than for performance-avoidance goals (Path $\mathrm{r} ; B=$ $.383, p<.05 ;$ see Figure 4; correlations are .157 and -.221 respectively). The approach/avoidance 
distinction also significantly moderated the association of learning goals with achievement — this association was more positive for performance-approach than for performance-avoidance goals (Path s; $B=-.217, p<.001$; see Figure 4; correlations are .140 and -.076 respectively). These findings suggest that performance and learning goals enhance achievement if they are approachoriented, but they undermine achievement if they are avoidant-oriented.

Goal operating and achievement (Paths t-u). For goal operating, helpless-oriented strategies correlated negatively, albeit nonsignificantly, with achievement $\left(r=-.102 ; r_{\mathrm{c}}=-.165\right.$, whereas mastery-oriented strategies correlated positively, and significantly, with achievement $(r=$ $\left..314 ; r_{\mathrm{c}}=.440\right)$. According to Cohen's (1988) conventions, these effects are small to moderate/large in magnitude. The association of mastery-oriented strategies with achievement was significantly stronger than the association of helpless-oriented strategies with achievement, $B=$ $.186, p<.001$.

Goal monitoring and achievement (Paths v-w). For goal monitoring, negative emotions correlated negatively, and significantly, with achievement $\left(r=-.324 ; r_{\mathrm{c}}=-.422\right)$, whereas higher expectations evaluations correlated positively, and significantly, with achievement $\left(r=.406 ; r_{\mathrm{c}}=\right.$ .548). According to Cohen's (1988) conventions, these effects are moderate to large in magnitude. The strength of these two associations differed significantly from each other, $B=.159, p<.001$, but both are relatively strongly linked with achievement.

\section{Study Characteristic Moderation Analyses}

The study-characteristic moderating variables were coded as follows: (a) domain: $0=$ academic, 1 = non-academic; (b) method of assessment: 0 = naturally occurring, $1=$ experimental induced. We first tested whether domain of implicit theory moderated any of the six associations of incremental beliefs with the self-regulatory processes. Three of the six effects were significant: The negative associations of incremental theories with helpless-oriented strategies $(B=-.086, p<$ 
$.001)$ and negative emotions $(B=-.165, p<.05)$ and the positive association of incremental theories with mastery-oriented strategies $(B=.062, p<.05)$ were stronger in the non-academic compared to the academic domain. Second, we tested whether method of assessment moderated any of the six associations of incremental beliefs with the self-regulatory processes. Three of the six effects were significant: the negative associations of incremental theories with performance goal orientation $(B=-.327, p<.001)$ and negative emotions $(B=-.117, p<.05)$ and the positive association of incremental theories with mastery-oriented strategies $(B=.213, p<.01)$ were stronger in studies that experimentally induced implicit theories as opposed to naturally assessing them. ${ }^{6}$

\section{Results of Publication Bias Tests}

To conduct tests of publication bias (Duval \& Tweedie, 2000; Rosenthal, 1979), we first excluded all unpublished studies. Next, we included all moderators and added sample size as another variable in the simultaneous regression analysis. Publication bias tests that assume "pure" relations with no moderators are inappropriate for the current study based both on theoretical (theory predicts moderated relations) and empirical grounds (the variance attributable to sampling error and the large number of statistically significant moderators). Results from both the trim and fill analyses (i.e., small differences in corrected values and limited number of imputed studies) and high fail-safe $\mathrm{N}$ values (i.e., 192 to 2,060) were consistent with the inference that publication bias cannot explain any of the links between implicit theories and self-regulatory processes and outcomes. In addition, we tested publication status as a moderator. Findings revealed publication status significantly moderated three of six effects linking implicit theories to self-regulatory processes, although all were rather small $(B=.047$ to .109$)$. Specifically, the negative association

\footnotetext{
${ }^{6}$ We explored gender as a moderator across all six processes. Results were inconclusive-only one of the six effects reached significance. Specifically, the negative association of implicit theories with performance goals was weaker when the percentage of women was larger.
} 
of incremental theories with performance goals, the positive association of incremental theories with mastery-oriented strategies, and the positive association of incremental theories with expectations were slightly stronger in published than in unpublished papers.

\section{Discussion}

The overall goals of the present meta-analysis were to provide both theoretical and empirical syntheses of the links between implicit theories and self-regulatory processes and outcomes. Toward these goals, we extended principles from Carver and Scheier's (1982, 1998) model of self-regulation to build the SOMA Model (Setting/Operating/Monitoring/Achievement). As illustrated in Figure 1, the SOMA Model identifies 23 effects, which we quantatively evaluated in the present quantitative review. We first examined the associations of implicit theories with the self-regulatory processes of goal setting (performance goals and learning goals), goal operating (helpless- and mastery-oriented strategies), and goal monitoring (negative emotions and expectations), testing relevant theoretical moderators for each process (see Paths $a-n)$. Next, we examined the association of implicit theories and the self-regulatory processes with the selfregulatory outcome of goal achievement (see Paths o-w). Finally, we tested relevant study characteristics as potential moderating influences--domain of implicit theory (non-academic vs. academic) and type of implicit theory assessment (naturally occurring vs. experimentally induced). In total, we meta-analyzed results from 113 samples and 28,217 research participants. We summarize the results, which are presented in Tables 2-3 and Figures 4-5, before discussing theoretical implications, practical applications, and limitations.

\section{Summary of Findings}

Direct associations of implicit theories with self-regulatory processes. Regarding goal setting, the present findings help to address two discrepancies in the literature. The first pertains to the strength and direction of the associations of implicit theories with goal setting processes. The 
present findings suggest that incremental (vs. entity) theories correlate negatively with performance goals and positively with learning goals, although these correlations are small to moderate in magnitude. The second issue pertains to the role of approach/avoidance as a moderator of the associations of implicit theories with goal setting processes. The present findings suggest that the negative association of implicit theories with performance goals is stronger for performance-avoidance goals than for performance-approach goals, and that the positive association of implicit theories with learning goals is stronger for learning-approach goals than for learning-avoidance goals. These results dovetail with early implicit theory research (Dweck, 2000; Dweck \& Leggett, 1988) within an academic context that construed performance goals primarily in terms of avoiding looking stupid (avoidance) and learning goals primarily in terms of seeking challenging learning opportunities (approach). These findings highlight the need for specificity of goal content for understanding links between implicit theories and goal setting processes

Regarding goal operating, the present findings help to address the strength of the direct relation between implicit theories and operating in the absence of a discrepancy. The present findings suggest that incremental (vs. entity) theories correlate negatively with helpless-oriented strategies and positively with mastery-oriented strategies. That is, incremental and entity theorists seek different means for reaching their goals before receiving information about their current performance. These associations are moderate in strength. Regarding goal monitoring, the present findings suggest incremental (vs. entity) theories correlate negatively with negative emotions and positively with expectations for success, with moderate effect sizes for the relation with negative emotions and small effect sizes for the relation with expectations for future success.

\section{Moderators of links between implicit theories and self-regulatory processes. In}

addition to examining approach/avoidance as a moderator of theoretical interest for links between implicit theories and goal setting processes, we also examined ego threat as a key moderator of 
links between implicit theories and the six self-regulatory processes. As predicted, the associations of implicit theories with performance and learning goals (the goal setting processes) and with helpless- and mastery-oriented strategies (the goal operating processes) were stronger in the presence versus the absence of an ego threat. However, due to the mismatch in assessments of ego threat and goal monitoring processes (see Figure 3), tests of the potential moderating effects of ego threat in the associations of implicit theories with negative emotions and expectations for success (the goal monitoring processes) were more exploratory. Results from the meta-analysis supported original self-control theory distinction (Carver \& Scheier, 1990, 1998), demonstrating that the associations of implicit theories with negative emotions and expectations for success, indicators of monitoring processes in the meta loop, did not vary significantly as a function of ego threat in the action loop, which taps information related to distance from desired end state but not information related to rate of progress. Whether new ego threat assessments, tapping into the meta loop (rate of change), would moderate the association of implicit theories with emotions or with expectations for success is an important issue for future research to address. Additionally, future work should explore if current ego threat assessments would moderate the association of implicit theories with a monitoring measure relevant to the action loop rather than the meta loop (see Figure 3).

We also examined two relevant study characteristics as moderators of the link between implicit theories and self-regulatory processes: domain of implicit theories (academic vs. nonacademic domain) and type of implicit theory assessment (naturally occurring vs. experimentally induced). Effects appear to be stronger in non-academic rather than academic domains and when implicit theories are manipulated rather than naturally assessed. It seems possible that new domains require even stronger evidence to reach the threshold for publication as researchers seek to offer extensions beyond an academic context. In addition, it seems plausible that studies manipulating theories (because they are done primarily in a laboratory setting) may be eliminating 
noise associated with experiments examining naturally occurring theories, thereby increasing power. Additionally, these manipulations may be especially potent and salient. Overall, however, although these interaction effects are notable, they are subject to many potential explanations. Thus, we are reluctant to draw firm conclusions about them, especially given that these moderators did not substantively alter any of our key conclusions regarding the effects in the SOMA Model.

In summary, examining the link between implicit theories and the six self-regulatory processes identified by the SOMA Model, results suggest that incremental theories are related: (a) negatively to performance goals, (b) positively to learning goals, (c) negatively to helplessoriented strategies, (d) positively to mastery-oriented strategies, (e) negatively to negative emotions regarding one's goal-pursuit, and (f) positively to optimistic expectation evaluations. Approach/avoidance distinctions are critical for understanding links with goal setting, such that implicit theories are more strongly related to performance avoidance and learning approach goals. Additionally, ego threat moderated the four goal setting and goal operating of these six findings (but neither of the monitoring processes), such that implicit theories more strongly predict selfregulatory processes in the presence vs. absence of an ego threat (see Figure 4). The strongest direct links between implicit theories and self-regulatory processes emerged for goal operating strategies and negative emotions. Such findings provide useful hints for understanding indirect links between implicit theories and achievement.

\section{Associations of implicit theories and self-regulatory processes with achievement. In} examining the link between implicit theories and self-regulatory processes and between selfregulatory processes and achievement outcomes, we sought to address two discrepancies in the literature. The first discrepancy relates to the strength of the direct link between implicit theories and achievement. Although incremental (vs. entity) theories correlated positively with goal achievement, this effect was small, which is consistent with implicit theories scholarship 
suggesting implicit theories generally exhibit modest direct links to achievement (e.g., Blackwell et al., 2007). Additionally, this direct effect is perhaps not surprising considering the links between implicit theories and self-regulatory processes.

The second discrepancy relates to the strength of the link between goal setting processes and achievement. Implicit theory scholarship (e.g., Dweck, 2000) and the motivation literature (e.g., Bargh et al., 2010) suggests that performance goals hinder achievement, whereas learning goals enhance it. In contrast, achievement goal theory suggests that performance goals (especially if approach-oriented) should foster achievement, whereas learning goals should be unrelated to achievement outcomes. Results, however, highlight the importance of understanding the specific content of the goal. Performance and learning goals were not directly associated with achievement. Rather, as outlined in the SOMA Model, we expected goal setting associations with achievement to be moderated by the approach/avoidance distinction. Results revealed significant moderating effects suggesting that approach goals correlated positively with achievement, whereas avoidance goals correlated negatively with achievement, regardless of performance or learning orientation. In summary, to understand the indirect link between implicit theories, goal setting, and achievement, researchers are advised to attend to the goal content (i.e., approach vs. avoidance).

In accordance with the SOMA Model, we suggest that the link between incremental beliefs and goal achievement is mediated not only by goal setting, but also by other self-regulatory processes (operating and monitoring). Regarding goal operating, helpless-oriented strategies were negatively correlated with goal achievement, although this effect was small and not statistically significant. Mastery-oriented strategies were positively and moderately to strongly correlated with achievement. These results suggest that incremental beliefs are likely to exhibit indirect effects on goal achievement by increasing mastery-oriented strategies. Regarding goal monitoring, negative emotions were negatively and moderately to strongly correlated with achievement, whereas 
expectations for success were positively and strongly correlated with achievement. These results suggest that incremental beliefs are likely to exhibit indirect effects on goal achievement by decreasing the tendency to experience anxiety and other negative emotions regarding one's goal pursuit and by increasing the tendency to adopt optimistic expectations about one's ability to achieve one's goals. Indeed, initial results from our model suggest that monitoring may be the most important of the three self-regulatory processes underlying the SOMA Model, as indicated empirically by the largest effect sizes, for achievement outcomes. However, for negative emotions, the sample size was rather small $(k=4)$ and thus results should be interpreted with caution until a larger sample is able to confirm findings.

In summary, the present results suggest that three of the six self-regulatory processes identified by the SOMA Model hold promise for directly linking incremental beliefs to goal achievement: (a) the increased tendency to adopt mastery-oriented strategies, (b) the decreased tendency to experience negative emotion regarding one's goal-pursuit, and (c) the increased tendency to report more positive success expectations. The present results suggest that the associations of incremental beliefs with the decreased tendency to adopt performance-oriented goals and with the increased tendency to adopt learning-oriented goals might not have a notable

direct impact on actual goal achievement. Rather, these associations depend on whether the goal is approach-oriented or avoidance-oriented, with approach predicting greater achievement and avoidance predicting lesser achievement. However, the links between self-regulatory processes and achievement were limited to the context of implicit theories and thus definitive conclusions await additional research.

\section{Theoretical Implications}

We now discuss several theoretical implications of our integration of implicit theory research and self-control theory. The SOMA Model not only synthesizes findings but also helps to 
identify where the extant implicit theories literature has insufficiently emphasized goal setting, goal operating, and goal monitoring processes. We discuss several implications of the SOMA Model for scholarship, focusing on these three crucial self-regulatory processes. We specify two areas of extension for each process (six areas in total), and we present the application of these areas in Table 4 to one specific achievement context: dieting. In addition, we discuss additional topics that now require empirical investigation in light of the merging of implicit theory research with the self-control theory perspective.

Goal Setting. Findings from the current meta-analysis suggest that incremental (vs. entity) theorists tend to set learning-oriented goals and tend not to set performance-oriented goals. Achievement goal theory (Elliot \& Harackiewicz, 1996) refined how implicit theories influence goal content (e.g., approach vs. avoidant content), but the literature has neglected other pertinent components of goal setting. Specifically, to gain greater insight into goal achievement, we suggest that scholars can build upon the SOMA Model to examine the importance and the specificity of the goals incremental and entity theorists set, two crucial components of the goal setting process (Austin \& Vancouver, 1996).

Goal importance refers to individuals' conviction for reaching their goal, including related constructs such as goal attractiveness (e.g., Brehm \& Self, 1989; Hollenbeck \& Williams, 1987), goal intensity (Locke, 1968), goal relevance (Ford, 1992), and goal commitment (e.g., Hollenbeck \& Klein, 1987). A small number of studies in the implicit theories literature has examined goal importance, and results have been inconsistent. For example, Elliot and McGregor (2001) reported a negative correlation between incremental theories and goal importance, which was assessed with items tapping how important participants felt it was to do well on an exam. In contrast, Burkley, Parker, Stermer, and Burkley (2010) reported a positive correlation between incremental theories 
and goal importance, which was assessed with items tapping how important participants felt it was to be good at math.

We hypothesize that such inconsistencies are due to moderating factors, including ego threat and goal fit. First, building on the SOMA Model, incremental (vs. entity) theorists should exhibit especially strong goal conviction in the presence of an ego-threat. Indeed, in the Burkley et al. (2010) study, in which incremental beliefs seemed to bolster evaluations of goal importance, researchers told all participants that they had failed a math exam. In the Elliot and McGregor (2001) paper, in which incremental beliefs seemed to undermine evaluations of goal importance, such a threat was absent. In short, building on the SOMA Model, we suggest that under conditions of threat, incremental theorists remain committed to the goal, whereas entity theorists become disengaged from the goal in favor of protecting their self-esteem by avoiding the appearance of incompetence. By reducing their goal conviction, entity theorists, if they fail again, can protect their self-esteem by claiming that the goal is unimportant to them.

Second, we suggest that whether incremental or entity theorists evaluate their goal as important will depend on whether that goal "fits" their implicit theory (Bianco, Higgins \& Klem, 2003). According to the principle of regulatory fit, people are more motivated to pursue a goal when the means of pursuing it fit their preferred means of goal pursuit (Higgins, 2000). As such, circumstances that help to align implicit theories with goal orientations (i.e., performance or learning goals) should cause people to evaluate the goal as especially important, which should ultimately increase the likelihood of achieving it. We know from the current meta-analysis that incremental theorists are more likely than entity theorists to set learning goals, and we suggest that goal conviction should be enhanced to the degree that their current circumstances fit that goal (e.g., emphasize learning opportunities). In contrast, entity theorists are more likely than incremental theorists to set performance goals, and we suggest goal conviction should be enhanced 
to the degree that their current circumstances emphasize performance outcomes. Indeed, in examining the assessment used in the Elliot and McGregor (2001) paper, in which the link between incremental theories and goal importance was negative, the content of the goal was oriented towards performance (i.e., perform well on the exam). In contrast, in the Burkley et al. (2010) study, in which the link between incremental theories and goal importance was positive, the content of the goal was more ambiguous (i.e., be good at math), which presumably allowed incremental theorists to conceptualize the goal in terms of mastering the material.

In addition to examining goal importance, we also suggest that future research on goal setting processes investigate goal specificity, which refers to the representation of the goal in specific quantitative terms versus more general qualitative terms. According to self-control theory, goal setting refers to the process of defining specific end states, yet implicit theory research examining goal setting has not always defined such end states precisely, often using vague goals (e.g., perform better than others) rather than specific goals (e.g., score in the top $10 \%$ on the final exam). Considering the lack of emphasis on specificity of the goals within implicit theory literature, it is difficult to discern how incremental and entity theorists are likely to differ on this dimension. Rather, more importantly, we suggest that such a lack of emphasis on specificity of goals contributes to empirical inconsistencies in the literature and weakens correlations between goal setting processes and goal achievement. For example, an emphasis on goal specificity may help to explain the nonsignificant associations of performance and learning goals with achievement in the current meta-analysis (see paths $\mathrm{p}$ and $\mathrm{q}$ in Figure 1 and the associated path coefficients in Figure 4). As an illustration of a non-specific goal, a study in the current analysis that revealed a small correlation between performance goals and achievement (Leondari \& Gialamas, 2002) assessed performance goals as student's desire to demonstrate superior ability (performance-approach, $r=.17$ ) or to avoid looking stupid (performance-avoidance, $r=-.09$ ). We 
suggest that in addition to the distinction between approach and avoidance, future work should address issues of specificity, as both learning and performance goals can be vague, rather than specific. Sharpening the specificity of goal setting assessments should enhance predictive validity, as specific goals consistently improve performance (Mento, Steel, \& Karren, 1987). For example, in the current meta-analysis the small magnitude of the link between learning-avoidance goals and achievement ( $r=-.076)$ may be due to lack of specificity in assessment.

Goal Operating. Findings from the current meta-analysis suggest that incremental (vs. entity) theorists are more likely to use mastery-oriented strategies and less likely to engage in helpless-oriented strategies. To gain greater insight into goal achievement, we suggest that scholars can build upon the SOMA Model to extend existing literature by examining the selfregulatory strategies and ability that incremental and entity theorists exhibit, two crucial components of the goal operating process.

Self-regulatory strategies refer to a diverse set of behaviors related to goal-pursuit activities. Research has primarily focused on perseverance toward vs. avoidance of goal-related activities, especially in the face of setbacks (e.g., Burnette, 2010). However, less attention has been allocated to how implicit theories differentially predict other goal pursuit strategies. We suggest that incremental theorists are likely to employ self-regulatory strategies that align with their learning goal orientation, whereas entity theorists are likely to employ self-regulatory strategies that align with their performance goal orientation. For example, within a dieting context, incremental theorists may adopt strategies that focus on learning how to cut calories and eat healthier, whereas entity theorists may adopt strategies that focus on taking a pill that suppresses appetite. Within an academic context, incremental theorists may adopt strategies that focus on reorganizing notes at the end of class to relate theoretical ideas to personal experiences, whereas 
entity theorists may adopt strategies that focus on memorizing only the material that is most likely to appear on the exam in order to most efficiently boost performance outcomes.

We suggest that the strategies hypothesized to be adopted by incremental theorists are not always better or worse than those hypothesized to be adopted by entity theorists. Rather, there are important moderators to bear in mind, and we again focus on ego threat. As outlined in the current meta-analysis and SOMA Model, after facing a setback or ego threat, incremental (vs. entity) theorists should be more likely to adopt challenging strategies that require increased effort. Redoubling effort in this manner is likely to foster achievement following setbacks under many circumstances, but it is unlikely to be the optimal strategy under all circumstances. In particular, when mastery is not an especially high priority (e.g., when seeking to pass the bar exam so one can practice law), more targeted, performance-oriented strategies might be more efficient and effective at enhancing achievement (e.g., higher score on exam). Similarly, when one seeks to address the symptoms of a goal failure rather than the underlying cause, it can be inefficient to go through the effort of developing mastery. For example, if one seeks to improve one's general affective state, it can, under some circumstances, be more efficient to take a psychotropic medication every morning rather than work through one's deep-rooted psychological issues. In such circumstances, entity-oriented strategies might promote the desired end-state more efficiently and perhaps even more effectively than incremental-oriented strategies.

In addition, it might be easier for entity (vs. incremental) theorists to shield performanceoriented goals from goal interference. For example, when studying for a standardized exam, entity theorists might be less likely than incremental theorists to become distracted by an interesting tidbit (e.g., to launch Google or Wikipedia to learn more about it despite the irrelevance of this additional learning for exam performance). Indeed, goal shielding theory assumes that goal inhibition can be influenced by the characteristics of the goals and the context in which the self- 
regulatory strategy unfolds (e.g., Shah, Friedman \& Kruglanski, 2002). We suggest that the pursuit of performance goals, especially in an environment that emphasizes such goals, causes entity theorists to pursue what Shah et al. (2002, p. 1262) called "a singleness of purpose." In contrast, the pursuit of learning goals, especially in an environment that emphasizes performance, may cause incremental theorists to become distracted by alternative goals (e.g., seeking to master vocabulary rather than to do well on exam), which can undermine achievement.

In addition to examining the self-regulatory strategies outlined above, scholars can also develop new insight into goal operating by examining self-regulatory ability. Although incremental (vs. entity) theorists are especially likely to report intentions to exert more effort, such intentions might not always yield success. Closing the gap between intentions and execution requires the capacity to exert self-control (e.g., Baumeister, Heatherton, \& Tice, 1994; Karoly, 1993). Self-regulatory ability refers to the capacity to alter affective, cognitive, and behavioral responses to support the pursuit of goals (Muraven \& Baumeister, 2000). We suggest that incremental theorists may report greater self-regulatory ability because they engage in more effortful self-regulation on a regular basis, as illustrated by findings in the current meta-analysis, and such activities may well strengthen their self-control over a period of time. It appears that individuals can strengthen their self-control ability by regularly engaging in such activities; just as exercise can strengthen muscles, regularly exerting self-control appears to strengthen willpower (Baumeister, Gailliot, DeWall, \& Oaten, 2006; Baumeister \& Tierney, 2011; Finkel, DeWall, Slotter, Oaten, \& Foshee, 2009). For example, self-regulatory strengthening interventions suggest that participants who followed the instructions to exercise self-control over time (e.g., improve posture) showed marked improvement two weeks later on self-regulatory tasks (Muraven, Baumeister, \& Tice, 1999). Such strengthening activities, which incremental theorists engage in 
more than entity theorists, can potentially help individuals develop self-control and resist future depletion.

Goal Monitoring. Findings from the current meta-analysis suggest that incremental theorists avoid negative emotions and retain positive expectations when evaluating the potential for future success. As discussed previously, scholars can measure monitoring either directly by assessing distance and direction in the action loop or indirectly by assessing individuals' subjective affective and cognitive experiences regarding their rate of goal progress in the meta loop. Because the implicit theories literature has largely neglected individuals' direct monitoring tendencies, our quantitative synthesis focused on individuals' indirect monitoring tendencies. However, in the present section, we discuss how future inquiry can employ direct assessments of monitoring — monitoring strategies and frequency — as such processes are essential for altering behaviors to maximize the chance for self-regulatory success (Baumeister \& Vohs, 2007).

First, we suggest scholars develop better understanding of goal monitoring by examining monitoring strategies. For example, within a dieting context, monitoring may involve posting daily updates to a blog that reports the number of pounds one has lost to date. Such a strategy, which involves public commitment and, consequently, can lead to greater success, clearly tracks progress and is used in several popular weight-loss programs (Nyer \& Dellande, 2010). However, it also has the potential to highlight deficiencies. The SOMA Model suggests that such unambiguous recognition of failure can cause entity theorists to experience elevated negative emotions and pessimistic expectations regarding future success. This fear of failure may make it less likely that entity theorists will use a monitoring strategy that can draw attention (their own or others) to discrepancies between actual and desired end states. On the other hand, incremental theorists may see such a strategy as an ideal opportunity for growth and development as regularly 
monitoring via public commitment allows them to constantly evaluate their current progress. For an incremental theorist, such information is important for reaching their goals.

In addition to monitoring strategies, we suggest that incremental and entity theorists may differ in the frequency of their monitoring of goal pursuits. Incremental theorists' desire to take advantage of learning opportunities, combined with their more positive emotional and cognitive reactions while monitoring (especially when confronting ego threat), should motivate them to seek feedback and monitor their goal more regularly. In contrast, entity theorists' fear of failure, combined with their negative emotional and cognitive reactions while monitoring (especially when confronting ego threat), should motivate them to avoid engaging in behaviors that could reveal discrepancies (i.e., monitoring). For example, a study that established a discrepancy between the actual and desired end state as inflexible showed that participants avoided the monitoring situation (Steenbarger \& Aderman, 1979). Such avoidance has implications for achievement, as frequent monitoring provides critical information about goal progress and can be used to discern whether additional action is needed and, if so, what strategies might be most appropriate (e.g., Pintrich, 2000; Sitzmann \& Ely, 2011).

Additional Theoretical Implications. Taking a step back from specific processes to focus on the big picture, one promising aspect of the SOMA Model involves the integration of the implicit theories literature with the process-rich theorizing involving the feedback loops of selfregulated behavior (Carver \& Scheier, 1982, 1998). Specifically, we focus here on developing direct assessments of monitoring in the action loop and ego threat in the meta loop to examine how implicit theories relate to these feedback loop dynamics. We discuss both the importance of perception in the assessment of goal monitoring and the need for research examining rate-ofprogress ego threats. 
First, as addressed in the introduction (see Figure 2), monitoring the distance between actual and desired end states is a critical component of the self-regulation of behavior in the action feedback loop. Yet, direct assessments of this type of monitoring have been largely absent in implicit theory work. We suggest that the best way to assess this monitoring process is to examine perceptual processes. As Carver and Scheier (1982) note, the central function of the feedback system in the action loop is not necessarily to produce behavior directly; rather, "its purpose is to create and maintain the perception of a specific desired condition" (p. 113). We suggest that incremental and entity theorists engage in this perceptual process in distinct ways. In particular, although both types of theorists are likely to detect ego threats (e.g., failure feedback), they are likely to perceive such threats differently. For entity theorists, knowing they have not reached the goal is all the information they need (i.e., action loop only), whereas for incremental theorists, with their focus on learning, more information can still be obtained investigating the discrepancy further (i.e., action loop and meta loop are both relevant).

Two recent neuroscience studies provide support for this perspective. Both studies find that entity and incremental theorists tend to be similar in detecting a mismatch between desired and actual end states. That is, implicit theories do not seem to be related to discrepancy detection. Rather, they relate to attention and conceptual processing of this information. For example, using event-related potentials (ERPs), Mangels and colleagues (2006) found that implicit theories likely predict subsequent self-regulatory behavior through top-down biasing of attention focused on goal-congruent information. Whereas entity theorists' perception is in line with their performancegoal orientation, incremental theorists' perception is in line with their learning-goal orientation. Specifically, although entity theorists and incremental theorists displayed comparable modulation of fronto-centrally distributed P3 activity (signifying mismatch or error) in the face of negative feedback, entity (vs. incremental) theorists exhibited an enhanced anterior frontal P3 (which may 
index greater affective salience of the negative feedback). Additionally, entity theorists were less likely than incremental theorists to engage in sustained processing of feedback relevant to future success. The authors concluded that entity theorists focus more on regulating negative emotions related to lack of potential for future progress, whereas incremental theorists focus more on encoding information critical for future success. That is, entity theorists seem to move almost immediately to the meta loop and believe that future progress is unlikely. Incremental theorists seem to remain attentive to information related to more deep-level processing of potential discrepancies between actual and desired end states and believe that future progress is still a possibility.

The second recent neuroscience study (Moser, Schroder, Heeter, Moran, \& Lee, 2011) supports and extends these initial implicit theory and perception links by examining two additional components of attention: error-related negativity responses (ERN) and error positive (Pe) responses. The authors of this second study argue that these measures are even more direct assessments of the monitoring of mistakes than those used in the Mangels and colleagues (2006) work reported above. Findings suggest that an incremental theory is associated with enhanced allocation of attention to mistakes, and that this awareness is associated with a greater ability to correct mistakes. Specifically, incremental theories predicted Pe, but not ERN, which suggests an association between incremental theories and enhanced error processing. ERN is associated with recognizing there is an error, whereas Pe reflects awareness of and attention allocation to the errors. These findings, in conjunction with those of Mangels and colleagues (2006) suggest that implicit theories predict marked differences in the perceptual dynamics related to direct goal monitoring assessments. Entity and incremental theorist differ not in whether they detect discrepancies but rather in how they attend to subsequent information relevant to correcting errors. These differences between entity and incremental theorists in perception during monitoring 
processes may help to explain differences in self-regulatory processes throughout the loop (e.g., behavior) and subsequent outcomes (e.g., achievement).

Building on these findings, we suggest that future implicit theory research continue to examine the direct link between theories and monitoring in the action loop (i.e., perception). In addition to examining if direct links exist between implicit theories and monitoring in the absence of discrepancies, we also note that future work should examine if ego-threat moderates the effects on perception (see Figure 3, cells 1 and 5). Based on both theorizing presented in the introduction related to ego-threat as a moderator and results from the current meta-analysis, we expect that egothreats (e.g., failure feedback) will strengthen the effect of implicit theories on perceptual processes.

In addition to addressing monitoring in the action loop (direct assessments and moderation by ego-threat), we suggest future research should also address ego threats in the meta loop (see Figure 3, cells 4 and 8). Although evidence from the current analysis (null moderation finding for ego-threat in action loop on monitoring outcome in meta loop) provides indirect support for the idea that entity and incremental may both believe that performance can be modified, empirical evidence directly testing these ideas are required for firm conclusions. Additionally, less is known about how entity and incremental theorists processes information directly tapping rate of progress. For example, if one is trying to lose 30 pounds and has lost 8 pounds after six weeks, is this an adequate rate of progress for both entity and incremental theorists? How does this information feed into the feedback loop depicted in Figure 2? Additionally, as predicted (see Figure 3, panel A cell 4), if entity theorists interpret this information as evidence that progress is too slow, does such information make them even more prone toward negative affect and negative expectations about the potential for success? We suggest that these and other questions related to the merging of implicit theories with self-control theory be explored in future research. 


\section{Practical Implications}

In addition to providing theoretical and empirical coherence and concrete suggestions for future research, the findings from the current meta-analysis may have considerable practical implications. The self-regulatory processes and findings outlined in the SOMA Model are applicable to a wide array of domains, including education, health, business, leadership, and STEM-related fields. By merging the implicit theory perspective with self-control theory and incorporating findings from the SOMA Model, researchers can begin to develop novel and effective interventions and policies. We offer two examples in the domains of academic achievement and obesity.

Regarding academic achievement, we examine ways to improve the academic performance of struggling students. Interventions designed to encourage an incremental view of intelligence help students facing challenges, such as those exposed to stereotype threat (e.g., Aronson et al., 2002) and those who feel they are not expected to succeed (Davis et al., 2011). These brief interventions aimed at fostering an incremental theory improved motivation and, at times, performance. However, these studies have yet to establish the mechanism or mechanisms through which such experimental manipulations and interventions exert their effects. The SOMA Model provides a theoretical framework for identifying which self-regulatory processes most effectively promote goal achievement. According to empirical findings from the current meta-analysis, across achievement domains and populations, the strongest mediators of the link from implicit theories to achievement are the adoption of mastery-oriented strategies and the avoidance of negative emotions regarding evaluations of goal-pursuits (see Figure 4). The other four mediators identified by the SOMA Model—the setting of performance-oriented goals, the setting of learning-oriented goals, the adoption of helpless strategies, and expectations for success regarding one's goalpursuit efforts - appear to be weaker because of the relatively weak association of incremental 
beliefs with the potential mediator or because of the relatively weak association of the potential mediator with achievement (or both). Prior to the meta-analysis, it was not obvious which of the putative mediators was going to hold the greatest promise for linking implicit theories to achievement, but empirically reviewing the literature from the perspective of the SOMA Model helps to identify the most promising mechanisms, information scholars can use when developing new interventions or honing existing ones.

Regarding obesity, we examine ways to increase the effectiveness of interventions designed to help people achieve and maintain a healthy body weight. A new movement, "health at every size” (http://www.haescommunity.org/), seeks to help individuals feel good about themselves, regardless of their body weight (Bacon, 2010). The movement emphasizes that the goal should not be to help individuals lose weight, but rather to help them feel better emotionally and physically at weights that are right for their body type. However, this message also informs individuals that their weight is stable and unchangeable, which are the defining features of an entity theory of body weight. Thus, we are suggesting that people need to be cognizant that the "health at every size" message inadvertently has implicit theory implications. Additionally, although this message may bolster the self-esteem of obese people, such boosts may have adverse self-regulatory consequences, especially in the face of the sort of setbacks that are nearly inevitable among long-term dieters. Thus, we suggest that policymakers and public health officials consider the implicit theory and self-regulation implications of the "health at every size" movement.

\section{Limitations}

Although both the SOMA Model and the current meta-analysis offer notable contributions to the implicit theories literature, neither is without limitations. We discuss one limitation related to the SOMA Model and a series of potential limitations related to interpreting the meta-analysis 
findings. The primary limitation of the SOMA Model relates to feedback loops. The model suggests that implicit theories drive self-regulatory processes, especially in response to ego threats, and that such processes in turn influence subsequent achievement (see Figure 1). This theorizing aligns with implicit theory research (e.g., Dweck, 2000; Molden \& Dweck, 2006), and many experimental studies support this causal ordering (e.g., Blackwell et al., 2007; Burnette, 2010; Hong et al., 1999). However, recent implicit theory research suggests that these associations may be more bidirectional than originally postulated. As just one example, recent research (e.g., Cadwallader, 2009) suggests that goal achievement (the endpoint in the SOMA Model) feeds back to influence the adoption of different implicit theories (the starting point in the SOMA Model). This view that beliefs, self-regulatory processes, and goal achievement mutually influence one another also aligns with self-control theory (Carver \& Scheier, 1982; 1998), which conceptualizes such dynamics in terms of a feedback loop rather than in terms of unidirectional linear associations. Future research could fruitfully explore such feedback loops.

In addition to this limitation of the SOMA Model, we discuss nine potential limitations (many of which apply to most meta-analyses) that scholars should consider when interpreting the meta-analytic findings, each of which can serve as a springboard for future research. First, some of the effect sizes for self-regulatory processes and links to achievement as well as analyses examining ego-threat were based on small sample sizes, and such samples tend to bias the effect size upward (Reynolds \& Day, 1984). For example, the effect size for the link between helplessoriented strategies and achievement was based on sets of studies numbering as few as three. Second, the extant literature did not include tests of incremental validity of implicit theories in predicting self-regulation beyond personality constructs such as self-esteem, dispositional optimism, or trait affect measures because there was an insufficient number of implicit theories studies including such constructs. However, we do note that experimental effects generally were 
just as strong, if not stronger, as non-experimental findings, which suggests that findings are not due to confounding with third variables. Third, the extant literature did not allow us to address unique and overall effects. For example, we could not assess the magnitude of the indirect association of implicit theories with goal achievement through goal setting processes beyond the indirect association of implicit theories with goal achievement through goal operating and monitoring processes. Likewise, we could not test an overall process model. Not only have no studies tested the overall SOMA Model (which was first introduced in the present article), but very few have even tested any of the model's specific mediation or mediated-moderation paths. Fourth, meta-analyses are always dependent on the quality of original studies, and all literatures have across-study variability on this dimension. Fortunately, however, the journal impact factor for studies included in the current meta-analysis revealed a mean of 2.37 , which suggests that the original studies tended to be of fairly high quality. Fifth, we excluded studies not written in English, although this only resulted in the exclusion of only $3.8 \%$ of the original pool of studies. Sixth, in analyzing the relations across the proposed SOMA Model, we investigated multiple relations, thereby potentially inflating our Type I error rate. However, considering that the focus of the current work is on determining effect sizes, rather than significance testing, and considering most of the effects did not derive from the same sample, we did not make adjustments to the metaanalytic results (Nakagawa, 2004). Seventh, publication status (yes vs. no) moderated three of the six links between implicit theories and self-regulatory processes such that effects were stronger in published relative to unpublished studies. Although publication bias tests such as the fail-safe $\mathrm{N}$ and the trim and fill suggest findings are quite robust, caution should be used in interpreting effect sizes. Eighth, only $14 \%$ of included studies had participants age 24 or older. Thus, future research should examine if these findings are robust across developmental stages. For example, it might be especially difficult to change individuals' implicit theories once they reach a certain age and have 
held that belief for a longer period of time, potentially rendering interventions less effective. And ninth, multicollinearity is a potential concern considering that some of the proposed moderators may be correlated. However, based on the low $k$ of some analyses, we chose not to conduct multivariate moderator analyses. As the number of studies on implicit theories grows, the application of multivariate techniques such as meta-regression with relative importance analysis may provide a more complete picture of the moderators in one another's presence and could help to address issues of multicollinearity for moderator tests (Tonidandel \& LeBreton, 2011). This type of analysis may also help to address Type I error rate issues related to running multiple independent tests.

Despite the potential limitations related to interpreting effects from the current metaanalysis, the present article also possesses considerable strengths. First, it represents the first empirical integration of the literature linking implicit theories and self-regulation, a timely contribution in light of the critical mass of research on this topic (total unique $N=28,217 ; k=$ 113) and the widespread impact of this research. Second, the meta-analysis assessed selfregulatory processes and outcomes (a) across diverse achievement domains (e.g., academic, athletics, work, weight), (b) with diverse methods (e.g., cross-section and experimental), and (c) within diverse populations (e.g., 10 different countries, range of age from kindergarten through middle adulthood). Third, the SOMA Model represents the first major theoretical integration of the research linking implicit theories and self-regulation; it not only imposes theoretical coherence on the extant literature, but also, as discussed previously, sets forth an exciting and accessible agenda for future research. Fourth, findings highlight the nuanced associations of implicit theories with self-regulation by providing the first panoramic view of the implicit theory literature (see Figure 1), thereby allowing scholars to examine when and how incremental beliefs are likely to promote effective self-regulation and goal achievement. 


\section{Conclusions}

Across disciplines, recent trends indicate a sustained interest in implicit theories, with extensions to numerous novel achievement contexts in recent years, including self-control (e.g., Job, Dweck, \& Walton, 2010; Mukhopadhyay \& Yeung, 2010), weight management (Burnette, 2010), leadership efficacy (Burnette et al., 2010), academic ability of children with mental disorders (Da Fonseca et al., 2010) and satisfaction with performance (Cho \& Johar, 2011). These diverse applications of the implicit theory perspective have influenced a broad range of subfields within psychological science, including social, personality, clinical, developmental, marketing, and organizational psychology. An overarching framework for understanding the link between implicit theories and self-regulation is timely considering this multidisciplinary expansion. We introduced such a framework in the current meta-analysis by adapting Carver and Scheier's (1982, 1998) model of self-regulation to integrate, underneath a single theoretical umbrella, diverse associations of implicit theories with goal setting, goal operating, goal monitoring, and goal achievement. In addition to imposing theoretical coherence upon an expanding literature, we presented empirical findings that speak to the direction and strength of the relation between implicit theories and self-regulatory processes and outcomes. We also addressed inconsistencies in the literature, identified relevant moderators, and suggested areas for future inquiry.

In summary, the present meta-analysis suggests that mindsets matter. That is, implicit theories are indeed consequential for self-regulatory processes and goal achievement. However, these consequential relations are nuanced. We sought to clarify when (e.g., when facing ego threats) and how (e.g., monitoring processes) implicit theories are consequential for goal achievement. Findings suggest that links are moderated and mediated — and very likely mediatedmoderated. Relations with goal achievement are robust for some plausible mediators, but not for others (see Figure 4). Thus, one important conclusion from the present meta-analysis is that the 
associations of implicit theories with self-regulation are not straightforward and that perhaps the literature would be better served by asking when and how implicit theories are consequential for self-regulation rather than asking if incremental theories are generally beneficial.

In looking toward the future of research linking the implicit theories perspective to goalrelated outcomes, we emphasize a need for studies that (a) incorporate self-control theory, (b) explore the overall SOMA Model, and (c) use these ideas and emerging findings to bolster interventions aimed at improving goal achievement. By providing an overarching theoretical framework and an empirical summary of the existing literature, the present work has the potential to help researchers across diverse disciplines sharpen their hypothesis generation process, extend implicit theories to novel achievement contexts, and develop and hone implicit theory-based interventions. 


\section{References}

*Ahmavaara, A., \& Houston, D. M. (2007). The effects of selective schooling and selfconcept on adolescents' academic aspiration: An examination of Dweck's selftheory. British Journal of Educational Psychology, 77, 613-632. doi:10.1348/000709906X120132

Ames, C. (1992). Classrooms: Goals, structures, and student motivation. Journal of Educational Psychology, 80, 260-267. doi:10.1037/0022-0663.80.3.260

*Aronson, J., Fried, C., \& Good, C. (2002). Reducing the effects of stereotype threat on African American college students by shaping theories of intelligence. Journal of Experimental Social Psychology, 38, 113-125. doi:10.1006/jesp.2001.1491

Aspinwall, L. G., \& Taylor, S. E. (1992). A stitch in time: Self-regulation and proactive coping. Psychological Bulletin, 121, 417-436. doi:10.1037/0033-2909.121.3.417

Austin, J. T., \& Vancouver, J. B. (1996). Goal constructs in psychology: Structure, process, and content. Psychological Bulletin, 120, 338-375. doi:10.1037/0033-2909.120.3.338

Bacon, L. (2010). Health at every size: The surprising truth about your weight. Dallas, TX: BenBella Books.

Bargh, J. A., Gollwitzer, P. M., \& Oettingen, G. (2010). Motivation. In S. Fiske, D. Gilbert, \& G. Lindzey (Eds.), Handbook of social psychology ( $5^{\text {th }}$ ed., pp. 268-316). Boston: McGrawHill.

Barron, K. E., \& Harackiewicz, J. M. (2001). Achievement goals and optimal motivation: Testing multiple goal models. Journal of Educational Psychology, 80, 706-722. doi:10.1037/0022-3514.80.5.706

Bastian, B., \& Haslam, N. (2006). Psychological essentialism and stereotype endorsement. Journal of Experimental Social Psychology, 42, 228-235. doi:10.1016/j.jesp.2005.03.003 
Baumeister, R. F., Gailliot, M., DeWall, C. N., \& Oaten, M. (2006). Self-regulation and personality: How interventions increase regulatory success, and how depletion moderates the effects of traits on behavior. Journal of Personality, 74, 1773-1802. doi:10.1111/j.1467-6494.2006.00428.x

Baumeister, R. F., Heatherton, T. F., \& Tice, D. M. (1993). When ego threats lead to selfregulation failure: Negative consequences of high self-esteem. Journal of Personality and Social Psychology, 64, 141-156. doi:10.1037/0022-3514.64.1.141

Baumeister, R. F., \& Tierney, J. (2011). Willpower: Rediscovering the greatest human strength. New York: Penguin Press.

Baumeister, R. F., \& Vohs, K. D. (2007). Self-regulation, ego depletion, and motivation. Social and Personality Psychology Compass, 1, 1-14. doi:10.1111/j.1751-9004.2007.00001.x

Baumeister, R. F., Vohs, K. D., DeWall, C. N., \& Zhang, L. (2007). How emotion shapes behavior: Feedback, anticipation, and reflection, rather than direct causation. Personality and Social Psychology Review, 11, 167-203. doi:10.1177/1088868307301033

Beer, J. S. (2002). Implicit self-theories of shyness. Journal of Personality and Social Psychology, 83, 1009-1024. doi:10.1037/0022-3514.83.4.1009

*Bempechat, J., London, P., \& Dweck, C. S. (1991). Children's conceptions of ability in major domains: An interview and experimental study. Child Study Journal, 21, 11-35.

*Bergen, R. (1991). Beliefs about intelligence and achievement-related behaviors. Unpublished doctoral dissertation, University of Illinois, Urbana-Champaign.

Bhaskar-Shrinivas, P., Harrison, D. A., Shaffer, M. A., \& Luk, D. M. (2005). Input-based and time-based models of international adjustment: Meta-analytic evidence and theoretical extensions. Academy of Management Journal, 48, 257-281.

doi:10.5465/AMJ.2005.16928400 
*Bernstein, D. (2006). The impact of implicit theories of intelligence on the motivation of students with learning challenges (Doctoral dissertation). Retrieved from http://fordham.bepress.com/dissertations/

Bianco, A. T., Higgins, E. T., \& Klem, A. (2003). How 'fun/importance' fit affects performance: Relating implicit theories to instructions. Personality and Social Psychology Bulletin, 29, 1091-1103. doi:10.1177/0146167203253481

*Biddle, S. J. H., Wang, C. K. J., Chatzisarantis, N. L. D., \& Spray, C. M. (2003). Motivation for physical activity in young people: Entity and incremental beliefs about athletic ability. Journal of Sports Sciences, 21, 973-990. doi:10.1080/02640410310001641377

*Blackwell, L. S., Trzesniewski, K. H., \& Dweck, C. S. (2007). Implicit theories of intelligence predict achievement across an adolescent transition: A longitudinal study and an intervention. Child Development, 78, 246-263. doi:10.1111/j.1467-8624.2007.00995.x

Borenstein, M., Hedges, L.V., Higgins, J. P. T., \& Rothstein, H. R. (2009). Introduction to metaanalysis. United Kingdom: Wiley. doi:10.1002/9780470743386

Bösch, H., Steinkamp, F., \& Boller, E. (2006). Examining psychokinesis: The interaction of human intention with random number generators-A meta-analysis. Psychological Bulletin, 132, 497-523. doi:10.1037/0033-2909.132.4.497

*Bråten, I., \& Strømsø, H. I. (2004). Epistemological beliefs and implicit theories of intelligence as predictors of achievement goals. Contemporary Educational Psychology, 29, 371-388. doi:10.1016/j.cedpsych.2003.10.001

*Bråten, I., \& Strøms $\varnothing$, H. I. (2005). The relationship between epistemological beliefs, implicit theories of intelligence, and self-regulated learning among Norwegian postsecondary students. British Journal of Educational Psychology, 75, 539565. doi:10.1348/000709905X25067 
*Bråten, I., \& Strømsø, H. I. (2006). Predicting achievement goals in two different academic contexts: A longitudinal study. Scandinavian Journal of Educational Research, 50, 127-148. doi:10.1080/00313830600575932

Brehm, J. W., \& Self, E. A. (1989). The intensity of motivation. Annual Review of Psychology, 40, 109-131. doi:10.1146/annurev.ps.40.020189.000545

Brissette, I., Scheier, M. F., \& Carver, C. S. (2002). The role of optimism and social network development, coping, and psychological adjustment during a life transition. Journal of Personality and Social Psychology, 82, 102-111. doi:10.1037/0022-3514.82.1.102

*Brown, E. D. (2009). Persistence in the face of academic challenge for economically disadvantaged children. Journal of Early Childhood Education, 7, 173-184. doi:10.1177/1476718X09102650

Bryk, A. S., \& Raudenbush, S. W. (1992). Hierarchical linear models: Applications and data analysis methods. Advanced qualitative techniques in the social sciences, 1 . Thousand Oaks, CA: Sage.

Burkley, M., Parker, J., Stermer, S. P., \& Burkley, E. (2010). Trait beliefs that make women vulnerable to math disengagement. Personality and Individual Differences, 48, 234-238. doi:10.1016/j.paid.2009.09.002

*Burnette, J. L. (2010). Implicit theories of body weight: Entity beliefs can weigh you down. Personality and Social Psychology Bulletin, 36, 410-422. doi:10.1177/0146167209359768

Burnette, J. L., \& Finkel, E. J. (2012). Buffering against weight gain following dieting setbacks: An implicit theory intervention. Journal of Experimental Social Psychology, 48, 721-725. doi:10.1016/j.jesp.2011.12.020 
*Burnette, J. L., Pollack, J. M. \& Hoyt, C. L. (2010). Individual differences in implicit theories of leadership ability and expectations: Predicting responses to stereotype threat. Journal of Leadership Studies, 3, 46-56. doi:10.1002/j1s.20138

*Burns, K. C., \& Isbell, L. M. (2007). Promoting malleability is not one size fits all: Priming implicit theories of intelligence as a function of self-theories. Self and Identity, 6, 51-63. doi:10.1080/15298860600823864

*Cadwallader, S.M. (2009). The implicit theories of intelligence of English adolescents identified as gifted and talented (Doctoral dissertation). Retrieved from http://go.warwick.ac.uk/wrap/2745

Carver, C.S. (2004). Self-regulation of action and affect. In R. F. Baumeister \& K. D. Vohs (Eds.), Handbook of self-regulation: Research, theory, and applications (pp. 13-39). New York: Guilford Press.

Carver, C. S., \& Scheier, M. F. (1982). Control theory: A useful conceptual framework for personality-social, clinical, and health psychology. Personality Bulletin, 92, 111-135. doi:10.1037/0033-2909.92.1.111

Carver, C. S., \& Scheier, M. F. (1990). Origins and functions of positive and negative affect: A control-process view. Psychological Review, 97, 19-35. doi:10.1037/0033-295X.97.1.19

Carver, C. S., \& Scheier, M. F. (1998). On the self-regulation of behavior. New York: Cambridge University Press.

Carver, C. S., \& Scheier, M. F. (2012). A model of behavioral self-regulation. In P. A. M. Van Lange, A. W. Kruglanski, \& E. T. Higgins (Eds.) Handbook of Theories of Social Psychology, Volume One (pp. 505-525). Thousand Oaks, CA: Sage. 
Cervone, D., Kopp, D. A., Schaumann, L., \& Scott, W. D. (1994). Mood, expectations and performance standards: Lower moods induce higher standards for performance. Journal of Personality and Social Psychology, 67, 499-512. doi:10.1037/0022-3514.67.3.499

${ }^{*}$ Chen, J. A., \& Pajares, F. (2010). Implicit theories of ability of Grade 6 science students: Relation to epistemological beliefs and academic motivation and achievement in science. Contemporary Educational Psychology, 35, 75-87. doi:10.1016/j.cedpsych.2009.10.003

${ }^{*}$ Chen, L. H., Chen, M. Y., Lin, M. S., Kee, Y. H., Kuo C. F., \& Shui, S. H. (2008). Implicit theory of athletic ability and self-handicapping in college students. Psychological Reports, 103, 476-484. doi:10.2466/pr0.103.2.476-484

Chiu, C., Hong, Y., \& Dweck, C. S. (1997). Lay dispositionism and implicit theories of personality. Journal of Personality and Social Psychology, 73, 19-30. doi:10.1037/0022-3514.73.1.19

Cho, C. K., \& Johar, G. V. (2011). Attaining satisfaction. Journal of Consumer Research, 38, 622631. doi:10.1086/660115

Church, M. A., Elliot, A. J., \& Gable, S. L. (2001). Perceptions of classroom environment, achievement goals, and achievement outcomes. Journal of Educational Psychology, 93, 43-54. doi:10.1037/0022-0663.93.1.43

Cohen, J. (1988). Statistical power analysis for the behavioral sciences (2nd edition). Hillsdale, NJ: Erlbaum.

Compas, B. E., Connor-Smith, J. K., Saltzman, H., Thomsen, A. H., \& Wadsworth, M. E. (2001). Coping with stress during childhood and adolescence: Problems, progress, and potential in theory and research. Psychological Bulletin, 127, 87-127. doi:10.1037/0033-2909.127.1.87

*Corrion, K., D’Arripe-Longueville, F., Chalabaev, A., Schiano-Lomoriello, S., Roussel, P., \& Cury, F. (2010). Effect of implicit theories on judgment of cheating acceptability in 
physical education: The mediating role of achievement goals. Journal of Sports Sciences, 28, 909-919. doi:10.1080/02640414.2010.484065

*Cury, F., Da Fonseca, D., \& Rufo, M. (2002). Perceptions of competence, implicit theory of ability, perception of motivational climate, and achievement goals: A test of the trichotomous conceptualization of endorsement of achievement motivation in the physical education setting. Perceptual and Motor Skills, 95, 233-244.

doi:10.2466/pms.2002.95.1.233

*Cury, F., Elliot, A. J., Da Fonseca, D., \& Moller, A. C. (2006). The social cognitive model of achievement motivation and the 2 × 2 achievement goal framework. Journal of Personality and Social Psychology, 90, 666-679. doi:10.1037/0022-3514.90.4.666

*Cury, F. Da Fonseca, D., Zahn, I., \& Elliot, A. (2008). Implicit theories and IQ test performance: A sequential meditational analysis. Journal of Experimental Social Psychology, 44, 783791. doi:10.1016/j.jesp.2007.07.003

*Da Fonseca, D., Cury, F., Fakra, E., Rufo, M., Poinso, F., Bounoua, L., \& Huguet, P. (2008). Implicit theories of intelligence and IQ test performance in adolescents with Generalized Anxiety Disorder. Behaviour Research and Therapy, 46, 529-536. doi:10.1016/j.brat.2008.01.006

*Da Fonseca, D., Cury, F., Santos, A., Payen, V., Bounoua, L., Brisswalter, J., Rufo, M., Poinso, F., \& Deruelle, C. (2009). When depression mediates the relationship between entity beliefs and performance. Child Psychiatry and Human Development, 40, 213-222. doi:10.1007/s10578-008-0122-9

*Da Fonseca, D., Cury, F., Santos, A., Sarrazin, P., Poinso, F., \& Deruelle, C. (2010). How to increase academic performance in children with oppositional defiant disorder? An implicit 
theory effect. Journal of Behavior Therapy and Experimental Psychiatry, 41, 234-237. doi:10.1016/j.jbtep.2010.01.008

*Davis, J. L., Burnette, J. L., Allison, S. T., \& Stone, H. (2011). Against the odds: Academic underdogs benefit from incremental theories. Social Psychology of Education, 14, 331346. doi:10.1007/s11218-010-9147-6

Diener, C. I., \& Dweck, C. S. (1978). An analysis of learned helplessness: Continuous changes in performance, strategy, and achievement cognitions following failure. Journal of Personality and Social Psychology, 36, 451-462. doi:10.1037/0022-3514.36.5.451

Diener, C. I., \& Dweck, C. S. (1980). An analysis of learned helplessness: II. The processing of success. Journal of Personality and Social Psychology, 39, 940-952. doi:10.1037/0022-3514.39.5.940

*Doron, D., Stephan, Y., Boiche, J., \& Le Scanff, C. (2009). Coping with examinations: Exploring relationships between students' coping strategies, implicit theories of ability, and perceived control. British Journal of Educational Psychology, 79, 515-528. doi:10.1348/978185409X402580

*Dupeyrat, C., \& Mariné, C. (2001). Implicit theories of intelligence, achievement goals, and learning strategy use. Psychologische Beitrage, 43, 34-52.

*Dupeyrat, C., \& Mariné, C. (2005). Implicit theories of intelligence, goal orientation, cognitive engagement, and achievement: A test of Dweck's model with returning to school adults. Contemporary Educational Psychology, 30, 43-59. doi:10.1016/j.cedpsych.2004.01.007

Duval, S., \& Tweedie, R. (2000). A nonparametric "trim and fill" method of accounting for publication bias in meta-analysis. Journal of the American Statistical Association 95, 89-98. doi: $10.2307 / 2669529$ 
Dweck, C. S. (1975). The role of expectations and attributions in the alleviation of learned helplessness. Journal of Personality and Social Psychology, 31, 674-685. doi:10.1037/h0077149

Dweck, C. S. (2000). Self-theories: Their role in motivation, personality, and development. Philadelphia: Psychology Press.

Dweck, C. S. (2009). Can personality be changed? The role of beliefs in personality and change. Current Directions in Psychological Science, 17, 391-394. doi:10.1111/j.1467-8721.2008.00612.x

Dweck, C. S. (2012). Implicit theories. In P. A. M. Van Lange, A. W. Kruglanski, \& E. T. Higgins (Eds.) Handbook of Theories of Social Psychology: Volume Two (pp. 43-61). Thousand Oaks, CA: Sage.

Dweck, C. S., Chiu, C., \& Hong, Y. (1995). Implicit theories: Elaboration and extension of the model. Psychological Inquiry, 6, 322-333. doi:10.1207/s15327965pli0604_12

Dweck, C. S., \& Leggett, E. L. (1988). A social-cognitive approach to motivation and personality. Psychological Review, 95, 256-273. doi:10.1037/0033-295X.95.2.256

Dweck, C. S., \& Molden, D. C. (2005). Self-theories: Their impact on competence motivation and acquisition. In A. J. Elliot \& C. S. Dweck (Eds.), Handbook of competence and motivation (pp. 122-140). New York: Guilford Press.

Dweck, C. S., \& Sorich, L. A. (1999). Mastery-oriented thinking. In C. R. Snyder (Ed.), Coping: The psychology of what works. New York: Oxford University Press.

*Ehrlinger, J. (2011). Implicit theories and performance. Unpublished raw data.

*Ehrlinger, J. \& Brewer, L. (2011). Implicit theories and task choice. Unpublished raw data.

*Ehrlinger, J., \& Conlon, K. E. (2011). Implicit theories and self-assessment. Unpublished raw data. 
*Ehrlinger, J., Conlon, K. E., Dweck, C. S., Park, J., \& Fay, A. (2011). How preferential allocation of attention contributes to overconfidence. Manuscript in preparation. Florida State University.

*Ehrlinger, J., \& Mitchum, X. (2011). Implicit theories and performance. Unpublished raw data. *El-Alayli, A., \& Baumgardner, A. (2003). If at first you don't succeed, what makes you try, try again? Effects of implicit theories and ability feedback in a performanceoriented climate. Self and Identity, 2, 119-135. doi:10.1080/15298860309031

Elliot, A. J. (1997). Integrating the "classic" and "contemporary" approaches to achievement motivation: A hierarchical model of approach and avoidance achievement motivation. In: Maehr, M. and Pintrich, P. (Eds.), Advances in Motivation and Achievement (Vol. 10, pp. 143-179). Greenwich, CT: JAI Press.

Elliot, A. J. (1999). Approach and avoidance motivation and achievement goals. Educational Psychologist, 34, 169-189. doi:10.1207/s15326985ep3403_3

Elliot, A. J., \& Church, M. A. (1997). A hierarchical model of approach and avoidance achievement motivation. Journal of Personality and Social Psychology, 72, 218-232. doi:10.1037/0022-3514.72.1.218

Elliot, A. J., \& Harackiewicz, J. M. (1996). Approach and avoidance achievement goals and intrinsic motivation: A meditational analysis. Journal of Personality and Social Psychology, 70, 461-475. doi:10.1037/0022-3514.70.3.461

*Elliot, A. J., \& McGregor, H. A. (2001). A 2 x 2 achievement goal framework. Journal of Personality and Social Psychology, 80, 501-519. doi:10.1037/0022-3514.80.3.501

Elliott, E. S., \& Dweck, C. S. (1988). Goals: An approach to motivation and achievement. Journal of Personality and Social Psychology, 54, 5-12. doi:10.1037/0022-3514.54.1.5

Erdley, C. A., Loomis, C. C., Cain, K. M., Dumas-Hines F., \& Dweck, C. S. (1997). 
Relations among children's social goals, implicit personality theories, and responses to social failure. Developmental Psychology, 33, 263-272. doi:10.1037/0012-1649.33.2.263

Finkel, E. J., Burnette, J. L., \& Scissors, L. E. (2007). Vengefully ever after: Destiny beliefs, state attachment anxiety, and forgiveness. Journal of Personality and Social Psychology, 92, 871-886. doi:10.1037/0022-3514.92.5.871

Finkel, E. J., DeWall, C. N., Slotter, E. B., Oaten, M., \& Foshee, V. A. (2009). Self-regulatory failure and intimate partner violence perpetration. Journal of Personality and Social Psychology, 97, 483-499. doi:10.1037/a0015433

Folkman, S., Lazarus, R. S., Gruen, R.J., \& DeLongis, A. (1986). Appraisal, coping, health status, and psychological symptoms. Journal of Personality and Social Psychology, 50, 571-579. doi:10.1037/0022-3514.50.3.571

Ford, M. E. (1992). Motivating humans: Goals, emotions, and personal agency beliefs. Thousand Oaks, CA: Sage.

Franiuk, R., Cohen, D., \& Pomerantz, E. M. (2002). Implicit theories of relationships: Implications for relationship satisfaction and longevity. Personal Relationships, 9 345-367. doi:10.1111/1475-6811.09401

Franiuk, R., Pomerantz, E. M., \& Cohen, D. (2004). The causal role of theories of relationships: Consequences for satisfaction and cognitive strategies. Personality and Social Psychology Bulletin, 30, 1494-1507. doi:10.1177/0146167204264894

*Froehlich, S. W. (2007). Gender differences in intelligence theory, achievement motivation and attributional style: Effects on choice of science, math and technology careers (Master's thesis). Retrieved from http://dspace.sunyconnect.suny.edu/

*Fryer, J. W. (2010). Stability and change in achievement goals across the middle school transition (Doctoral dissertation). Retrieved from https://urresearch.rochester.edu/ 
*Garofano, C. M. (2006). Initial testing of the continuous employee development model: Outcome expectations and work-related implicit theory (Doctoral dissertation). Retrieved from http://ucf.catalog.fcla.edu/cf.jsp

*Gonida, E., Kiosseoglou, G., \& Leondari, A. (2006). Implicit theories of intelligence, perceived academic competence, and school achievement: Testing alternative models. American Journal of Psychology, 119, 223-238. doi:10.2307/20445336

*Good, C., Aronson, J., \& Inzlicht, M. (2003). Improving adolescents' standardized test performance: An intervention to reduce the effects of stereotype threat. Applied Developmental Psychology, 24, 645-662. doi:10.1016/j.appdev.2003.09.002

Grant, H., \& Dweck, C.S. (2003). Clarifying achievement goals and their impact. Journal of Personality and Social Psychology, 85, 541-553. doi:10.1037/0022-3514.85.3.541

*Greene, J. A., Costa, L. J., Robertson, J., Pan, Y., \& Deekens, V. M. (2010). Exploring relations among college students' prior knowledge, implicit theories of intelligence, and selfregulated learning in a hypermedia environment. Computers \& Education, 55, 1-17. doi:10.1016/j.compedu.2010.04.013

*Greenwald, J. M. (2010). Antecedents of core confidence latent construct: Direct and reciprocal links (Doctoral dissertation). Retrieved from ProQuest Dissertations and Theses database. (AAT 3437022).

Harackiewicz, J. M., Barron, K. E., Pintrich, P. R., Elliot, A. J., \& Thrash, T. M. (2002). Revision of achievement goal theory: Necessary and illuminating. Journal of Educational Psychology, 94, 638-645. doi:10.1037/0022-0663.94.3.638

Haselhuhn, M., Schweitzer, M., \& Wood, A. (2010). How implicit beliefs influence trust recovery. Psychological Science, 21, 645-648. doi:10.1177/095679761

Hedges, L. V., \& Pigott, T. D. (2001). The power of statistical tests in meta-analysis. 
Psychological Methods, 3, 203-217. doi: 10.1037/1082-989X.6.3.203

Henderson, V., \& Dweck, C. (1990). Adolescence and achievement. In S. Feldman \& G. Elliott (Eds.), At the threshold: Adolescent development (pp. 308-329). Cambridge, MA: Harvard University Press.

Higgins, E. T. (2000). Making a good decision: Value from fit. American Psychologist, 55, 12171230. doi:10.1037/0003-066X.55.11.1217

Higgins, J. P. T., Thompson, S.G., Deeks, J. J., \& Altman, D. G. (2003). Measuring inconsistency in meta-analyses. British Journal of Medicine, 327, 557-560. doi:10.1136/bmj.327.7414.557

Hollenbeck, J. R., \& Klein, H. J. (1987). Goal commitment and the goal-setting process: Problems, prospects, and proposals for future research. Journal of Applied Psychology, 72, 212-220. doi:10.1037/0021-9010.72.2.212

Hollenbeck, J. R., \& Williams, C. R. (1987). Goal importance, self-focus, and the goal-setting process. Journal of Applied Psychology, 72, 204-211. doi:10.1037/0021-9010.72.2.204

*Hong, Y., Chiu, C., Dweck, C. S., Lin, D., \& Wan, W. (1999). Implicit theories, attributions, and coping: A meaning system approach. Journal of Personality and Social Psychology, 77, 588-599. doi:10.1037/0022-3514.77.3.588

*Howell, A. J., \& Buro, K. (2009). Implicit theories, achievement goals, and procrastination: A meditational analysis. Learning and Individual Differences, 19, 151-154. doi:10.1016/j.lindif.2008.08.006

*Hoyt, C. L., Burnette, J. L., \& Innella, A. N. (2011). I can do that: The impact of implicit theories on leadership role model effectiveness. Personality and Social Psychology Bulletin. doi:10.1177/0146167211427922 
Huffcutt, A. I., Arthur, W. (1995). Development of a new outlier statistic for meta-analytic data. Journal of Applied Psychology, 80, 327-334. doi:10.1037/0021-9010.80.2.327

Hunter, J. E., \& Schmidt, F. L. (1990). Methods of meta-analysis: Correcting error and bias in research findings. New York: Sage.

Hunter, J. E., \& Schmidt, F. L. (2004). Methods of meta-analysis: Correcting error and bias in research findings $\left(2^{\text {nd }}\right.$ ed.). Thousand Oaks, CA: Sage.

*Job, V., Dweck, C. S., \& Walton, G. M. (2010). Ego depletion-Is it all in your head? Implicit theories about willpower affect self-regulation. Psychological Science, 1-8. doi:10.1177/0956797610384745

*Johnson, V. D. (2009). Growth mindset as a predictor of smoking cessation (Doctoral dissertation). Retrieved from http://etd.ohiolink.edu/

Karoly, P. (1993). Mechanisms of self-regulation: A systems view. Annual Review of Psychology, 44, 23-52. doi:10.1146/annurev.ps.44.020193.000323

Kasimatis, M., Miller, M., \& Marcussen, L. (1996). The effects of implicit theories on exercise motivation. Journal of Research in Personality, 30, 510-516. doi:10.1006/jrpe.1996.0037

Keith, N., \& Frese, M. (2005). Self-regulation in error management training: Emotion control and metacognition as mediators of performance effects. Journal of Applied Psychology, 90, 677-691. doi:10.1037/0021-9010.90.4.677

Kelly, G. A. (1955). The psychology of personal constructs (Vols. 1 \& 2). N.Y.: Norton.

*Kennett, D. J., \& Keefer, K. (2006). Impact of learned resourcefulness and theories of intelligence on academic achievement of university students: An integrated approach. Educational Psychology, 26, 441-457. doi:10.1080/01443410500342062

Knee, C. R. (1998). Implicit theories of relationships: Assessment and prediction of 
romantic relationship initiation, coping, and longevity. Journal of Personality and Social Psychology, 74, 360-370. doi:10.1037/0022-3514.74.2.360

*Kornilova, T. V., Kornilov, S. A., \& Chumakova, M. A. (2009). Subjective evaluations of intelligence and academic self-concept predict academic achievement: Evidence from a selective student population. Learning and Individual Differences, 19, 586-608. doi:10.1016/j.lindif.2009.08.001

*Kray, L. J., \& Haselhuhn, M. P. (2007). Implicit negotiation beliefs and performance: Experimental and longitudinal evidence. Journal of Personality and Social Psychology, 93, 49-64. doi:10.1037/0022-3514.93.1.49

Landis, J. R., \& Koch, G. G. (1977). The measurement of observer agreement for categorical data. Biometrics, 33, 159-174. doi:10.2307/2529310

*Law, Y. (2009). The role of attribution beliefs, motivation and strategy use in Chinese fifthgraders' reading comprehension. Educational Research, 51, 77-95. doi:10.1080.00131880802704764

Leary, M. R., Terry, M. L., Allen, A. B., \& Tate, E. B. (2009). The concept of ego threat in social and personality psychology: Is ego threat a viable scientific construct? Personality and Social Psychology Review, 13, 151-164. doi:10.1177/1088868309342595

*Leondari, A., \& Gialamas, V. (2002). Implicit theories, goal orientations, and perceived competence: Impact on students' achievement behavior. Psychology in the Schools, 39, 279-291. doi:10.1002/pits.10035

Lipsey, M. W., \& Wilson, D. B. (2001). Practical Meta-Analysis. Thousand Oaks, CA: Sage Publications.

Locke, E. A. (1968). Toward a theory of task motivation and incentives. Organizational Behavior and Human Performance, 3, 157-189. doi:10.1016/0030-5073(68)90004-4 
Locke, E. A., \& Latham, G. P. (2002). Building a practically useful theory of goal setting and task motivation: A 35-year odyssey. American Psychologist, 57, 705-717. doi:10.1037/0003-066X.57.9.705

*Mangels, J. A., Butterfield, B., Lamb, J., Good, C., \& Dweck, C. S. (2006). Why do beliefs about intelligence influence learning success? A social cognitive neuroscience model. Social Cognitive and Affective Neuroscience, 1, 75-86. doi:10.1093/scan/ns1013

*Martocchio, J. J. (1994). Effects of conceptions of ability on anxiety, expectations, and learning in training. Journal of Applied Psychology, 79, 819-825. doi:10.1037/0021-9010.79.6.819

*Maurer, T. J., Mitchell, D. R. D., \& Barbeite, F. G. (2002). Predictors of attitudes toward a 360degree feedback system and involvement in post-feedback management development activity. Journal of Occupational and Organizational Psychology, 75, 87-107. doi:10.1348/096317902167667

*Maurer, T. J., Wrenn, K. A., Pierce, H. R., Tross, S. A., \& Collins, W. C. (2003). Beliefs about 'improvability' of career-relevant skills: Relevance to job/task analysis, competency modeling, and learning orientation. Journal of Organizational Behavior, 24, 107-131. doi:10.1002/job.182

McDaniel, M. A., Rothstein, H. R., \& Whetzel, D. L. (2006). Publication bias: A case study of four test vendors. Personnel Psychology, 59, 927-953. doi:10.1111/j.1744-6570.2006.00059.x

Mento, A. J., Steel, R. P., \& Karren, R. J. (1987). A meta-analytic study of the effects of goal setting on task performance: 1966-1984. Organizational Behavior and Human Decision Processes, 39, 52-83. doi:10.1016/0749-5978(87)90045-8 
Middleton, M., \& Midgley, C. (1997). Avoiding the demonstration of lack of ability: An underexplored aspect of goal theory. Journal of Educational Psychology, 89, 710-718. doi:10.1037/0022-0663.89.4.710

Molden, D. C., \& Dweck, C. S. (2006). Finding "meaning” in psychology: A lay theories approach to self-regulation, social perception, and social development. American Psychologist, 61, 192-203. doi:10.1037/0003-066X.61.3.192

*Moreno, J. A., Gonzalez-Cutre, D., Martin-Albo, J., \& Cervello, E. (2010). Motivation and performance in physical education: An experimental test. Journal of Sports Science and Medicine, 9, 79-85.

Moser, J. S., Schroder, H. S., Heeter, C., Moran, T. P., \& Lee, Y.-H. (2011). Mind your errors: Evidence for a neural mechanism linking growth mind-set to adaptive posterror adjustments. Psychological Science, 22, 1484-1489. doi:10.1177/0956797611419520

Moskowitz, G. B., \& Grant, H. (2009). The psychology of goals. New York: Guilford Press. Muraven, M., \& Baumeister, R. F. (2000). Self-regulation and depletion of limited resources: Does self-control resemble a muscle? Psychological Bulletin, 126, 247-259. doi:10.1037/0033-2909.126.2.247

Muraven, M., Baumeister, R. F., \& Tice, D. M. (1999). Longitudinal improvement of selfregulation through practice: Building self-control strength through repeated exercise. The Journal of Social Psychology, 139, 446-457. doi:10.1080/00224549909598404

Mukhopadhyay, A., \& Yeung, C. W. M. (2010). Building character: Effects of lay theories of selfcontrol on the selection of products for children. Journal of Marketing Research, 47, 240250. doi:10.1509/jmkr.47.2.240 
Murphy, M., \& Dweck, C. S. (2010). A culture of genius: How an organization's lay theory shapes people's cognition, affect and behavior. Personality and Social Psychology Bulletin, 36, 283-296. doi:10.1177/0146167209347380

Nakagawa, S. (2004). A farewell to Bonferroni: The problems of low statistical power and publication bias. Behavioral Ecology, 15, 1044-1045. doi: 10.1093/beheco/arh107

Nicholls, J. G. (1984). Achievement motivation: Conceptions of ability, subjective experience, task choice, and performance. Psychological Review, 91, 328-346. doi:10.1037/0033-295X.91.3.328

*Nichols, J. D., White, J. J., \& Price, M. (2006). Beliefs of intelligence, knowledge acquisition, and motivational orientation: A comparative analysis of Hispanic/Latino and Anglo youth. Multicultural Perspectives, 8, 39-48. doi:10.1207/s15327892mcp0804_7

Niiya, Y., Crocker, J., \& Bartmess, E. (2004). From vulnerability to resilience: Learning orientations buffer contingent self-esteem from failure. Psychological Science, 15, 801805. doi:10.1111/j.0956-7976.2004.00759.x

*Nussbaum, A. D., \& Dweck, C. S. (2008). Defensiveness vs. remediation: Self-theories and modes of self-esteem maintenance. Personality and Social Psychology Bulletin, 34, 127134. doi:10.1177/0146167207312960

Nyer, P. U., \& Dellande, S. (2010). Public commitment as a motivator for weight loss. Psychology and Marketing, 27, 1-12. doi:10.1002/mar.20316

*Ollfors, M., \& Andersson, S. I. (2007). Ability of stress, sense of control and self-theories to predict Swedish high school students' grades. Educational Research and Evaluation, 13, 143-169. doi:10.1080/13803610701434241

*Ommundsen, Y. (2003). Implicit theories of ability and self-regulation strategies in physical education classes. Educational Psychology, 23, 141-157. 
doi:10.1080/01443410303224

*Ommundsen, Y., Haugen, R., \& Lund, T. (2005). Academic self-concept, implicit theories of ability, and self-regulation strategies. Scandinavian Journal of Educational Research, 49, 461-474. doi:10.1080/00313830500267838

Park, J. K., \& John, D. R. (2010). Got to get you into my life: Do brand personalities rub off on consumers? The Journal of Consumer Research, 37, 655-669. doi:10.1086/655807

Patsopoulos, N. A., Evangelou, E., Ioannidis, J. P. A. (2008). Sensitivity of between-study heterogeneity in meta-analysis: Proposed metrics and empirical evaluation. International Journal of Epidemiology, 37, 1148-1157. doi:10.1093/ije/dyn065

Payne, S. C., Youngcourt, S. S., \& Beaubien, J. M. (2007). A meta-analytic examination of the goal orientation nomological net. Journal of Applied Social Psychology, 92, 128-150. doi:10.1037/0021-9010.92.1.128

Pekrun, R., Goetz, T., Titz, W., \& Perry, R. P. (2002). Academic emotions in students' selfregulated learning and achievement: A program of qualitative and quantitative research. Educational Psychologist, 37, 91-105. doi:10.1207/S15326985EP3702_4

Piaget, J. (1928/1964). Judgment and reasoning in the child. Patterson, NJ: Littlefield, Adams, \& Co. doi: $10.4324 / 9780203207260$

Piaget, J., \& Garcia, R. (1991). Toward a logic of meanings. New York: Viking.

Pintrich, P. R. (2000). Multiple goals, multiple pathways: The role of goal orientations in learning and achievement. Journal of Educational Psychology, 92, 544-555. doi:10.1037/0022-0663.92.3.544

Pintrich, P. R., \& Garcia, T. (1991). Student goal orientation and self-regulation in the college classroom. In M. L. Maehr \& P. R. Pintrich (Eds.), Advances in motivation and 
achievement: Goals and self-regulatory processes, (Vol.7, pp.371-402). Greenwich, CT: JAI Press.

Plaks, J. E., Grant, H., \& Dweck, C. S. (2005). Violations of implicit theories and the sense of prediction and control: Implications for motivated person perception. Journal of Personality and Social Psychology, 88, 245-262. doi:10.1037/0022-3514.88.2.245

*Plaks, J. E., \& Stecher, K. (2007). Unexpected improvement, decline, and stasis: A prediction confidence perspective on achievement success and failure. Journal of Personality and Social Psychology, 93, 667-684. doi:10.1037/0022-3514.93.4.667

Porath, C. L., \& Bateman, T. S. (2006). Self-regulation: From goal orientation to job performance. Journal of Applied Psychology, 91, 185-192. doi:10.1037/0021-9010.91.1.185

Rattan, A., \& Dweck, C. S. (2010). Who confronts prejudice?: The role of implicit theories in the motivation to confront prejudice. Psychological Science, 21, 952-959. doi:10.1177/0956797610374740

Reynolds, S., \& Day, J. (1984). Monte Carlo studies of effect size estimates and their approximations in meta-analysis. A paper presented at the annual meeting of the American Educational Research Association, Toronto, ON, Canada. (ERIC Document Reproduction Service No. ED 253 567).

*Rhodewalt, F. (1994). Conceptions of ability, achievement goals, and individual differences in self-handicapping behavior: On the application of implicit theories. Journal of Personality, 62, 67-85. doi:10.1111/j.1467-6494.1994.tb00795.x

*Riley, W. H. (2003). The relation between two models of how children's achievement-related beliefs affect academic task engagement and achievement. (Doctoral dissertation). Retrieved from etd.lib.fsu/theses/available/etd-09222003-211145/

*Robins, R. W., \& Pals, J. L. (2002). Implicit self-theories in the academic domain: 
Implications for goal orientation, attributions, affect, and self-esteem change.

Self and Identity, 1, 313-336. doi:10.1080/15298860290106805

*Roedel, T. D., \& Schraw, G. (1995). Beliefs about intelligence and academic goals. Contemporary Educational Psychology, 20, 464-468. doi:10.1006/ceps.1995.1033

Rosenthal, R. (1979). The "file drawer problem" and tolerance for null results. Psychological Bulletin, 86, 638-641. doi:10.1037/0033-2909.86.3.638

Ross, M. (1989). Relation of implicit theories to the construct of personal histories. Psychological Review, 96, 341-357. doi:10.1037/0033-295X.96.2.341

Rydell, R. J., Hugenberg, K., Ray, D., \& Mackie, D. M. (2007). Implicit theories about groups and stereotyping. The role of group entitativity. Personality and Social Psychology Bulletin, 33, 549-558. doi:10.1177/0146167206296956

*Sarrazin, P., Biddle, S., Famose, J.P., Cury, F., Fox, K., \& Durand, M. (1996). Goal orientations and conceptions of the nature of sport ability in children: A social cognitive approach. British Journal of Social Psychology, 35, 399-414. doi:10.1111/j.2044-8309.1996.tb01104.x

*Sawyer, T.P., \& Hollis-Sawyer, L.A. (2005). Predicting stereotype threat, test anxiety, and cognitive ability test performance: An examination of three models. International Journal of Testing, 5, 225-2426. doi:10.1207/s15327574ijt0503_3

Schunk, D. H. (1995). Expectations and education and instruction. In J. E. Maddux (Ed.), Expectations, adaptation, and adjustment: Theory, research, and application (pp. 281303). New York: Plenum Press.

Senko, C., Hulleman, C. S., \& Harackiewicz, J. M. (2011). Achievement goal theory at the crossroads: Old controversies, current challenges, and new directions. Educational Psychologist, 46, 26-47. doi:10.1080/00461520.2011.538646 
Implicit Theories and Self-Regulation 92

Shah, J. Y., Friedman, R., \& Kruglanski, A. W. (2002). Forgetting all else: On the antecedents and consequences of goal shielding. Journal of Personality and Social Psychology, 83, 12611280. doi:10.1037/0022-3514.83.6.1261

*Shih, S. S. (2009). An examination of factors related to Taiwanese adolescents' reports of avoidance strategies. The Journal of Educational Research, 102, 377-388. doi:10.3200/JOER.102.5.377-388

*Siegle, D., Rubenstein, L. D. V., Pollard, E., \& Romey, E. (2010). Exploring the relationship of college freshmen honor students' effort and ability attribution, interest, and implicit theory of intelligence with perceived ability. Gifted Child Quarterly, 54, 92-101. doi:10.1177/0016986209355975

Sitzmann, T., \& Ely, K. (2011). A meta-analysis of self-regulated learning in work-related training and educational attainment: What we know and where we need to go. Psychological Bulletin, 137, 421-442. doi:10.1037/a0022777

Spinath, B., Spinath, F. M., Riemann, R., \& Angleitner, A. (2003). Implicit theories about personality and intelligence and their relationship to actual personality and intelligence. Personality and Individual Differences, 35, 939-951. doi:10.1016/S0191-8869(02)00310-0

*Spray, C. M., Wang, C. K. J., Biddle, S. J. H., Chatzisarantis, N. L. D., \& Warburton, V. E. (2006). An experimental test of self-theories of ability in youth sport. Psychology of Sport and Exercise, 7, 255-267. doi:10.1016/j.psychsport.2005.05.001

Steenbarger, B. N., \& Aderman, D. (1979). Objective self-awareness as a nonaversive state: Effect of anticipating discrepancy reduction. Journal of Personality, 47, 330-339. doi:10.1111/j.1467-6494.1979.tb00206.x 
*Stevenson, S. J. (2006). Understanding strenuous and moderate intensity exercise participation and motivation: A social-cognitive perspective (Master's thesis). Retrieved from http://esr.lib.ttu.edu/

*Stevenson, S. J., \& Lochbaum, M. R. (2008). Understanding exercise motivation: Examining the revised social-cognitive model of achievement motivation. Journal of Sport Behavior, 31, $389-412$.

*Stump, G., Husman, J., Chung, W., \& Done, A. (2009). Student beliefs about intelligence: Relationship to learning. 39th ASEE/IEEE Frontiers in Education Conference. San Antonio, TX.

*Sue-Chan, C., \& Wood, R. E. (2009). The moderating effect of trainee implicit beliefs on the relationship between cognitive modeling orientation and training outcomes. Applied Psychology: An International Review, 58, 304-335. doi:10.1111/j.1464-0597.2008.00349.x

*Tabernero, C., \& Wood, R. E. (1999). Implicit theories versus the social construal of ability in self-regulation and performance on a complex task. Organizational Behavior and Human Decision Processes, 78, 104-127. doi:10.1006/obhd.1999.2829

*Taylor, M. W. (2009). Changing students' minds about mathematics: Examining short-term changes in the beliefs of middle-school students. In S. L. Swars, D. W. Stinson, \& S. Lemons-Smith (Eds.). Proceedings of the 31st annual meeting of the North American Chapter of the International Group for the Psychology of Mathematics Education (pp. 105112). Atlanta, GA: Georgia State University.

*Thompson, C. N. (2006). Implicit theories go applied: Conception of ability at work. (Master's thesis). Retrieved from http://etd.ohiolink.edu/ 
*Thompson, T., \& Musket, S. (2005). Does priming for mastery goals improve the performance of students with an entity view of ability? British Journal of Educational Psychology, 75, 391-409. doi:10.1348/000709904X22700

*Thorsheim, T. E. (2002). Modification of ability beliefs and help-seeking behavior in response to self-verifying and non-self-verifying performance feedback. (Doctoral dissertation). Retrieved from http://catalog.lib.utexas.edu/

Tonidandel, S., \& LeBreton, J. M. (2011). Relative importance analysis: A useful supplement to regression analysis. Journal of Business and Psychology, 26, 1-9. doi:10.1007/s10869-0109204-3

Valentiner, D. P., Mounts, N. S., Durik, A. M., \& Gier-Lonsway, S. L. (2011). Shyness mindset: Applying mindset theory to the domain of inhibited social behavior. Personality and Individual Differences, 50, 1174-1179. doi:10.1016/j.paid.2011.01.021

Viechtbauer, W. (2005). Bias and efficiency of meta-analytic variance estimators in the randomeffects model. Journal of Educational and Behavioral Statistics, 30(3), 261-293. doi: 10.3102/10769986030003261

Viechtbauer, W., \& Cheung, M. W.-L. (2010). Outlier and influence diagnostics for meta-analysis. Research Synthesis Methods, 1, 112-125. doi:10.1002/jrsm.11

*Wang, C. K., \& Biddle, S. J. H. (2001). Young people's motivational profiles in physical activity: A cluster analysis. Journal of Sport \& Exercise Psychology, 23, 1-22.

*Wang, C. K., \& Biddle, S. J. H. (2003). Intrinsic motivation towards sports in Singaporean students: The role of sport ability beliefs. Journal of Health Psychology, 8, 515-523. doi:10.1177/13591053030085004

*Wang, C. K., Chatzisarantis, N. L., Spray, C. M., \& Biddle, S. J. H. (2002). Achievement goal profiles in school physical education: Differences in self-determination, sport ability 
beliefs, and physical activity. British Journal of Educational Psychology, 72, 433-445. doi:10.1348/000709902320634401

*Wilson, A. R. (2009). Malleable view of intelligence as intervention for stereotype threat: Overcoming math underperformance in women (Master's thesis). Retrieved from http://thescholarship.ecu.edu/

Zimmerman, B. J. (2002). Becoming a self-regulated learner: An overview. Theory into Practice, 41, 64-70. doi:10.1207/s15430421tip4102_2 
Table 1

SOMA Model descriptions and examples from existing literature

\begin{tabular}{|c|c|c|c|c|c|c|}
\hline & \multicolumn{2}{|c|}{ Setting } & \multicolumn{2}{|c|}{ Operating } & \multicolumn{2}{|c|}{ Monitoring } \\
\hline & $\begin{array}{l}\text { Performance- } \\
\text { Oriented Goal }\end{array}$ & $\begin{array}{c}\text { Learning- } \\
\text { Oriented Goal } \\
\end{array}$ & $\begin{array}{c}\text { Helpless-Oriented } \\
\text { Strategy }\end{array}$ & $\begin{array}{c}\text { Mastery-Oriented } \\
\text { Strategy }\end{array}$ & Negative Emotions & Expectations \\
\hline $\begin{array}{l}\text { Overarching } \\
\text { Question }\end{array}$ & $\begin{array}{l}\text { Do I focus on } \\
\text { outperforming } \\
\text { others? }\end{array}$ & $\begin{array}{l}\text { Do I focus on } \\
\text { mastering the task? }\end{array}$ & $\begin{array}{l}\text { Do I avoid goal- } \\
\text { directed behaviors? }\end{array}$ & $\begin{array}{l}\text { Do I engage in goal- } \\
\text { directed behaviors } \\
\text { aimed at improving } \\
\text { performance? }\end{array}$ & $\begin{array}{l}\text { In evaluating goal } \\
\text { progress, do I feel bad } \\
\text { about discrepancies or } \\
\text { anxious about future } \\
\text { performance? }\end{array}$ & $\begin{array}{l}\text { In evaluating goal } \\
\text { progress, do I believe } \\
\text { that I can reach my } \\
\text { goal in the future? }\end{array}$ \\
\hline $\begin{array}{l}\text { Illustrative } \\
\text { Example }\end{array}$ & $\begin{array}{l}\text { I focus on a } \\
\text { particular score, } \\
\text { such as a } 90 \% \text { on the } \\
\text { test, as the end state. }\end{array}$ & $\begin{array}{l}\text { I focus on mastering } \\
\text { the task, such as } \\
\text { learning the class } \\
\text { material, as the end } \\
\text { state. }\end{array}$ & $\begin{array}{l}\text { I experience a lack of } \\
\text { desire to pursue goal- } \\
\text { directed behaviors. }\end{array}$ & $\begin{array}{l}\text { I increase my efforts to } \\
\text { reach my goal. }\end{array}$ & $\begin{array}{l}\text { I feel hopeless or } \\
\text { anxious when } \\
\text { evaluating my goal } \\
\text { progress thus far. }\end{array}$ & $\begin{array}{l}\text { I believe in my ability } \\
\text { to reach my goal. }\end{array}$ \\
\hline $\begin{array}{l}\text { Example } \\
\text { Assessment } \\
\text { Item }\end{array}$ & $\begin{array}{l}\text { "It is important for } \\
\text { me to do better than } \\
\text { others."a }\end{array}$ & $\begin{array}{l}\text { "I study because I } \\
\text { like to learn."b" }\end{array}$ & $\begin{array}{l}\text { "I will try easier weight } \\
\text { management } \\
\text { programs." " }\end{array}$ & $\begin{array}{l}\text { "I would work harder } \\
\text { in this class." }\end{array}$ & $\begin{array}{l}\text { "I feel apprehensive } \\
\text { about using } \\
\text { computers." }\end{array}$ & $\begin{array}{l}\text { "I expect myself to do } \\
\text { well in the golf putting } \\
\text { test today.", }\end{array}$ \\
\hline
\end{tabular}

a Sample item from Cury et al. (2002, p. 237).

b Sample item from Dupeyrat \& Mariné (2001, p. 49).

c Sample item from Burnette (2010, p. 412).

d Sample item from Blackwell et al. (2007, p. 250).

e Sample item from Martocchio (1994, p. 821).

${ }^{f}$ Sample item from Spray et al. (2006, p. 260). 
Table 2. Predicting the three self-regulatory processes from implicit theories. Goal setting includes performance orientation ("Perform") and learning orientation ("Learn"), goal operating includes helpless-oriented strategies ("Helpless") and mastery-oriented strategies ("Mastery"), and goal monitoring includes negative emotion ("Neg. Emotion") and expectations ("Expectations"). These rows represent dependent variables and incremental theories represent the independent predictor variable.

\begin{tabular}{|c|c|c|c|c|c|c|c|c|c|c|c|}
\hline Process & $k$ & $n$ & $1-\beta$ & $r$ & $95 \% \mathrm{CI}$ & $r_{c}$ & $\begin{array}{c}\text { I-squared } \\
(\%)\end{array}$ & $\operatorname{Goal}(B)$ & $\begin{array}{l}\text { Approach/ } \\
\text { Avoid }\end{array}$ & Threat $(B)$ & $\begin{array}{c}\text { No Threat/ } \\
\text { Threat }\end{array}$ \\
\hline \multicolumn{12}{|l|}{$\begin{array}{l}\text { Goal Setting } \\
\left(B=.062^{* * * *}\right)\end{array}$} \\
\hline Perform & 30 & 7635 & 1.00 & $-.151^{* * *}$ & $-.199 ;-.102$ & -.196 & 76.3 & $-.130^{* * *}$ & $-.061 /-.184$ & $-.104^{*}$ & $-.125 /-.226$ \\
\hline Learn & 36 & 9184 & 1.00 & $.187^{* * *}$ & $.143 ; .230$ & .241 & 76.7 & $-.144^{* * *}$ & $.181 / .039$ & $.100^{* * *}$ & $.173 / .265$ \\
\hline \multicolumn{12}{|l|}{$\begin{array}{l}\text { Goal Operating } \\
\left(B=-.033^{*}\right)\end{array}$} \\
\hline Helpless & 19 & 10093 & .999 & $-.238^{* * *}$ & $-.293 ;-.182$ & -.323 & 85.0 & $\mathrm{n} / \mathrm{a}$ & -- & $-.096^{* *}$ & $-.247 /-.313$ \\
\hline Mastery & 35 & 6853 & .999 & $.227^{* * *}$ & $.162 ; .290$ & .313 & 86.1 & $\mathrm{n} / \mathrm{a}$ & -- & $.138^{* * *}$ & $.186 / .315$ \\
\hline \multicolumn{12}{|l|}{$\begin{array}{l}\text { Goal Monitoring } \\
(B=-.038)\end{array}$} \\
\hline Neg. Emotion & 13 & 1515 & 1.00 & $-.233^{* * *}$ & $-.314 ;-.148$ & -.292 & 57.6 & $\mathrm{n} / \mathrm{a}$ & -- & .089 & $-.306 /-.164$ \\
\hline Expectations & 43 & 13709 & 1.00 & $.157^{* * *}$ & $.126 ; .188$ & .196 & 65.4 & $\mathrm{n} / \mathrm{a}$ & -- & -.016 & $.165 / .154$ \\
\hline
\end{tabular}

${ }^{*} p<.05, \stackrel{* *}{p}<.01, \stackrel{* * *}{p} p<.001$

Note. $k=$ number of studies; $n=$ sample size; $1-\beta=$ statistical power of detecting a correlation of .20 or greater; $r=$ observed effect size; $95 \% \mathrm{CI}=95$ percent confidence interval of $r ; r_{c}=$ effect size corrected for unreliability; $I^{2}=$ test of heterogeneity; $B=$ unstandardized regression coefficient. Approach $=0 ;$ Avoid $=1 ;$ No threat $=0$, Threat $=1$.

\footnotetext{
${ }^{7}$ The total $k$ in this Table $=176$ and the $N=48,989$. This is different from the total unique $k$ of 113 and unique $N$ of 28,217 because some samples contributed multiple effects (e.g., link between implicit theories and performance goals and implicit theories and learning goals).
} 
Table 3. Predicting goal achievement from implicit theories and from the three self-regulatory processes. Goal setting includes performance orientation ("Perform") and learning orientation ("Learn"), goal operating includes helpless-oriented strategies ("Helpless") and mastery-oriented strategies ("Mastery"), and goal monitoring includes negative emotion ("Neg. Emotion") and expectations ("Expectations"). In contrast to Table 2, in this table, the rows represent independent variables (incremental theories and self-regulatory processes) and achievement represents the dependent variable. ${ }^{8}$

\begin{tabular}{|c|c|c|c|c|c|c|c|c|c|}
\hline Predictor & $k$ & $n$ & $1-\beta$ & $r$ & $95 \% \mathrm{CI}$ & $r_{c}$ & $\begin{array}{c}\text { I-squared } \\
(\%)\end{array}$ & Goal (B) & $\begin{array}{c}\text { Approach/ } \\
\text { Avoid }\end{array}$ \\
\hline
\end{tabular}

\section{Goal Setting}

$$
\begin{gathered}
(B=.009) \\
\text { Perform } \\
\text { Learn }
\end{gathered}
$$

$\begin{array}{lcc}7 & 1880 & .975 \\ 4 & 845 & .847\end{array}$

$-.022$

$\begin{array}{cc}-.073 ; .029 & -.024 \\ -.036 ; .099 & .039\end{array}$

14.59$$
\begin{aligned}
& -.383^{* * *} \\
& -.217^{* * *}
\end{aligned}
$$

\section{.638}

.195

$-.102$

$$
\begin{gathered}
-.232 ; .031 \\
.120 ; .485
\end{gathered}
$$

-.165
.440

\section{5}

91.5

$n / a$
$n / a$

$n / a$

Goal Monitoring
$\left(B=.159^{* * *}\right)$

Neg. Emotion
Expectations

$\begin{array}{ccc}4 & 514 & .183 \\ 15 & 4976 & .679\end{array}$

$-.324^{* *}$
$.406^{* *}$
$-.501 ;-.120 \quad-.422$
$.327 ; .479 \quad .548$
72.0
89.7

$n / a$
$n / a$

$n / a$

${ }^{\dagger} p<.10, \stackrel{*}{p}<.05, \stackrel{* *}{p}<.01, \stackrel{* * *}{p}<.001$

\footnotetext{
${ }^{8}$ The total $k$ in this Table $=97$ and the $N=22,889$. This is different from the total unique $k$ of 113 and unique $N$ of 28,217 because some samples contributed multiple effects (e.g., link between implicit theories and achievement and learning goals and achievement).
} 
Note. $k=$ number of studies; $n=$ sample size; $1-\beta=$ statistical power of detecting a correlation of .20 or greater; $r=$ observed effect size; $95 \% \mathrm{CI}=95$ percent confidence interval of $r ; r_{c}=$ effect size corrected for unreliability; $I^{2}=$ test of heterogeneity; $B=$ unstandardized regression coefficient. Approach $=0$, Avoid $=1$. 
Table 4. Future directions for implicit theory research employing the SOMA Model

\begin{tabular}{|c|c|c|c|c|c|c|}
\hline & \multicolumn{2}{|c|}{ Setting } & \multicolumn{2}{|c|}{ Operating } & \multicolumn{2}{|c|}{ Monitoring } \\
\hline & $\begin{array}{c}\text { Goal } \\
\text { Importance } \\
\end{array}$ & Goal Specificity & $\begin{array}{c}\text { Self-Regulatory } \\
\text { Strategy }\end{array}$ & $\begin{array}{c}\text { Self-Regulatory } \\
\text { Ability }\end{array}$ & $\begin{array}{c}\text { Monitoring } \\
\text { Strategies }\end{array}$ & $\begin{array}{l}\text { Monitoring } \\
\text { Frequency }\end{array}$ \\
\hline $\begin{array}{l}\text { General } \\
\text { Question }\end{array}$ & $\begin{array}{l}\text { How committed } \\
\text { am I to the goal? }\end{array}$ & $\begin{array}{l}\text { What is the level of } \\
\text { specificity of the goal } \\
\text { I pursue? }\end{array}$ & $\begin{array}{l}\text { What strategy or } \\
\text { strategies do I adopt } \\
\text { to reach my goal? }\end{array}$ & $\begin{array}{l}\text { Do I have the self- } \\
\text { regulatory ability to } \\
\text { operate as planned? }\end{array}$ & $\begin{array}{l}\text { What strategies do I } \\
\text { adopt to monitor } \\
\text { progress? Are these } \\
\text { strategies more or less } \\
\text { effective at detecting } \\
\text { discrepancies? }\end{array}$ & $\begin{array}{l}\text { How often do I } \\
\text { monitor my progress } \\
\text { on the goal? }\end{array}$ \\
\hline $\begin{array}{l}\text { Illustrative } \\
\text { Example }\end{array}$ & $\begin{array}{l}\text { I am strongly } \\
\text { committed to } \\
\text { achieving my } \\
\text { dieting goal. }\end{array}$ & $\begin{array}{l}\text { I set the specific, } \\
\text { quantifiable goal of } \\
\text { losing } 10 \text { pounds } \\
\text { before my wedding } \\
\text { date. }\end{array}$ & $\begin{array}{l}\text { I adopt the strategy } \\
\text { of limiting calories } \\
\text { in order to lose } \\
\text { weight. }\end{array}$ & $\begin{array}{l}\text { I am capable of } \\
\text { restricting my } \\
\text { calories to } 1500 \text { per } \\
\text { day. }\end{array}$ & $\begin{array}{l}\text { I post my body-weight } \\
\text { to a webpage tracking } \\
\text { my progress. }\end{array}$ & I weigh myself daily. \\
\hline $\begin{array}{l}\text { Example } \\
\text { Hypothesis }\end{array}$ & $\begin{array}{l}\text { Incremental and } \\
\text { entity theorists will } \\
\text { be more committed } \\
\text { to their goal when } \\
\text { the goal orientation } \\
\text { aligns with their } \\
\text { theory (goal fit). }\end{array}$ & $\begin{array}{l}\text { Incremental and } \\
\text { entity theorists with } \\
\text { more specific goals } \\
\text { will report greater } \\
\text { achievement. }\end{array}$ & $\begin{array}{l}\text { Incremental and } \\
\text { entity theorists } \\
\text { employ self- } \\
\text { regulatory strategies } \\
\text { that align with their } \\
\text { goal orientation } \\
\text { (goal fit). }\end{array}$ & $\begin{array}{l}\text { Incremental (vs. } \\
\text { entity) theorists } \\
\text { develop more self- } \\
\text { control because they } \\
\text { engage in more self- } \\
\text { regulation } \\
\text { strengthening. }\end{array}$ & $\begin{array}{l}\text { Incremental (vs. } \\
\text { entity) theorists are } \\
\text { more likely to use } \\
\text { monitoring strategies } \\
\text { that highlight } \\
\text { discrepancies because } \\
\text { of their growth- } \\
\text { oriented mindset. }\end{array}$ & $\begin{array}{l}\text { Incremental (vs. } \\
\text { entity) theorists } \\
\text { evaluate their } \\
\text { progress on goal } \\
\text { pursuits more often } \\
\text { because of their } \\
\text { desire to take } \\
\text { advantage of learning } \\
\text { opportunities. }\end{array}$ \\
\hline
\end{tabular}

Note: The columns in this table parallel the structure of Table 1, highlighting two promising topics for future research within each self-regulatory process (setting, operation, and monitoring), and illustrating how one could apply these topics in the dieting domain. The first two rows directly parallel Table 1, whereas the third row in Table 4 focuses on hypotheses and implications for future research rather than on example assessment items from extant research as in Table 1. 


\section{Figure Captions}

Figure 1. SOMA (Setting/Operating/Monitoring/Achievement) Model linking implicit theories and selfregulation.

Note. Each labeled path represents a specific hypothesis we evaluate meta-analytically in the present review. The solid lines represent direct effects, whereas the dotted lines represent interaction effects. Paths a and b represent links between incremental (vs. entity) beliefs and goal setting: performance goals and learning goals, respectively. Paths $\mathrm{c}$ and $\mathrm{d}$ represent moderation of Paths a and b by approach/avoidance categories of goals. Paths e and f represent links between incremental (vs. entity) beliefs and goal operating: helpless-oriented strategies and mastery-oriented strategies, respectively. Paths g and h represent links between incremental (vs. entity) beliefs and goal monitoring: negative emotions and expectations, respectively. Paths i through $\mathrm{n}$ represent moderation of implicit theories and self-regulatory processes by ego threat. Path o represents the link between incremental (vs. entity) beliefs and goal achievement. Paths $\mathrm{p}$ and $\mathrm{q}$ represent links between goal setting (performance goals and learning goals, respectively) and goal achievement. Paths $r$ and s represent moderation of Paths $\mathrm{p}$ and $\mathrm{q}$, respectively, by approach/avoidance. Paths $t$ and $u$ represent links between goal operation (helplessoriented strategies and mastery-oriented strategies, respectively) and goal achievement. Finally, paths v and $w$ represent links between goal monitoring (negative emotions and expectations, respectively) and goal achievement.

Figure 2. Action feedback loop linking goal setting, goal operating, goal monitoring, and the input function.

Note. Path a' represents the direct link from goal setting to goal operating, whereas Path a represents the link from goal setting to goal monitoring once the input function is present (i.e., once one can evaluate the distance between one's current state and one's standard).

Figure 3. Illustration of the disconnect between our hypotheses (Panel A) and the extant literature (Panel B) vis-à-vis moderation of the links between incremental beliefs and monitoring processes by ego threat.

Note. As highlighted by the dashed circles in Cells 3 and 7, the extant literature does not allow for clear moderational hypotheses for instances in which the ego threat measure assesses distance and the dependent measure is velocity-relevant (Cell 3), but that is the only cell for which the extant literature provides relevant data (Cell 7). Consequently, in contrast to our clear moderational hypotheses for goal setting and goal operating processes, our investigation of possible moderating effects for goal monitoring hypotheses is exploratory.

Figure 4. Meta-analytic results.

Note. Effect size estimates for the direct effects (solid lines) are observed correlations ( $r$ ); effect size estimates for the moderational effects (dotted lines) are regression coefficients $(B)$. Due to limitations in the published data (see discussion for elaboration), the effect size estimates come from separate analyses investigating each path rather than from a simultaneous model estimating all or multiple paths.

Figure 5. Effect sizes for implicit theories and self-regulatory processes for ego threat and no ego threat.

Note. Goal setting represents performance-oriented goal ("Perform") and learning-oriented goals ("Learn"), goal operating represents helpless-oriented strategies ("Helpless") and mastery-oriented strategies ("Mastery"), and goal monitoring represents negative emotion ("Neg. Emotion") and expectations ("Expectations"). Above each analysis, we report the number of studies included (i.e., $k$ ) and the number of participants (i.e., $n$ ). 
Figure 1

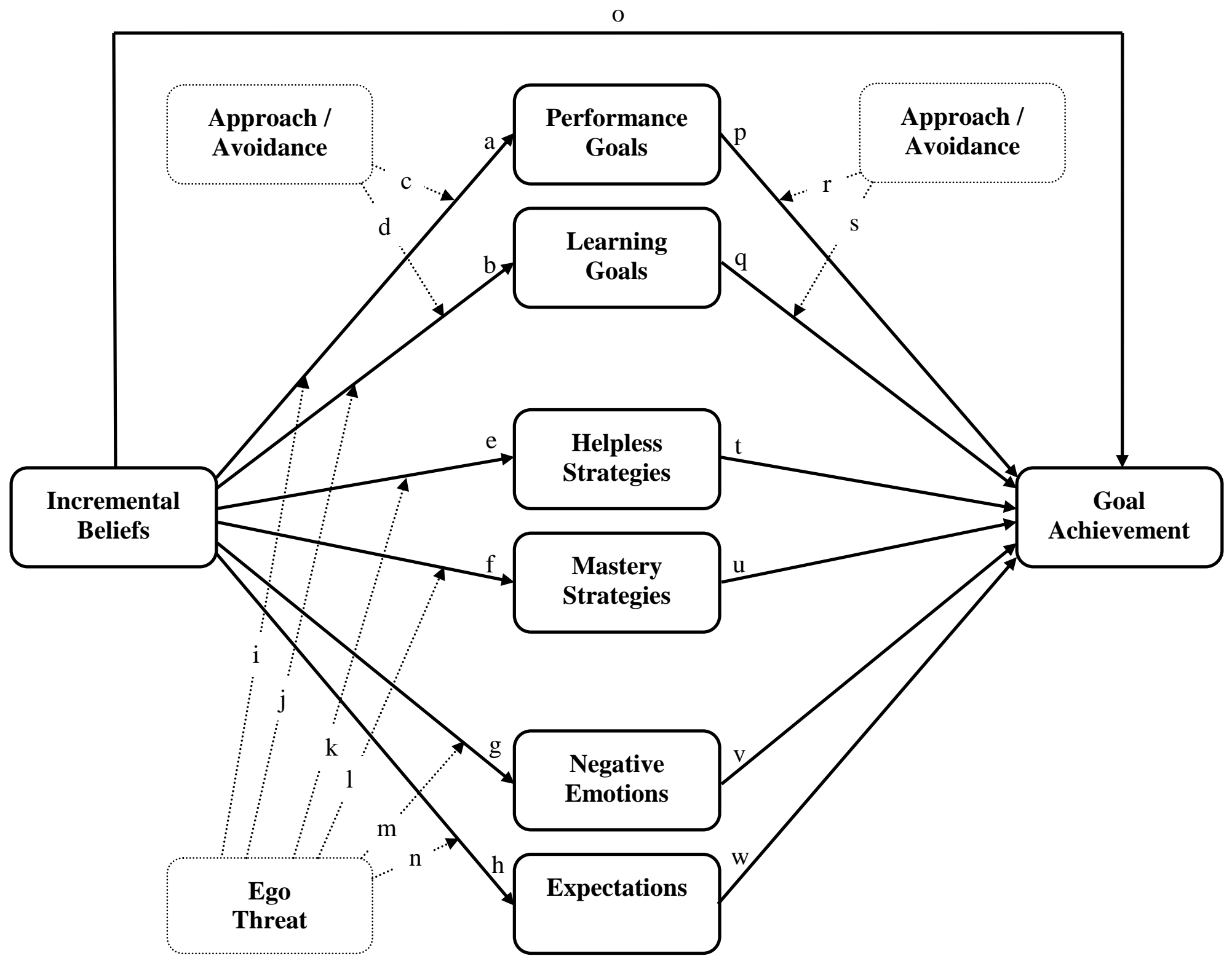


Figure 2

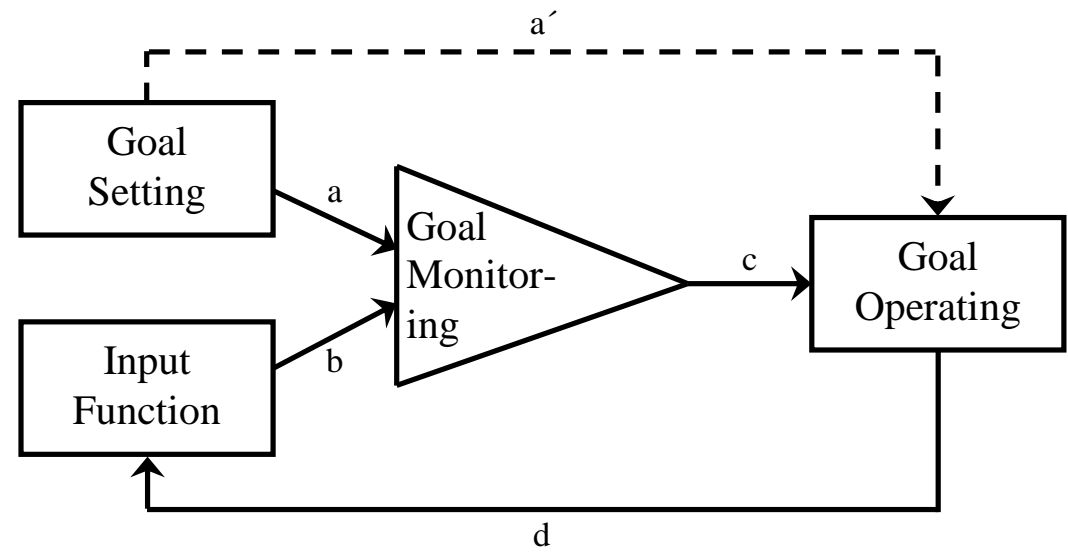


Figure 3

\section{Panel A: Hypotheses}

\section{Measure of Ego Threat}

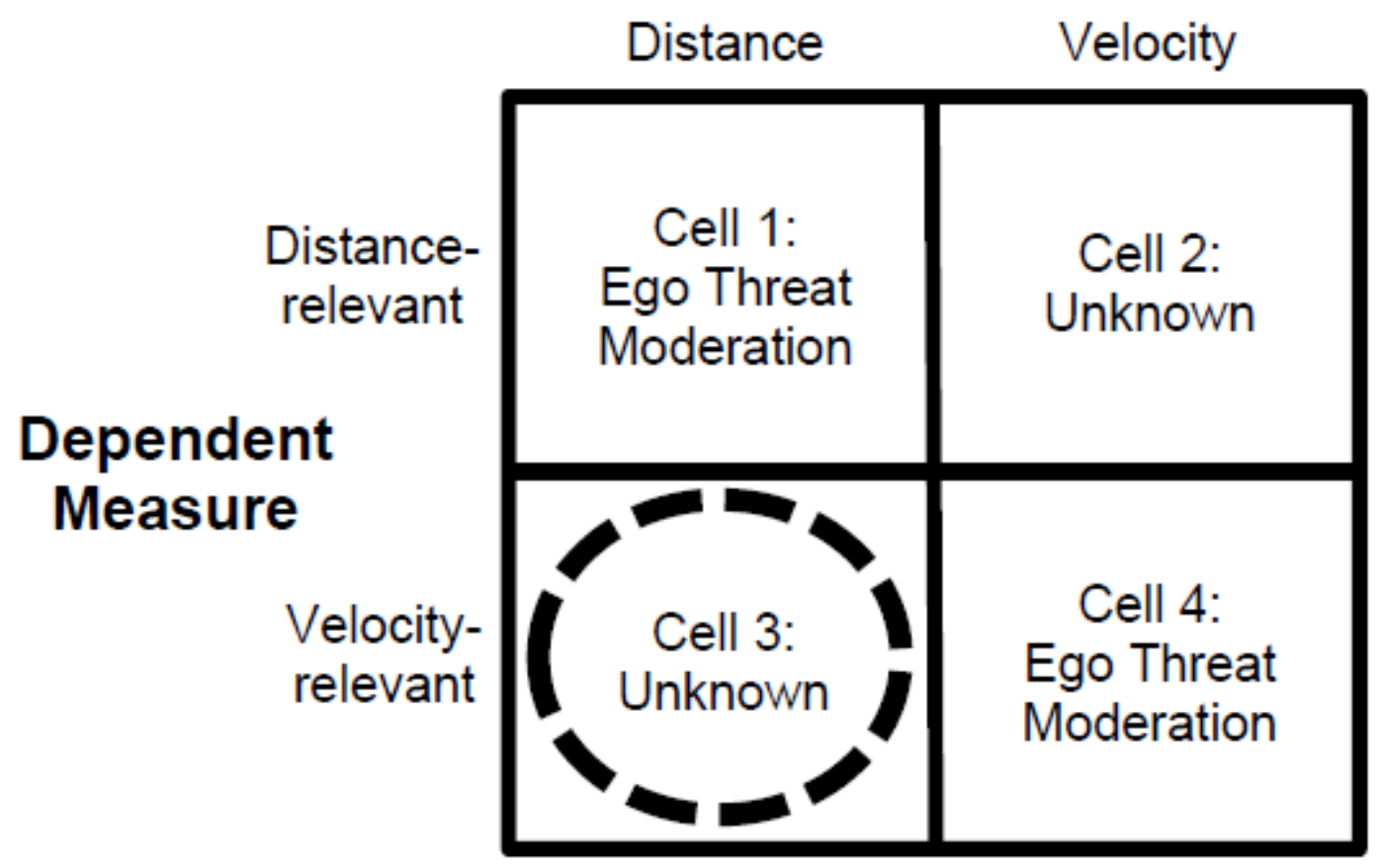




\section{Panel B: Extant Literature}

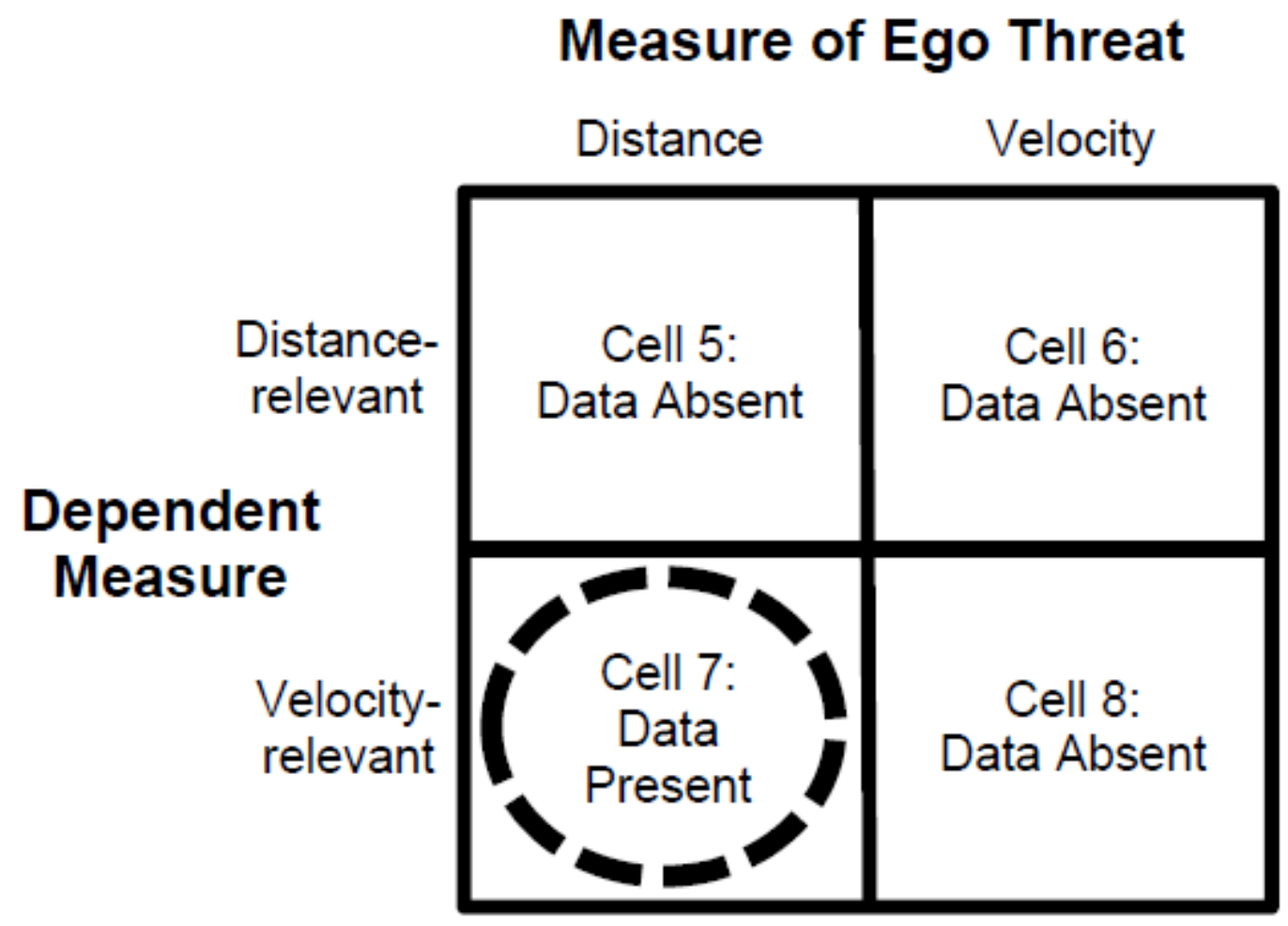


Figure 4

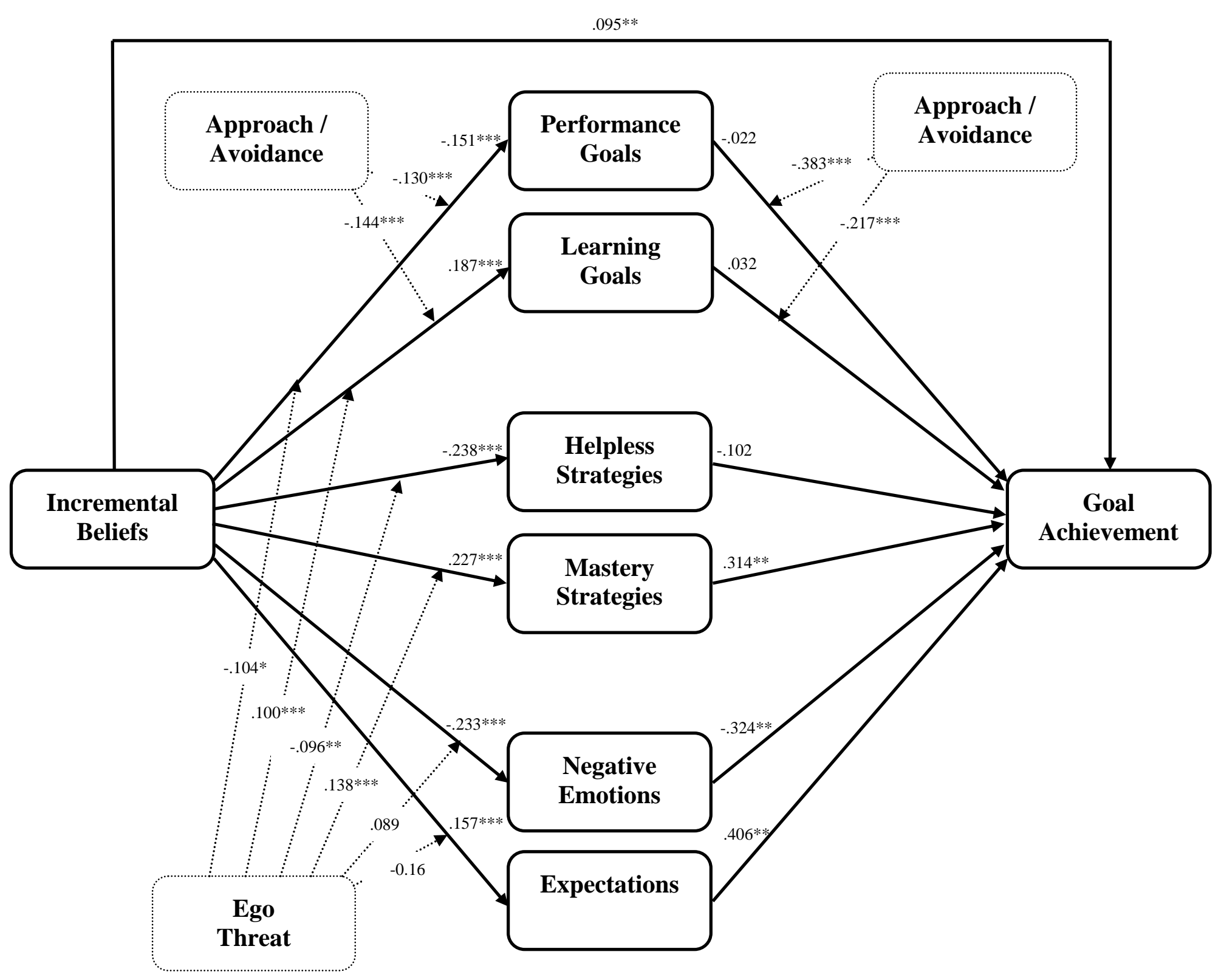


Figure 5

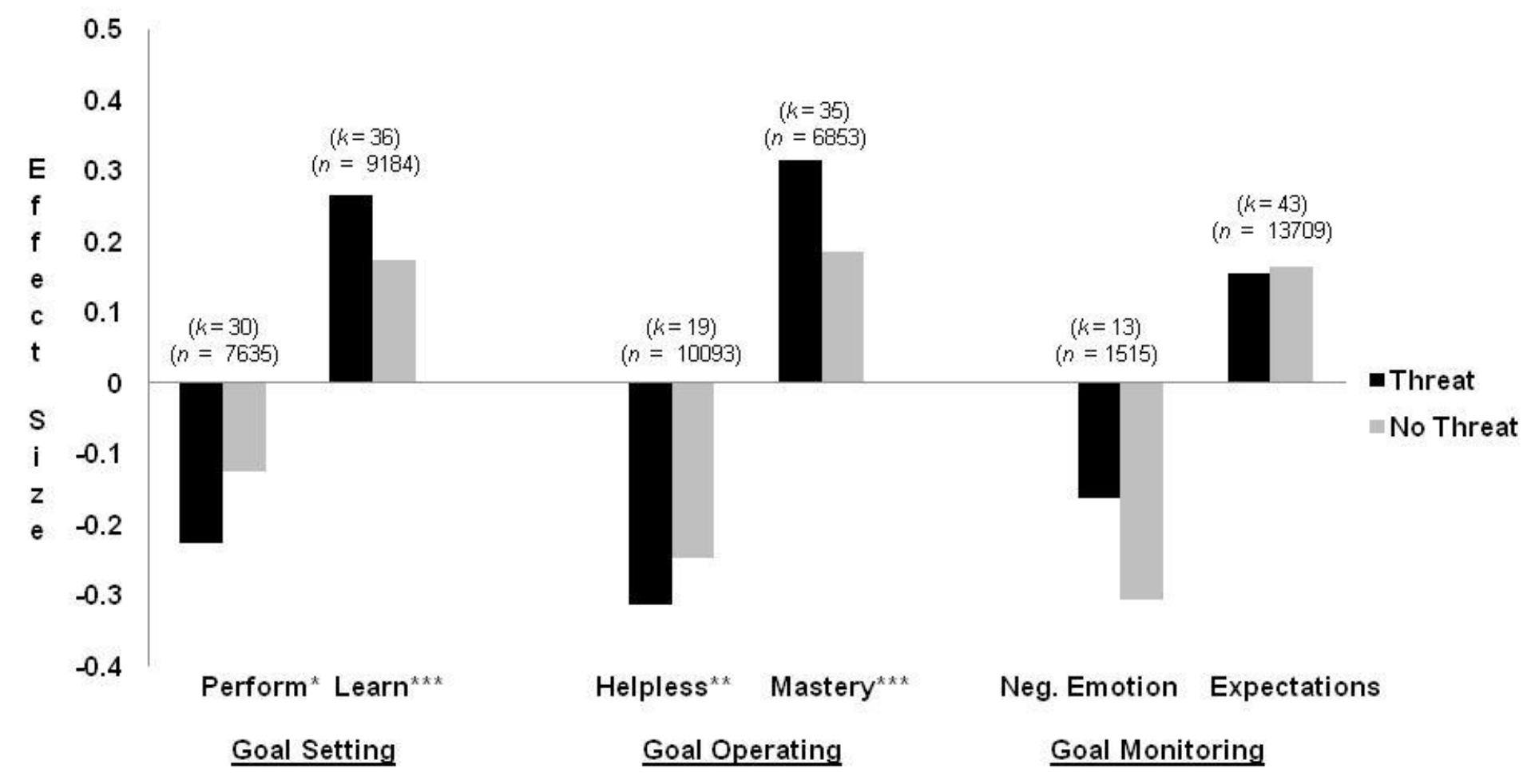

Significant differences are noted next to $\mathrm{x}$-axis labels as follows: $* \mathrm{p}<.05,{ }^{* *} p<.01, * * * p<.001$ 
Appendix 1. Listing of articles used to generate values in Table 2 linking implicit theories to the six selfregulatory processes. Articles are in alphabetical order and organized by DV predicting implicit theory. ${ }^{9}$

\begin{tabular}{|c|c|c|c|c|c|c|c|c|}
\hline Author(s) & Year & Published & Sample & $N$ & Nationality & IV & DV & $r$ \\
\hline Bernstein & 2006 & No & & 93 & U.S. & Implicit Theories & Perform & -0.11 \\
\hline Biddle et al. & 2003 & Yes & & 570 & U.K. & Implicit Theories & Perform & -0.03 \\
\hline Braten \& Strøms $\varnothing$ & 2004 & Yes & & 80 & Norway & Implicit Theories & Perform & -0.07 \\
\hline Braten \& Strøms $\emptyset$ & 2006 & Yes & 1 & 80 & Norway & Implicit Theories & Perform & -0.03 \\
\hline Braten \& Strøms $\varnothing$ & 2006 & Yes & 2 & 105 & Norway & Implicit Theories & Perform & -0.11 \\
\hline Cadwallader & 2009 & No & & 155 & U.K. & Implicit Theories & Perform & -0.02 \\
\hline Chen \& Pajares & 2010 & Yes & & 508 & U.S. & Implicit Theories & Perform & -0.22 \\
\hline Corrion et al. & 2010 & Yes & & 477 & France & Implicit Theories & Perform & -0.20 \\
\hline Cury et al. & 2002 & Yes & & 682 & France & Implicit Theories & Perform & -0.20 \\
\hline Cury et al. & 2006 & Yes & 1 & 96 & France & Implicit Theories & Perform & -0.37 \\
\hline Cury et al. & 2006 & Yes & 2 & 463 & France & Implicit Theories & Perform & -0.15 \\
\hline Dupeyrat \& Marine & 2001 & Yes & & 142 & France & Implicit Theories & Perform & 0.07 \\
\hline Dupeyrat \& Marine & 2005 & Yes & & 76 & France & Implicit Theories & Perform & -0.08 \\
\hline Elliot \& McGregor & 2001 & Yes & & 182 & U.S. & Implicit Theories & Perform & -0.09 \\
\hline Fryer & 2010 & No & & 104 & U.S. & Implicit Theories & Perform & -0.27 \\
\hline Howell \& Buro & 2009 & Yes & & 397 & U.S. & Implicit Theories & Perform & -0.09 \\
\hline Leondari \& Gialamas & 2002 & Yes & & 451 & Greece & Implicit Theories & Perform & 0.08 \\
\hline Mangels et al. & 2006 & Yes & 1 & 47 & U.S. & Implicit Theories & Perform & -0.60 \\
\hline Maurer et al. & 2002 & Yes & & 150 & U.S. & Implicit Theories & Perform & -0.25 \\
\hline Rhodewalt & 1994 & Yes & & 80 & U.S. & Implicit Theories & Perform & -0.12 \\
\hline Robins \& Pals & 2002 & Yes & & 363 & U.S. & Implicit Theories & Perform & -0.31 \\
\hline Roedel \& Schraw & 1995 & Yes & & 157 & U.S. & Implicit Theories & Perform & -0.23 \\
\hline Sarrazin et al. & 1996 & Yes & 1 & 194 & U.K. & Implicit Theories & Perform & -0.13 \\
\hline Sarrazin et al. & 1996 & Yes & 2 & 304 & France & Implicit Theories & Perform & -0.07 \\
\hline Spray et al. & 2006 & Yes & 1 & 123 & U.K. & Implicit Theories & Perform & -0.32 \\
\hline Stevenson & 2006 & No & & 357 & U.S. & Implicit Theories & Perform & -0.04 \\
\hline Stevenson \& Lochbaum & 2008 & Yes & 1 & 148 & U.S. & Implicit Theories & Perform & -0.11 \\
\hline Stevenson \& Lochbaum & 2008 & Yes & 2 & 386 & U.S. & Implicit Theories & Perform & -0.04 \\
\hline Thompson & 2006 & No & & 569 & U.S. & Implicit Theories & Perform & -0.07 \\
\hline Thompson \& Musket & 2005 & Yes & & 96 & Australia & Implicit Theories & Perform & -0.57 \\
\hline Bempechat et al. & 1991 & Yes & & 36 & U.S. & Implicit Theories & Learn & 0.48 \\
\hline
\end{tabular}

\footnotetext{
${ }^{9}$ When multiple effect sizes were reported in the same sample for the link between implicit theories and the same dependent variable, we took an average.
} 


\begin{tabular}{|c|c|c|c|c|c|c|c|c|}
\hline Bernstein & 2006 & No & & 93 & U.S. & Implicit Theories & Learn & 0.28 \\
\hline Biddle et al. & 2003 & Yes & & 570 & U.K. & Implicit Theories & Learn & 0.29 \\
\hline Blackwell et al. & 2007 & Yes & & 373 & U.S. & Implicit Theories & Learn & 0.34 \\
\hline Braten \& Strøms $\emptyset$ & 2005 & Yes & 1 & 108 & Norway & Implicit Theories & Learn & 0.09 \\
\hline Braten \& Strømsø & 2005 & Yes & 2 & 178 & Norway & Implicit Theories & Learn & 0.09 \\
\hline Braten \& Strøms $\emptyset$ & 2006 & Yes & 1 & 80 & Norway & Implicit Theories & Learn & 0.18 \\
\hline Braten \& Strøms $\varnothing$ & 2006 & Yes & 2 & 105 & Norway & Implicit Theories & Learn & 0.09 \\
\hline Cadwallader & 2009 & No & & 155 & U.K. & Implicit Theories & Learn & 0.21 \\
\hline Chen \& Pajares & 2010 & Yes & & 508 & U.S. & Implicit Theories & Learn & 0.38 \\
\hline Corrion et al. & 2010 & Yes & & 477 & France & Implicit Theories & Learn & 0.16 \\
\hline Cury et al. & 2002 & Yes & & 682 & France & Implicit Theories & Learn & 0.23 \\
\hline Cury et al. & 2006 & Yes & 1 & 96 & France & Implicit Theories & Learn & 0.30 \\
\hline Cury et al. & 2006 & Yes & 2 & 463 & France & Implicit Theories & Learn & 0.15 \\
\hline Dupeyrat \& Marine & 2001 & Yes & & 142 & France & Implicit Theories & Learn & 0.23 \\
\hline Dupeyrat \& Marine & 2005 & Yes & & 76 & France & Implicit Theories & Learn & 0.29 \\
\hline Elliot \& McGregor & 2001 & Yes & & 182 & U.S. & Implicit Theories & Learn & 0.13 \\
\hline Froehlich & 2007 & No & & 227 & U.S. & Implicit Theories & Learn & 0.37 \\
\hline Fryer & 2010 & No & & 104 & U.S. & Implicit Theories & Learn & -0.11 \\
\hline Garofano & 2006 & No & & 474 & U.S. & Implicit Theories & Learn & 0.12 \\
\hline Howell \& Buro & 2009 & Yes & & 397 & U.S. & Implicit Theories & Learn & 0.00 \\
\hline Kray \& Haselhuhn & 2007 & Yes & & 36 & U.S. & Implicit Theories & Learn & 0.39 \\
\hline Leondari \& Gialamas & 2002 & Yes & & 451 & Greece & Implicit Theories & Learn & 0.16 \\
\hline Maurer et al. & 2003 & Yes & & 267 & U.S. & Implicit Theories & Learn & 0.09 \\
\hline Rhodewalt & 1994 & Yes & & 80 & U.S. & Implicit Theories & Learn & 0.17 \\
\hline Robins \& Pals & 2002 & Yes & & 363 & U.S. & Implicit Theories & Learn & 0.25 \\
\hline Roedel \& Schraw & 1995 & Yes & & 157 & U.S. & Implicit Theories & Learn & 0.02 \\
\hline Sarrazin et al. & 1996 & Yes & 1 & 194 & U.K. & Implicit Theories & Learn & 0.01 \\
\hline Sarrazin et al. & 1996 & Yes & 2 & 304 & France & Implicit Theories & Learn & 0.33 \\
\hline Spray et al. & 2006 & Yes & & 123 & U.S. & Implicit Theories & Learn & 0.09 \\
\hline Stevenson & 2006 & No & & 357 & U.S. & Implicit Theories & Learn & 0.16 \\
\hline Stevenson \& Lochbaum & 2008 & Yes & 1 & 148 & U.S. & Implicit Theories & Learn & 0.22 \\
\hline Stevenson \& Lochbaum & 2008 & Yes & 2 & 386 & U.S. & Implicit Theories & Learn & 0.15 \\
\hline Tabernero \& Wood & 1999 & Yes & & 68 & Spain & Implicit Theories & Learn & 0.47 \\
\hline Thompson & 2006 & No & & 569 & U.S. & Implicit Theories & Learn & 0.07 \\
\hline Wang \& Biddle & 2003 & Yes & & 155 & Singapore & Implicit Theories & Learn & 0.34 \\
\hline Biddle et al. & 2003 & Yes & & 2969 & U.K. & Implicit Theories & Helpless & -0.28 \\
\hline Brown & 2009 & Yes & & 103 & U.S. & Implicit Theories & Helpless & -0.32 \\
\hline
\end{tabular}




\begin{tabular}{|c|c|c|c|c|c|c|c|c|}
\hline Burnette & 2010 & Yes & 1 & 264 & U.S. & Implicit Theories & Helpless & -0.14 \\
\hline Burnette & 2010 & Yes & 2 & 287 & U.S. & Implicit Theories & Helpless & -0.20 \\
\hline Chen et al. & 2008 & Yes & & 264 & Taiwan & Implicit Theories & Helpless & -0.39 \\
\hline Doron et al. & 2009 & Yes & & 410 & France & Implicit Theories & Helpless & -0.04 \\
\hline Dupeyrat \& Marine & 2001 & Yes & & 142 & France & Implicit Theories & Helpless & 0.07 \\
\hline Dupeyrat \& Marine & 2005 & Yes & & 76 & France & Implicit Theories & Helpless & -0.07 \\
\hline Froehlich & 2007 & No & & 227 & U.S. & Implicit Theories & Helpless & -0.40 \\
\hline Howell \& Buro & 2009 & Yes & & 397 & U.S. & Implicit Theories & Helpless & -0.13 \\
\hline Job et al. & 2010 & Yes & & 41 & U.S. & Implicit Theories & Helpless & -0.55 \\
\hline Nichols et al. & 2006 & Yes & & 418 & U.S. & Implicit Theories & Helpless & -0.13 \\
\hline Nussbaum \& Dweck & 2008 & Yes & 1 & 29 & U.S. & Implicit Theories & Helpless & -0.49 \\
\hline Nussbaum \& Dweck & 2008 & Yes & 2 & 80 & U.S. & Implicit Theories & Helpless & -0.38 \\
\hline Ommundsen et al. & 2005 & Yes & & 228 & Norway & Implicit Theories & Helpless & -0.22 \\
\hline Robins \& Pals & 2002 & Yes & & 363 & U.S. & Implicit Theories & Helpless & -0.48 \\
\hline Shih & 2009 & Yes & & 461 & Taiwan & Implicit Theories & Helpless & -0.10 \\
\hline Wang \& Biddle & 2001 & Yes & & 2510 & U.K. & Implicit Theories & Helpless & -0.29 \\
\hline Wang et al. & 2002 & Yes & & 824 & U.K. & Implicit Theories & Helpless & -0.23 \\
\hline Ahmavaara \& Houston & 2007 & Yes & & 856 & U.K. & Implicit Theories & Mastery & 0.18 \\
\hline Bergen & 1991 & No & & 95 & U.S. & Implicit Theories & Mastery & -0.06 \\
\hline Bernstein & 2006 & No & & 93 & U.S. & Implicit Theories & Mastery & 0.32 \\
\hline Blackwell et al. & 2007 & Yes & 1 & 99 & U.S. & Implicit Theories & Mastery & 0.22 \\
\hline Blackwell et al. & 2007 & Yes & 2 & 373 & U.S. & Implicit Theories & Mastery & 0.45 \\
\hline Braten \& Strømsø & 2005 & Yes & 1 & 108 & Norway & Implicit Theories & Mastery & 0.04 \\
\hline Braten \& Strømsø & 2005 & Yes & 2 & 178 & Norway & Implicit Theories & Mastery & -0.01 \\
\hline Burnette & 2010 & Yes & & 60 & U.S. & Implicit Theories & Mastery & 0.30 \\
\hline Burns \& Isbell & 2007 & Yes & & 84 & U.S. & Implicit Theories & Mastery & 0.22 \\
\hline Cury et al. & 2008 & Yes & 1 & 47 & France & Implicit Theories & Mastery & 0.41 \\
\hline Cury et al. & 2008 & Yes & 2 & 86 & France & Implicit Theories & Mastery & 0.34 \\
\hline Doron et al. & 2009 & Yes & & 410 & France & Implicit Theories & Mastery & 0.22 \\
\hline Dupeyrat \& Marine & 2001 & Yes & & 142 & France & Implicit Theories & Mastery & 0.20 \\
\hline Dupeyrat \& Marine & 2005 & Yes & & 76 & France & Implicit Theories & Mastery & 0.19 \\
\hline Fryer & 2010 & No & & 104 & U.S. & Implicit Theories & Mastery & 0.09 \\
\hline Garofano & 2006 & No & & 305 & U.S. & Implicit Theories & Mastery & 0.06 \\
\hline Hong et al. & 1999 & Yes & & 60 & Hong Kong & Implicit Theories & Mastery & 0.80 \\
\hline Job et al. & 2010 & Yes & & 41 & U.S. & Implicit Theories & Mastery & 0.27 \\
\hline Johnson & 2009 & No & & 197 & U.S. & Implicit Theories & Mastery & 0.33 \\
\hline Kennett \& Keefer & 2006 & Yes & & 244 & U.S. & Implicit Theories & Mastery & 0.20 \\
\hline
\end{tabular}




\begin{tabular}{|c|c|c|c|c|c|c|c|c|}
\hline Law & 2009 & Yes & & 120 & U.S. & Implicit Theories & Mastery & 0.26 \\
\hline Maurer et al. & 2002 & Yes & & 150 & U.S. & Implicit Theories & Mastery & 0.09 \\
\hline Nichols et al. & 2006 & Yes & & 418 & U.S. & Implicit Theories & Mastery & 0.07 \\
\hline Nussbaum \& Dweck & 2008 & Yes & 1 & 29 & U.S. & Implicit Theories & Mastery & 0.14 \\
\hline Nussbaum \& Dweck & 2008 & Yes & 2 & 80 & U.S. & Implicit Theories & Mastery & 0.28 \\
\hline Ommundsen & 2003 & Yes & & 343 & Norway & Implicit Theories & Mastery & 0.51 \\
\hline Ommundsen et al. & 2005 & Yes & & 228 & Norway & Implicit Theories & Mastery & 0.26 \\
\hline Plaks \& Stecher & 2007 & Yes & 1 & 104 & U.S. & Implicit Theories & Mastery & 0.08 \\
\hline Plaks \& Stecher & 2007 & Yes & 2 & 118 & U.S. & Implicit Theories & Mastery & 0.56 \\
\hline Riley & 2003 & Yes & & 291 & U.S. & Implicit Theories & Mastery & -0.07 \\
\hline Robins \& Pals & 2002 & Yes & & 363 & U.S. & Implicit Theories & Mastery & 0.39 \\
\hline Stevenson & 2006 & No & & 357 & U.S. & Implicit Theories & Mastery & 0.22 \\
\hline Stump et al. & 2009 & No & & 437 & U.S. & Implicit Theories & Mastery & 0.18 \\
\hline Sue-Chan \& Wood & 2009 & Yes & & 65 & U.S. & Implicit Theories & Mastery & 0.18 \\
\hline Thorsheim & 2002 & No & & 92 & U.S. & Implicit Theories & Mastery & -0.27 \\
\hline Burns \& Isbell & 2007 & Yes & & 84 & U.S. & Implicit Theories & Neg. Emotion & -0.18 \\
\hline Cury et al. & 2008 & Yes & 1 & 47 & France & Implicit Theories & Neg. Emotion & -0.47 \\
\hline Cury et al. & 2008 & Yes & 2 & 86 & France & Implicit Theories & Neg. Emotion & -0.40 \\
\hline Da Fonseca et al. & 2008 & Yes & & 28 & France & Implicit Theories & Neg. Emotion & -0.21 \\
\hline Da Fonseca et al. & 2009 & Yes & & 353 & France & Implicit Theories & Neg. Emotion & -0.15 \\
\hline Davis et al. & 2011 & Yes & & 165 & U.S. & Implicit Theories & Neg. Emotion & -0.19 \\
\hline El-Alayli \& Baumgardner & 2003 & Yes & & 41 & U.S. & Implicit Theories & Neg. Emotion & -0.31 \\
\hline Hoyt et al. & 2011 & Yes & 2 & 55 & U.S. & Implicit Theories & Neg. Emotion & -0.40 \\
\hline Martocchio & 1994 & Yes & & 76 & U.S. & Implicit Theories & Neg. Emotion & -0.07 \\
\hline Nussbaum \& Dweck & 2008 & Yes & & 26 & U.S. & Implicit Theories & Neg. Emotion & -0.16 \\
\hline Robins \& Pals & 2002 & Yes & & 363 & U.S. & Implicit Theories & Neg. Emotion & -0.13 \\
\hline Spray et al. & 2006 & Yes & & 123 & U.K. & Implicit Theories & Neg. Emotion & -0.03 \\
\hline Tabernero \& Wood & 1999 & Yes & & 68 & Spain & Implicit Theories & Neg. Emotion & -0.52 \\
\hline Ahmavaara \& Houston & 2007 & Yes & & 856 & U.K. & Implicit Theories & Expectations & 0.18 \\
\hline Bergen & 1991 & No & & 95 & U.S. & Implicit Theories & Expectations & 0.01 \\
\hline Biddle et al. & 2003 & Yes & & 570 & U.K. & Implicit Theories & Expectations & 0.17 \\
\hline Braten \& Strøms $\emptyset$ & 2005 & Yes & 1 & 108 & Norway & Implicit Theories & Expectations & -0.11 \\
\hline Braten \& Strøms $\varnothing$ & 2005 & Yes & 2 & 178 & Norway & Implicit Theories & Expectations & 0.28 \\
\hline Burnette & 2010 & Yes & 1 & 60 & U.S. & Implicit Theories & Expectations & 0.33 \\
\hline Burnette & 2010 & Yes & 2 & 264 & U.S. & Implicit Theories & Expectations & 0.17 \\
\hline Burnette & 2010 & Yes & 3 & 287 & U.S. & Implicit Theories & Expectations & 0.27 \\
\hline
\end{tabular}




\begin{tabular}{|c|c|c|c|c|c|c|c|c|}
\hline Burnette et al. & 2010 & Yes & & 51 & U.S. & Implicit Theories & Expectations & 0.32 \\
\hline Burns \& Isbell & 2007 & Yes & & 84 & U.S. & Implicit Theories & Expectations & 0.29 \\
\hline Chen \& Pajares & 2010 & Yes & & 508 & U.S. & Implicit Theories & Expectations & 0.34 \\
\hline Cury et al. & 2002 & Yes & & 682 & France & Implicit Theories & Expectations & 0.15 \\
\hline Cury et al. & 2006 & Yes & 1 & 96 & France & Implicit Theories & Expectations & 0.01 \\
\hline Cury et al. & 2006 & Yes & 2 & 463 & France & Implicit Theories & Expectations & 0.01 \\
\hline Davis et al. & 2011 & Yes & & 165 & U.S. & Implicit Theories & Expectations & 0.11 \\
\hline Dupeyrat \& Marine & 2001 & Yes & & 142 & France & Implicit Theories & Expectations & -0.10 \\
\hline Froehlich & 2007 & No & & 227 & U.S. & Implicit Theories & Expectations & 0.30 \\
\hline Fryer & 2010 & No & & 104 & U.S. & Implicit Theories & Expectations & 0.14 \\
\hline Garofano & 2006 & No & & 474 & U.S. & Implicit Theories & Expectations & 0.15 \\
\hline Gonida et al. & 2006 & Yes & 1 & 187 & U.S. & Implicit Theories & Expectations & 0.27 \\
\hline Gonida et al. & 2006 & Yes & 2 & 232 & U.S. & Implicit Theories & Expectations & 0.15 \\
\hline Greenwald & 2010 & No & & 596 & U.S. & Implicit Theories & Expectations & 0.08 \\
\hline Hoyt et al. & 2011 & Yes & 1 & 46 & U.S. & Implicit Theories & Expectations & 0.19 \\
\hline Hoyt et al. & 2011 & Yes & 2 & 55 & U.S. & Implicit Theories & Expectations & 0.28 \\
\hline Kornilova et al. & 2009 & Yes & & 300 & U.S. & Implicit Theories & Expectations & 0.11 \\
\hline Kray \& Haselhuhn & 2007 & Yes & & 38 & U.S. & Implicit Theories & Expectations & 0.27 \\
\hline Leondari \& Gialamas & 2002 & Yes & & 451 & Greece & Implicit Theories & Expectations & 0.03 \\
\hline Martocchio & 1994 & Yes & & 76 & U.S. & Implicit Theories & Expectations & 0.38 \\
\hline Maurer et al. & 2002 & Yes & & 150 & U.S. & Implicit Theories & Expectations & 0.14 \\
\hline Maurer et al. & 2003 & Yes & 1 & 257 & U.S. & Implicit Theories & Expectations & 0.20 \\
\hline Maurer et al. & 2003 & Yes & 2 & 267 & U.S. & Implicit Theories & Expectations & 0.30 \\
\hline Moreno et al. & 2010 & Yes & & 363 & U.S. & Implicit Theories & Expectations & 0.06 \\
\hline Nussbaum \& Dweck & 2008 & Yes & 1 & 26 & U.S. & Implicit Theories & Expectations & -0.09 \\
\hline Nussbaum \& Dweck & 2008 & Yes & 2 & 29 & U.S. & Implicit Theories & Expectations & 0.04 \\
\hline Ollfors \& Andersson & 2007 & Yes & & 918 & U.S. & Implicit Theories & Expectations & 0.23 \\
\hline Riley & 2003 & No & & 291 & U.S. & Implicit Theories & Expectations & 0.11 \\
\hline Robins \& Pals & 2002 & Yes & & 363 & U.S. & Implicit Theories & Expectations & 0.09 \\
\hline Spray et al. & 2006 & Yes & & 123 & U.K. & Implicit Theories & Expectations & 0.13 \\
\hline Stevenson & 2006 & No & & 357 & U.S. & Implicit Theories & Expectations & 0.13 \\
\hline Stump et al. & 2009 & No & & 437 & U.S. & Implicit Theories & Expectations & 0.03 \\
\hline Tabernero \& Wood & 1999 & Yes & & 68 & Spain & Implicit Theories & Expectations & 0.43 \\
\hline Wang \& Biddle & 2001 & Yes & & 2,510 & U.K. & Implicit Theories & Expectations & 0.16 \\
\hline Wang \& Biddle & 2003 & Yes & & 155 & U.K. & Implicit Theories & Expectations & 0.12 \\
\hline
\end{tabular}


Appendix 2. Listing of articles used to generate values in Table 3 linking implicit theory and self-regulatory processes to achievement. Articles are in alphabetical order broken down by IV predicting DV of achievement. $^{10}$

\begin{tabular}{|c|c|c|c|c|c|c|c|c|}
\hline Author(s) & Year & Published & Sample & $N$ & Nationality & IV & DV & $r$ \\
\hline Aronson et al. & 2002 & Yes & & 79 & U.S. & Implicit Theory & Achievement & -0.21 \\
\hline Bergen & 1991 & No & & 95 & U.S. & Implicit Theory & Achievement & -0.35 \\
\hline Blackwell et al. & 2007 & Yes & 1 & 91 & U.S & Implicit Theory & Achievement & 0.57 \\
\hline Blackwell et al. & 2007 & Yes & 2 & 373 & U.S & Implicit Theory & Achievement & 0.22 \\
\hline Burnette & 2010 & Yes & & 287 & U.S & Implicit Theory & Achievement & -0.07 \\
\hline Burns \& Isbell & 2007 & Yes & & 84 & U.S & Implicit Theory & Achievement & -0.13 \\
\hline Cadwallader & 2009 & No & & 155 & U.K. & Implicit Theory & Achievement & -0.18 \\
\hline Chen \& Pajares & 2010 & Yes & & 508 & U.S. & Implicit Theory & Achievement & 0.29 \\
\hline Cury et al. & 2006 & Yes & 1 & 96 & France & Implicit Theory & Achievement & 0.23 \\
\hline Cury et al. & 2006 & Yes & 2 & 463 & France & Implicit Theory & Achievement & 0.16 \\
\hline Cury et al. & 2008 & Yes & 1 & 47 & France & Implicit Theory & Achievement & 0.30 \\
\hline Cury et al. & 2008 & Yes & 2 & 86 & France & Implicit Theory & Achievement & 0.28 \\
\hline Da Fonseca et al. & 2008 & Yes & & 28 & France & Implicit Theory & Achievement & 0.39 \\
\hline Da Fonseca et al. & 2009 & Yes & & 353 & France & Implicit Theory & Achievement & 0.11 \\
\hline Da Fonseca et al. & 2010 & Yes & & 25 & France & Implicit Theory & Achievement & 0.41 \\
\hline Dupeyrat \& Marine & 2005 & Yes & & 76 & France & Implicit Theory & Achievement & 0.12 \\
\hline Ehrlinger & 2010 & No & 1 & 86 & U.S. & Implicit Theory & Achievement & -0.07 \\
\hline Ehrlinger & 2010 & No & 2 & 95 & U.S. & Implicit Theory & Achievement & -0.23 \\
\hline Ehrlinger & 2010 & No & 3 & 105 & U.S. & Implicit Theory & Achievement & -0.21 \\
\hline Ehrlinger & 2010 & No & 4 & 144 & U.S. & Implicit Theory & Achievement & -0.12 \\
\hline Ehrlinger \& Brewer & 2011 & No & & 100 & U.S. & Implicit Theory & Achievement & -0.12 \\
\hline Ehrlinger \& Conlon & 2011 & No & 1 & 73 & U.S. & Implicit Theory & Achievement & 0.35 \\
\hline Ehrlinger \& Conlon & 2011 & No & 2 & 122 & U.S. & Implicit Theory & Achievement & -0.05 \\
\hline Ehrlinger \& Conlon & 2011 & No & 3 & 242 & U.S. & Implicit Theory & Achievement & 0.02 \\
\hline Ehrlinger et al. & 2011 & No & 1 & 53 & U.S. & Implicit Theory & Achievement & -0.08 \\
\hline Ehrlinger et al. & 2011 & No & 2 & 122 & U.S. & Implicit Theory & Achievement & -0.16 \\
\hline Ehrlinger \& Mitchum & 2010 & No & & 66 & U.S. & Implicit Theory & Achievement & -0.21 \\
\hline Elliot \& McGregor & 2001 & Yes & & 182 & U.S. & Implicit Theory & Achievement & 0.00 \\
\hline Fryer & 2010 & No & & 104 & U.S. & Implicit Theory & Achievement & 0.13 \\
\hline Gonida et al. & 2006 & Yes & 1 & 187 & Greece & Implicit Theory & Achievement & 0.25 \\
\hline Gonida et al. & 2006 & Yes & 2 & 232 & Greece & Implicit Theory & Achievement & 0.22 \\
\hline
\end{tabular}

\footnotetext{
${ }^{10}$ When multiple effect sizes were reported in the same sample for links between implicit theories or processes and the same achievement outcome, we took an average
} 


\begin{tabular}{|c|c|c|c|c|c|c|c|c|}
\hline Good et al. & 2003 & Yes & & 138 & U.S. & Implicit Theory & Achievement & -0.37 \\
\hline Greene et al. & 2010 & Yes & & 171 & U.S. & Implicit Theory & Achievement & -0.10 \\
\hline Greenwald & 2010 & No & & 596 & U.S. & Implicit Theory & Achievement & 0.34 \\
\hline Hong et al. & 1999 & Yes & & 97 & U.S. & Implicit Theory & Achievement & 0.07 \\
\hline Hoyt et al. & 2011 & No & & 46 & U.S. & Implicit Theory & Achievement & 0.28 \\
\hline Johnson & 2009 & No & & 197 & U.S. & Implicit Theory & Achievement & 0.70 \\
\hline Kornilova et al. & 2009 & Yes & & 300 & U.S. & Implicit Theory & Achievement & 0.07 \\
\hline Kray \& Haselhuhn & 2007 & Yes & 1 & 38 & U.S. & Implicit Theory & Achievement & 0.52 \\
\hline Kray \& Haselhuhn & 2007 & Yes & 2 & 52 & U.S. & Implicit Theory & Achievement & 0.40 \\
\hline Kray \& Haselhuhn & 2007 & Yes & 3 & 65 & U.S. & Implicit Theory & Achievement & 0.28 \\
\hline Law & 2009 & Yes & & 120 & $\begin{array}{c}\text { Hong } \\
\text { Kong } \\
\end{array}$ & Implicit Theory & Achievement & 0.30 \\
\hline Leondari \& Gialamas & 2002 & Yes & & 451 & Greece & Implicit Theory & Achievement & 0.09 \\
\hline Ollfors \& Andersson & 2007 & Yes & & 918 & Sweden & Implicit Theory & Achievement & 0.13 \\
\hline Riley & 2003 & Yes & & 291 & U.S. & Implicit Theory & Achievement & 0.22 \\
\hline Robins \& Pals & 2002 & Yes & & 363 & U.S. & Implicit Theory & Achievement & -0.20 \\
\hline Sawyer \& Hollis-Sawyer & 2005 & Yes & & 189 & U.S. & Implicit Theory & Achievement & -0.32 \\
\hline Siegle et al. & 2010 & Yes & & 149 & U.S. & Implicit Theory & Achievement & 0.04 \\
\hline Stump et al. & 2009 & No & & 437 & U.S. & Implicit Theory & Achievement & -0.02 \\
\hline Sue-Chan \& Wood & 2009 & Yes & & 55 & U.S. & Implicit Theory & Achievement & -0.15 \\
\hline Tabernero \& Wood & 1999 & Yes & & 68 & Spain & Implicit Theory & Achievement & 0.31 \\
\hline Taylor & 2009 & No & & 17 & U.S. & Implicit Theory & Achievement & 0.12 \\
\hline Wang \& Biddle & 2001 & Yes & & 2,510 & U.K. & Implicit Theory & Achievement & 0.25 \\
\hline Wang et al. & 2002 & Yes & & 824 & U.K. & Implicit Theory & Achievement & 0.11 \\
\hline Wilson & 2009 & No & & 92 & U.S. & Implicit Theory & Achievement & 0.29 \\
\hline Chen \& Pajares & 2010 & Yes & & 508 & U.S. & Perform & Achievement & -0.03 \\
\hline Cury et al. & 2006 & Yes & 1 & 96 & France & Perform & Achievement & -0.01 \\
\hline Cury et al. & 2006 & Yes & 2 & 463 & France & Perform & Achievement & 0 \\
\hline Dupeyrat \& Marine & 2005 & Yes & & 76 & France & Perform & Achievement & 0.13 \\
\hline Elliot \& McGregor & 2001 & Yes & & 182 & U.S. & Perform & Achievement & -0.08 \\
\hline Fryer & 2010 & No & & 104 & U.S. & Perform & Achievement & -0.07 \\
\hline Leondari \& Gialamas & 2002 & Yes & & 451 & Greece & Perform & Achievement & 0.04 \\
\hline Cury et al. & 2006 & Yes & 1 & 96 & France & Learn & Achievement & 0.17 \\
\hline Cury et al. & 2006 & Yes & 2 & 463 & France & Learn & Achievement & 0.10 \\
\hline Elliot \& McGregor & 2001 & Yes & & 182 & U.S. & Learn & Achievement & 0.10 \\
\hline Fryer & 2010 & No & & 104 & U.S. & Learn & Achievement & 0.11 \\
\hline
\end{tabular}




\begin{tabular}{|c|c|c|c|c|c|c|c|c|}
\hline Burnette & 2010 & Yes & & 287 & U.S. & Helpless & Achievement & -0.01 \\
\hline Dupeyrat \& Marine & 2005 & Yes & & 76 & France & Helpless & Achievement & -0.14 \\
\hline Law & 2009 & Yes & & 120 & U.S. & Helpless & Achievement & -0.21 \\
\hline Blackwell et al. & 2007 & Yes & & 373 & U.S. & Mastery & Achievement & -0.02 \\
\hline Cury et al. & 2006 & Yes & & 96 & France & Mastery & Achievement & 0.16 \\
\hline Cury et al. & 2008 & Yes & 1 & 47 & France & Mastery & Achievement & 0.49 \\
\hline Cury et al. & 2008 & Yes & 2 & 86 & France & Mastery & Achievement & 0.44 \\
\hline Dupeyrat \& Marine & 2005 & Yes & & 76 & France & Mastery & Achievement & 0.35 \\
\hline Fryer & 2010 & No & & 104 & U.S. & Mastery & Achievement & 0.17 \\
\hline Law & 2009 & Yes & & 120 & U.S. & Mastery & Achievement & 0.20 \\
\hline Riley & 2003 & No & & 291 & U.S. & Mastery & Achievement & 0.61 \\
\hline Sue-Chan \& Wood & 2009 & Yes & & 55 & U.S. & Mastery & Achievement & 0.35 \\
\hline Cury et al. & 2008 & Yes & 1 & 47 & France & Neg. Emotion & Achievement & -0.43 \\
\hline Cury et al. & 2008 & Yes & 2 & 86 & France & Neg. Emotion & Achievement & -0.45 \\
\hline Da Fonseca et al. & 2008 & Yes & & 28 & France & Neg. Emotion & Achievement & -0.32 \\
\hline Da Fonseca et al. & 2009 & Yes & 1 & 353 & France & Neg. Emotion & Achievement & -0.14 \\
\hline Burnette & 2010 & Yes & & 287 & U.S. & Expectations & Achievement & 0.30 \\
\hline Chen \& Pajares & 2010 & Yes & & 508 & U.S. & Expectations & Achievement & 0.55 \\
\hline Cury et al. & 2006 & Yes & 1 & 463 & France & Expectations & Achievement & 0.21 \\
\hline Cury et al. & 2006 & Yes & 2 & 96 & France & Expectations & Achievement & 0.27 \\
\hline Fryer & 2010 & No & & 104 & U.S. & Expectations & Achievement & 0.38 \\
\hline Gonida et al. & 2006 & Yes & 1 & 232 & U.S. & Expectations & Achievement & 0.50 \\
\hline Gonida et al. & 2006 & Yes & 2 & 187 & U.S. & Expectations & Achievement & 0.61 \\
\hline Greenwald & 2010 & No & & 596 & U.S. & Expectations & Achievement & 0.23 \\
\hline Kornilova et al. & 2009 & Yes & & 300 & U.S. & Expectations & Achievement & 0.51 \\
\hline Kray \& Haselhuhn & 2007 & Yes & & 38 & U.S. & Expectations & Achievement & 0.01 \\
\hline Leondari \& Gialamas & 2002 & Yes & & 451 & Greece & Expectations & Achievement & 0.52 \\
\hline Ollfors \& Andersson & 2007 & Yes & & 918 & U.S. & Expectations & Achievement & 0.26 \\
\hline Riley & 2003 & No & & 291 & U.S. & Expectations & Achievement & 0.42 \\
\hline Stump et al. & 2009 & Yes & & 437 & U.S. & Expectations & Achievement & 0.43 \\
\hline Tabernero \& Wood & 1999 & Yes & & 68 & Spain & Expectations & Achievement & 0.62 \\
\hline
\end{tabular}


Appendix 3a. Visual reprensentation of effect sizes and confidence intervals (Table 2, Appendix 1) for the relation between Implicit Theories and the outcome of Perform. The final (bottom) entry in each display represents the mean effect size and the overall confidence interval across all of the effects shown.

Correlation and $95 \% \mathrm{Cl}$

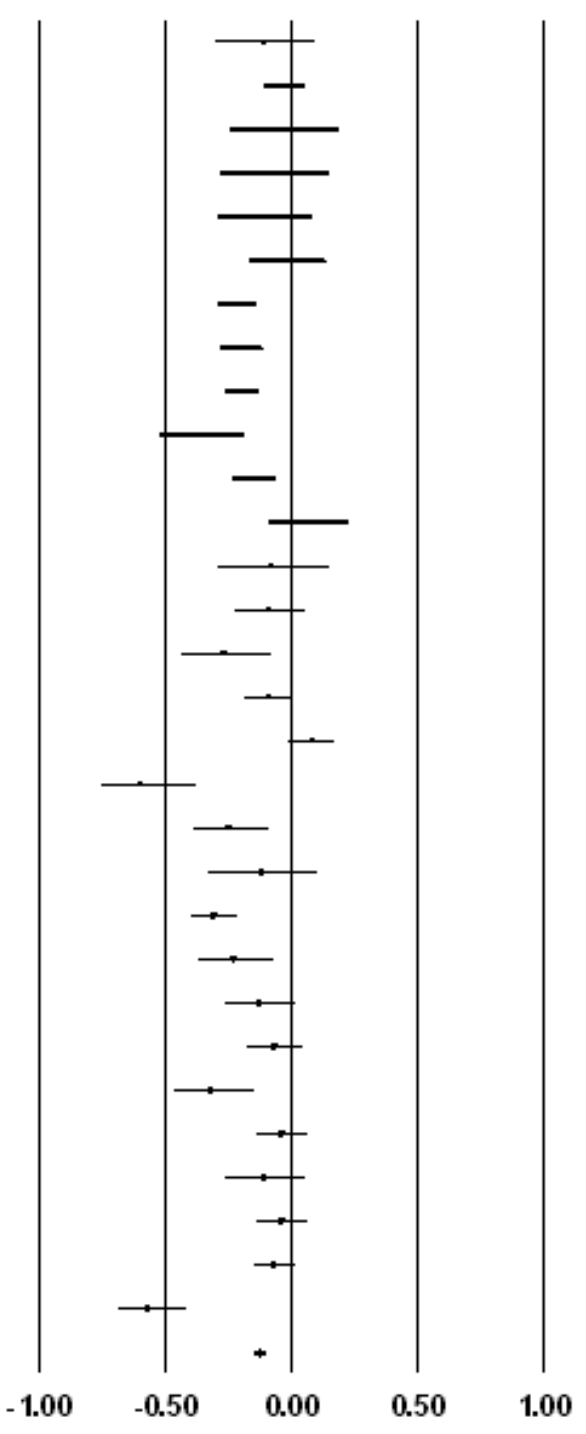


Appendix 3b. Visual reprensentation of effect sizes and confidence intervals (Table 2, Appendix 1) for the relation between Implicit Theories and the outcome of Learn. The final (bottom) entry in each display represents the mean effect size and the overall confidence interval across all of the effects shown.

Correlation and $95 \% \mathrm{Cl}$

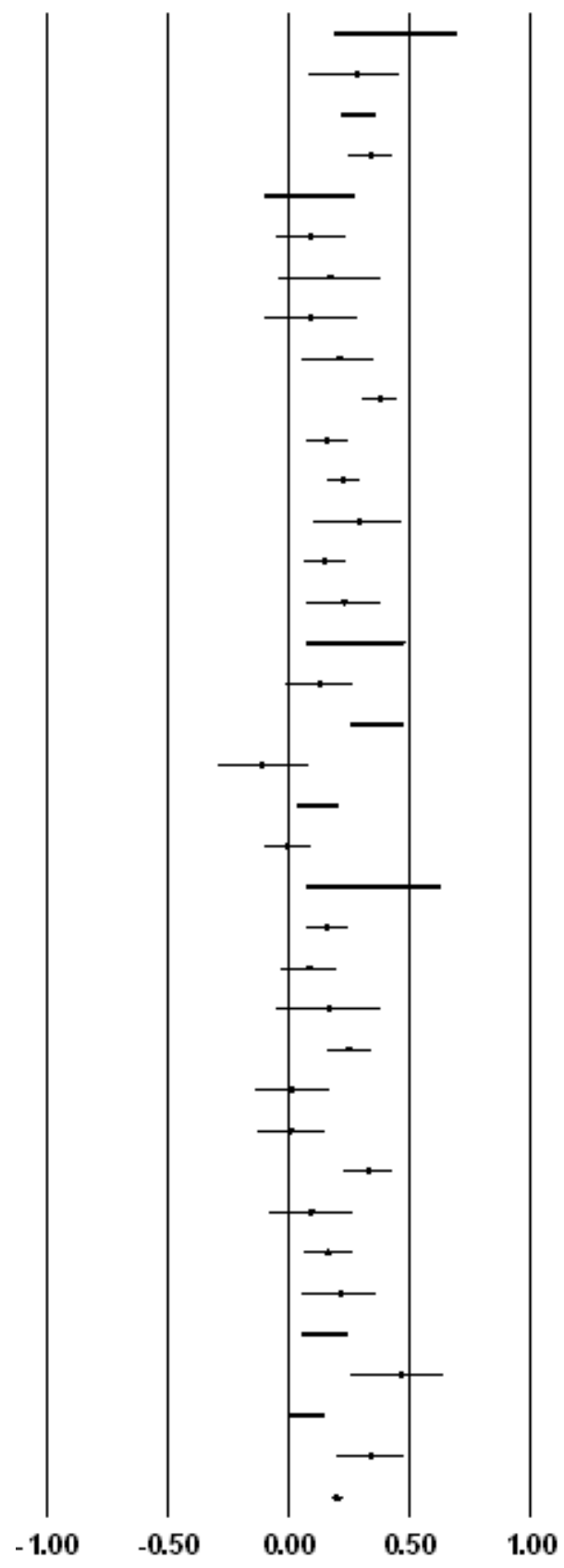


Appendix 3c. Visual reprensentation of effect sizes and confidence intervals (Table 2, Appendix 1) for the relation between Implicit Theories and the outcome of Helpless. The final (bottom) entry in each display represents the mean effect size and the overall confidence interval across all of the effects shown.

\section{Correlation and $95 \% \mathrm{Cl}$}

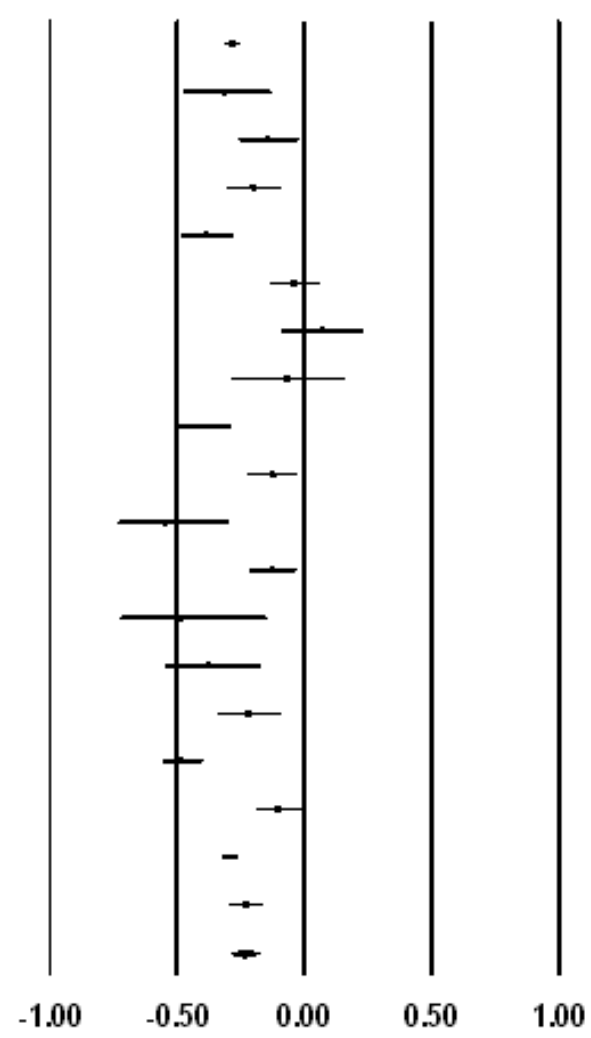


Appendix 3d. Visual reprensentation of effect sizes and confidence intervals (Table 2, Appendix 1) for the relation between Implicit Theories and the outcome of Mastery. The final (bottom) entry in each display represents the mean effect size and the overall confidence interval across all of the effects shown.

Correlation and $95 \% \mathrm{Cl}$

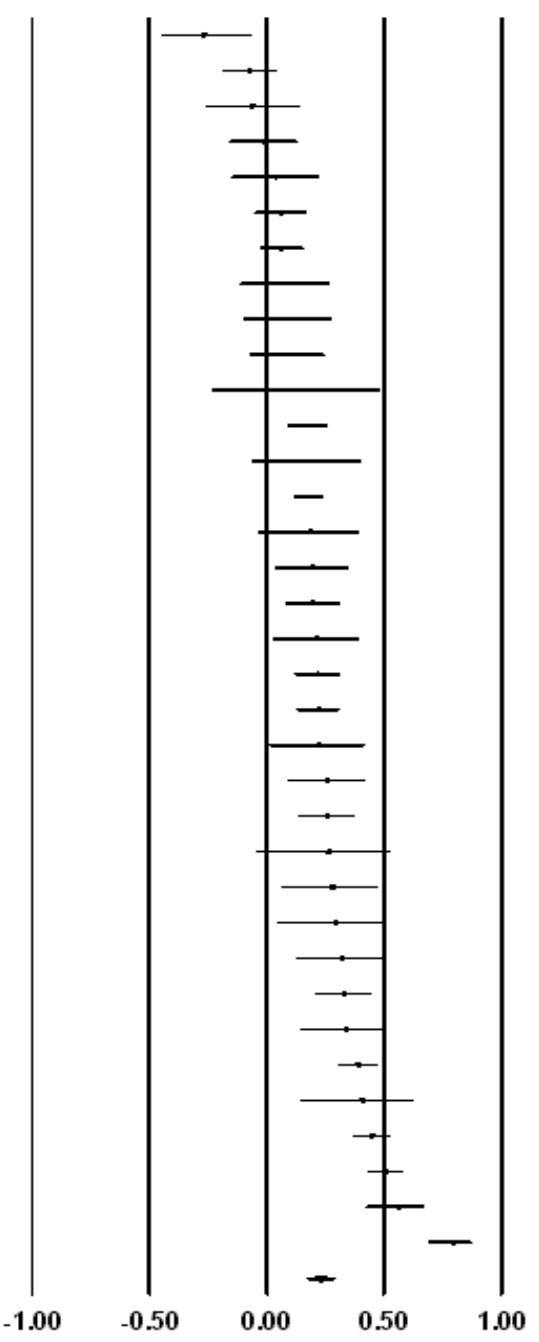


Appendix 3e. Visual reprensentation of effect sizes and confidence intervals (Table 2, Appendix 1) for the relation between Implicit Theories and the outcome of Neg. Emotion. The final (bottom) entry in each display represents the mean effect size and the overall confidence interval across all of the effects shown.

Correlation and $95 \% \mathrm{Cl}$

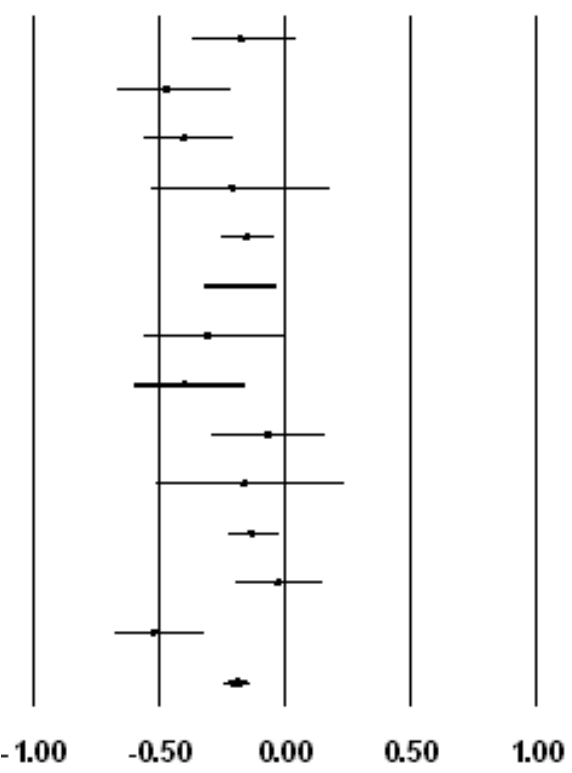


Appendix 3f. Visual reprensentation of effect sizes and confidence intervals (Table 2, Appendix 1) for the relation between Implicit Theories and the outcome of Expectations. The final (bottom) entry in each display represents the mean effect size and the overall confidence interval across all of the effects shown.

Correlation and $95 \% \mathrm{Cl}$

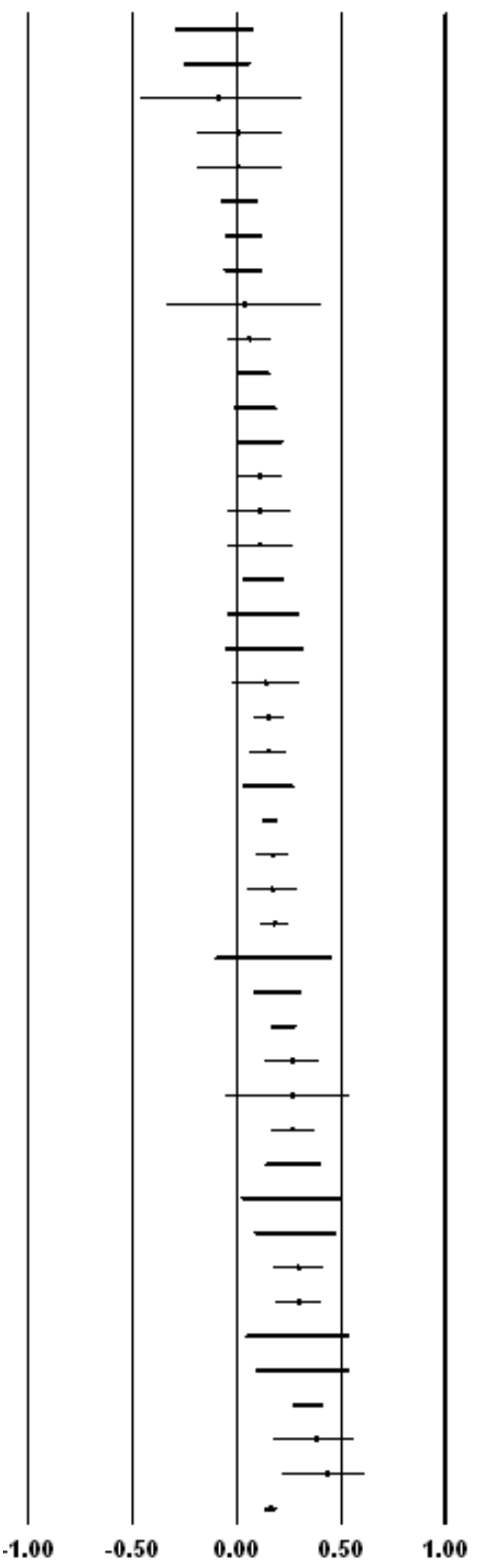


Appendix 4a. Visual reprensentation of effect sizes and confidence intervals (Table 3, Appendix 2) for the relation between Implicit Theories and the outcome of Achievement. The final (bottom) entry in each display represents the mean effect size and the overall confidence interval across all of the effects shown.

Correlation and $95 \% \mathrm{Cl}$

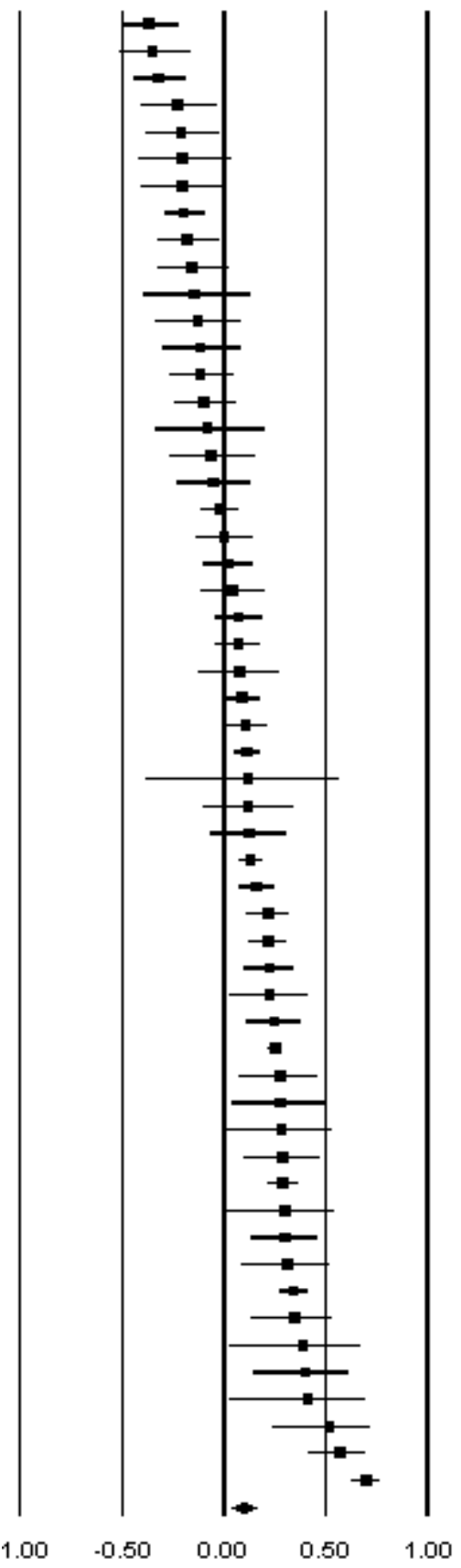


Appendix 4b. Visual reprensentation of effect sizes and confidence intervals (Table 3, Appendix 2) for the relation between Perform and the outcome of Achievement. The final (bottom) entry in each display represents the mean effect size and the overall confidence interval across all of the effects shown.

Correlation and $95 \% \mathrm{Cl}$

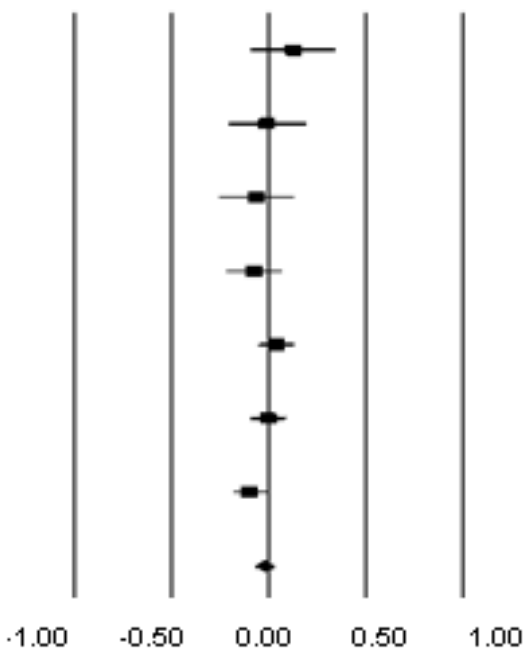


Appendix 4c. Visual reprensentation of effect sizes and confidence intervals (Table 3, Appendix 2) for the relation between Learn and the outcome of Achievement. The final (bottom) entry in each display represents the mean effect size and the overall confidence interval across all of the effects shown.

Correlation and $95 \% \mathrm{Cl}$

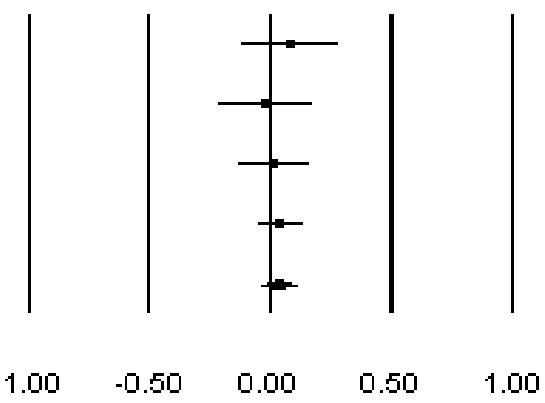


Appendix 4d. Visual reprensentation of effect sizes and confidence intervals (Table 3, Appendix 2) for the relation between Helpless and the outcome of Achievement. The final (bottom) entry in each display represents the mean effect size and the overall confidence interval across all of the effects shown.

Correlation and $95 \% \mathrm{Cl}$

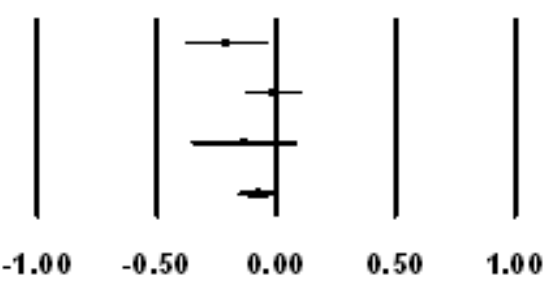


Appendix 4e. Visual reprensentation of effect sizes and confidence intervals (Table 3, Appendix 2) for the relation between Mastery and the outcome of Achievement. The final (bottom) entry in each display represents the mean effect size and the overall confidence interval across all of the effects shown.

Correlation and $95 \% \mathrm{Cl}$

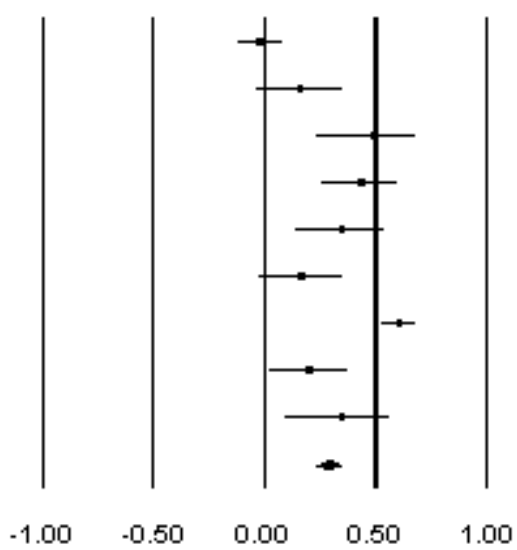


Appendix 4f. Visual reprensentation of effect sizes and confidence intervals (Table 3, Appendix 2) for the relation between Neg. Emotion and the outcome of Achievement. The final (bottom) entry in each display represents the mean effect size and the overall confidence interval across all of the effects shown.

Correlation and $95 \% \mathrm{Cl}$

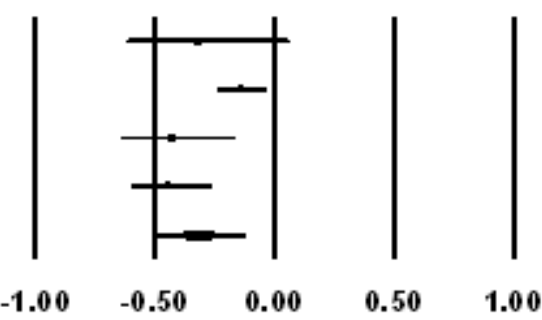


Appendix 4g. Visual reprensentation of effect sizes and confidence intervals (Table 3, Appendix 2) for the relation between Expectations and the outcome of Achievement. The final (bottom) entry in each display represents the mean effect size and the overall confidence interval across all of the effects shown.

Comelation and $95 \% \mathrm{Cl}$

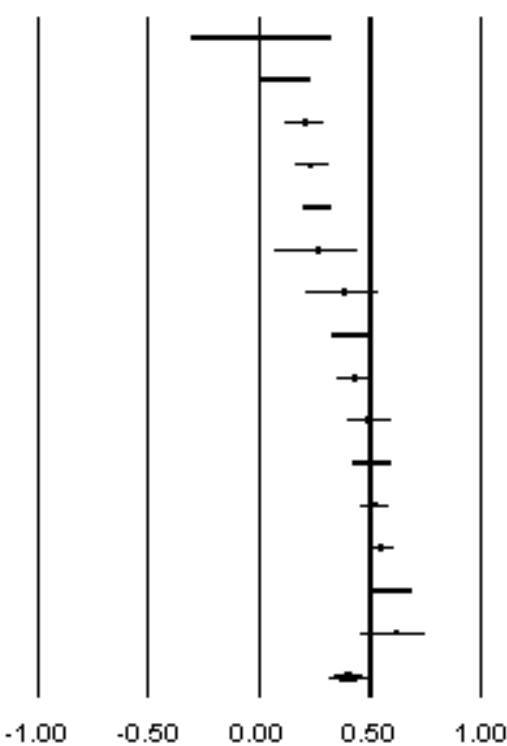

